\title{
Silver-Mediated Perfluoroalkylation of Terminal Alkynes with Perfluoroalkyl lodides
}

Junlan Li,${ }^{\dagger}$ Lihua Liu,${ }^{\S}$ Kaiting Zheng, ${ }^{\dagger}$ Chenggong Zheng, ${ }^{\dagger}$ Hua Xiao, ${ }^{*}, \S$ and Shilu

$$
\text { Fan } *, \dagger, \dot{\dagger}
$$

${ }^{\dagger}$ School of Chemistry and Chemical Engineering, Hefei University of Technology, 193 Tunxi Road, Anhui, 230000, People's Republic of China

$\$$ Key Laboratory of Organofluorine Chemistry, Shanghai Institute of Organic Chemistry, Chinese Academy of Sciences, Shanghai 200032, China

${ }^{\S}$ School of Food and Biological Engineering, Hefei University of Technology, 193 Tunxi Road, Anhui, 230009, China 


\section{List of Content}

Representative results for optimization of silver-mediated perfluoroalkylation of 1a S3

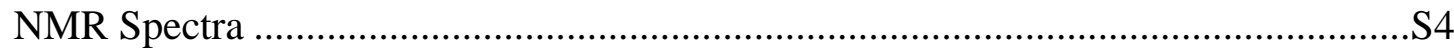




\section{Representative results for optimization of silver-mediated perfluoroalkylation of}

\section{$1 \mathrm{a}$}

To a septum capped $25 \mathrm{~mL}$ of sealed tube were added silver salt (1.2 equiv) and $t \mathrm{BuOLi}$ (2.0 equiv) under $\mathrm{N}_{2}$, followed by DMAC (deg.) $(2.0 \mathrm{~mL})$ with stirring. $1 \mathrm{a}(0.2 \mathrm{mmol})$ and $\mathbf{2 b}(0.6 \mathrm{mmol})$ was then added subsequently. The sealed tube was screw capped and heated (oil bath). After stirring for $12 \mathrm{~h}$, the reaction mixture was cooled to room temperature. The yield was determined by ${ }^{19} \mathrm{~F}$ NMR before working up. If necessary, the reaction mixture was diluted with ethyl acetate, washed with brine, dried over $\mathrm{Na}_{2} \mathrm{SO}_{4}$, filtered and concentrated. The residue was purified with silica gel chromatography (Petroleum ether $(100 \%))$ to provide pure product.

Table S1 Representative results for optimization of silver-mediated perfluoroalkylation of $1 \mathbf{a}^{a}$

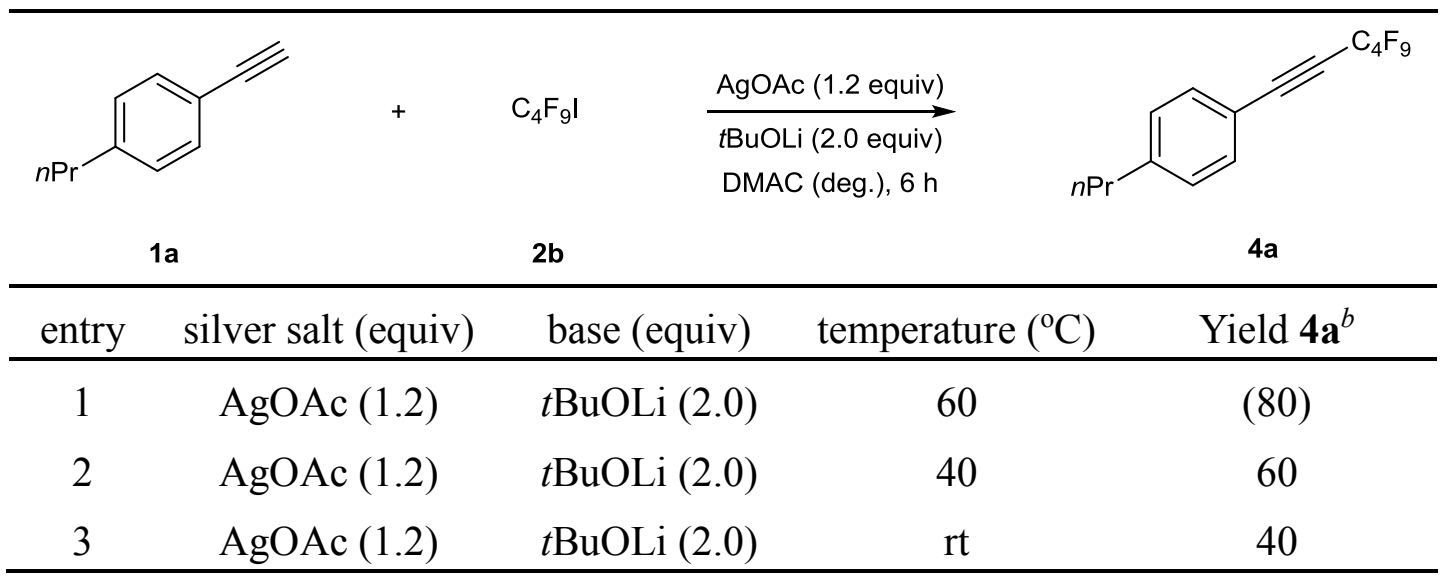

${ }^{a}$ Reaction conditions (unless otherwise specified): 1a $(0.2 \mathrm{mmol}, 1.0$ equiv), $\mathbf{2 b}(0.6 \mathrm{mmol}, 3.0$ equiv), silver salt ( $0.24 \mathrm{mmol}, 1.2$ equiv), base ( $0.4 \mathrm{mmol}, 2.0$ equiv), solvent $(2.0 \mathrm{~mL}), 80^{\circ} \mathrm{C}, 6 \mathrm{~h}$. ${ }^{b} \mathrm{NMR}$ yield determined by ${ }^{19} \mathrm{~F}$ NMR using fluorobenzene as the internal standard. The number in parentheses is the yield of the isolated product. deg. = degas. 
NMR Spectra

1-(perfluorohex-1-yn-1-yl)-4-propylbenzene (4a)
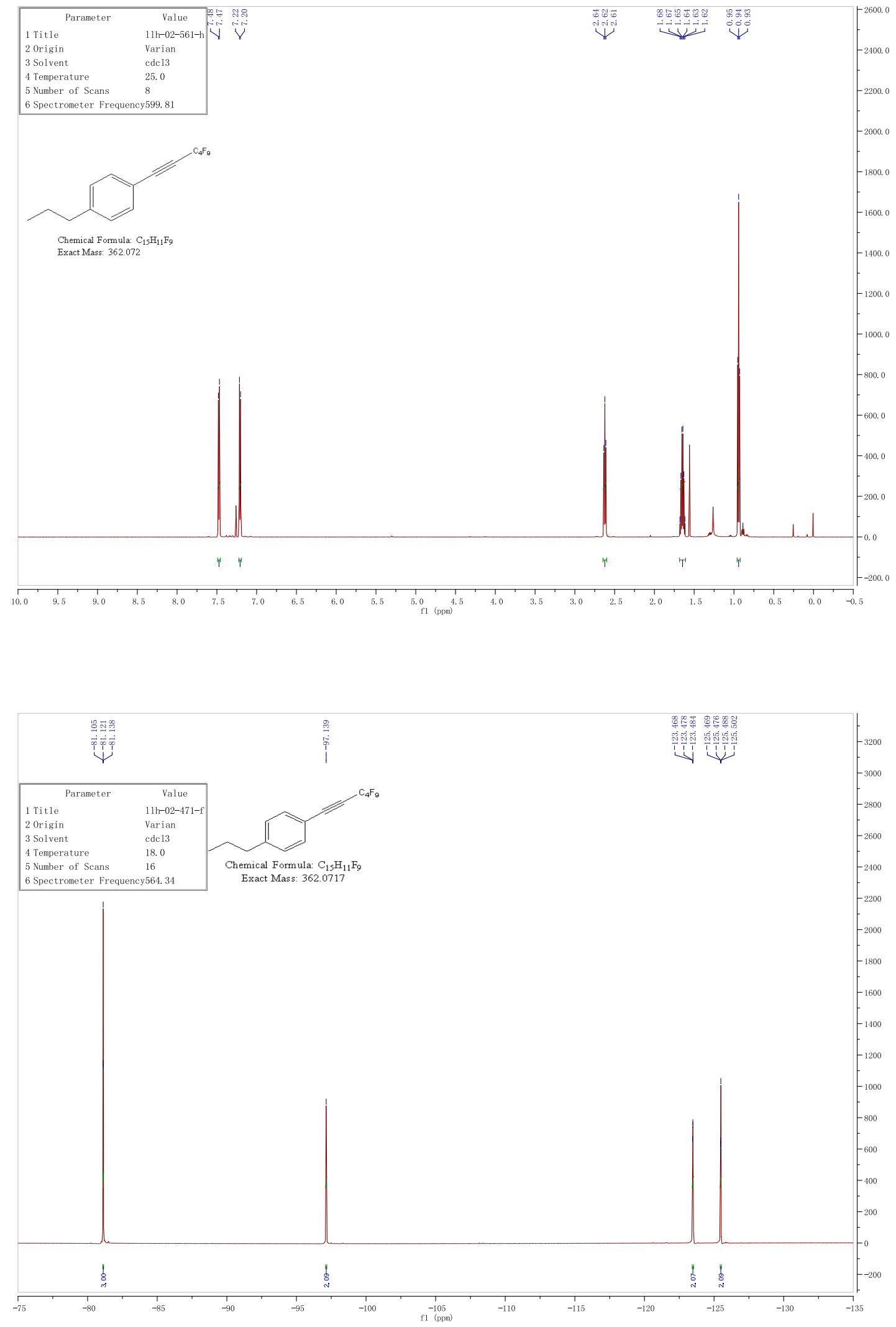


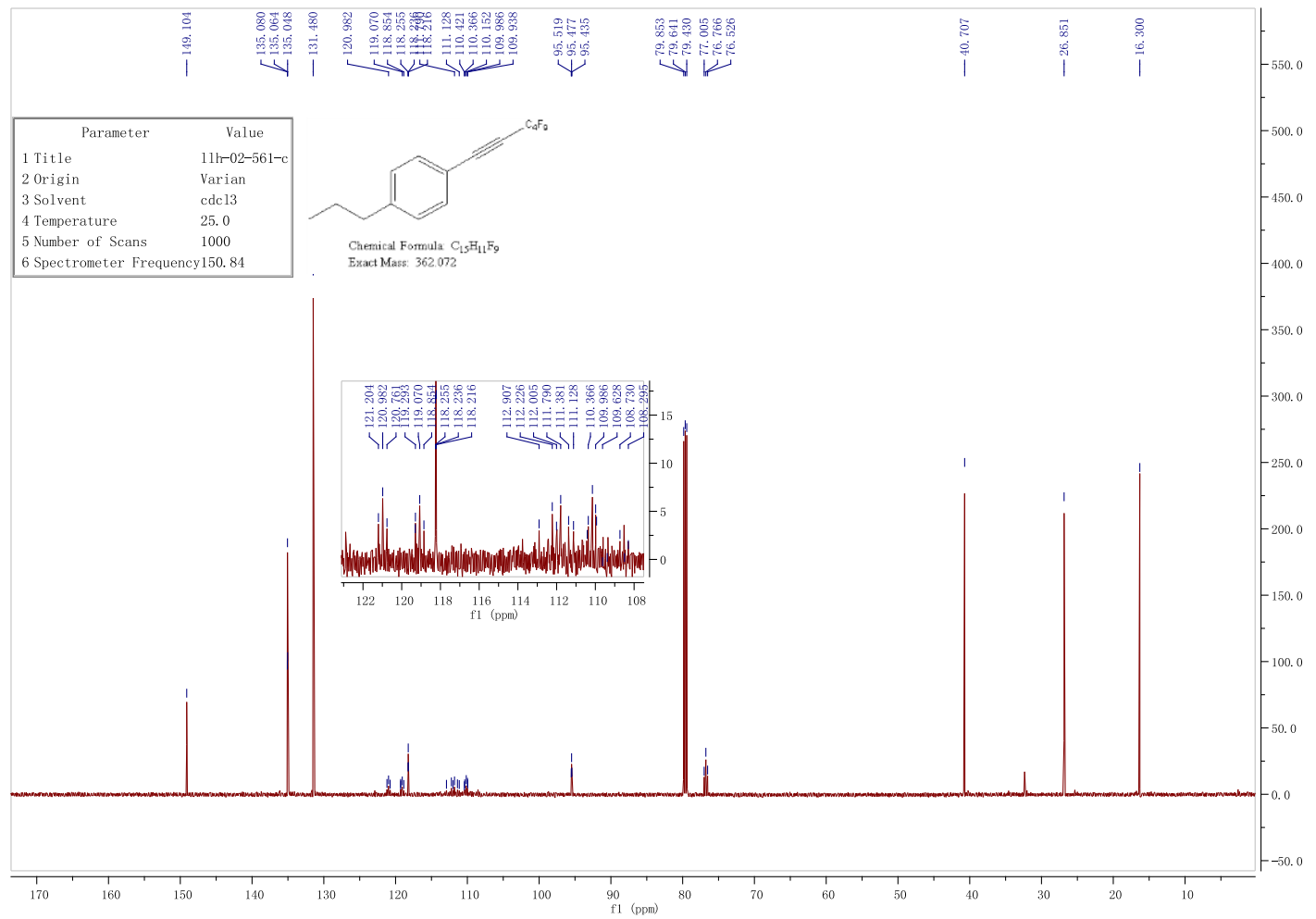

1-pentyl-4-(perfluorohex-1-yn-1-yl)benzene (4b)

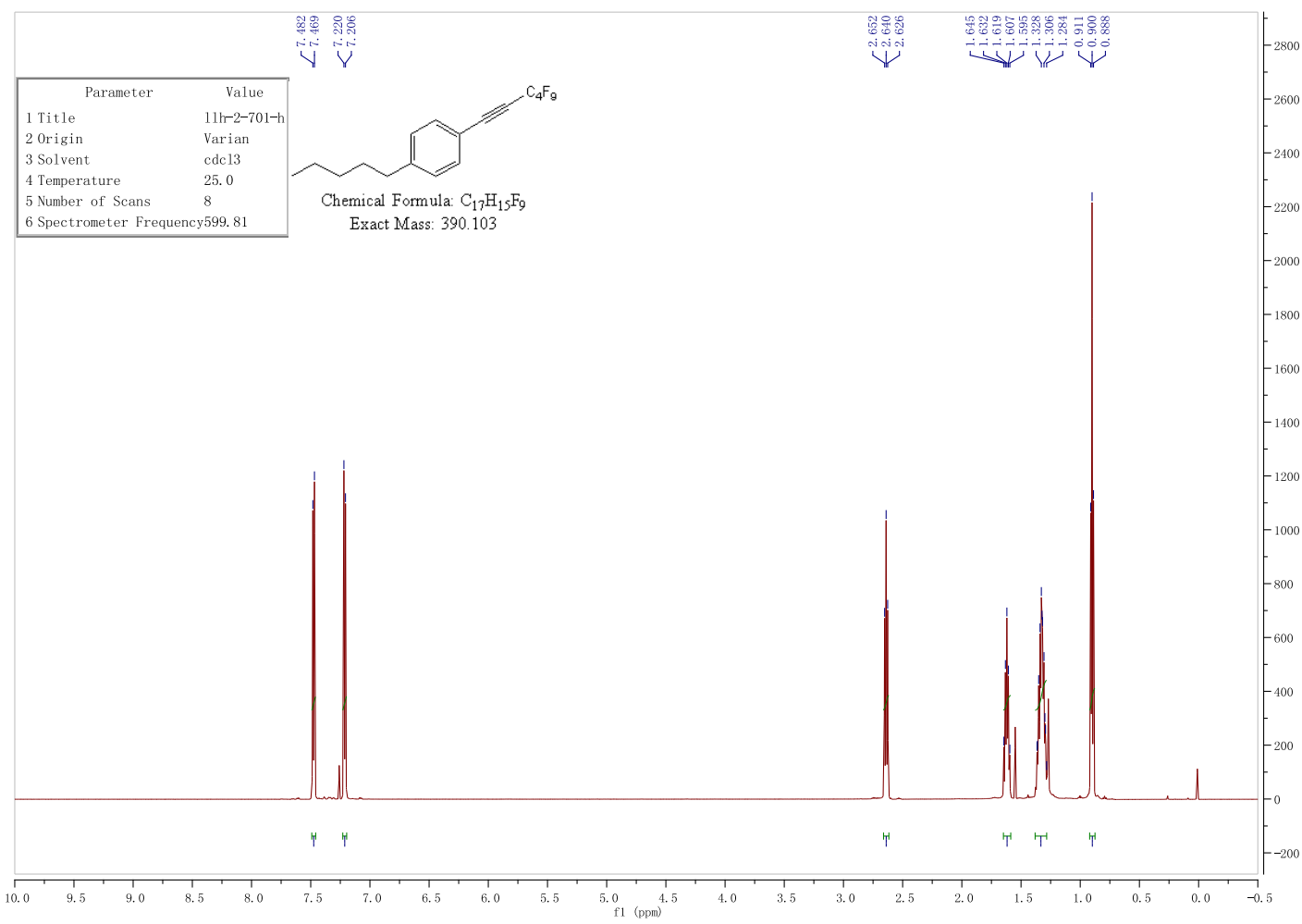



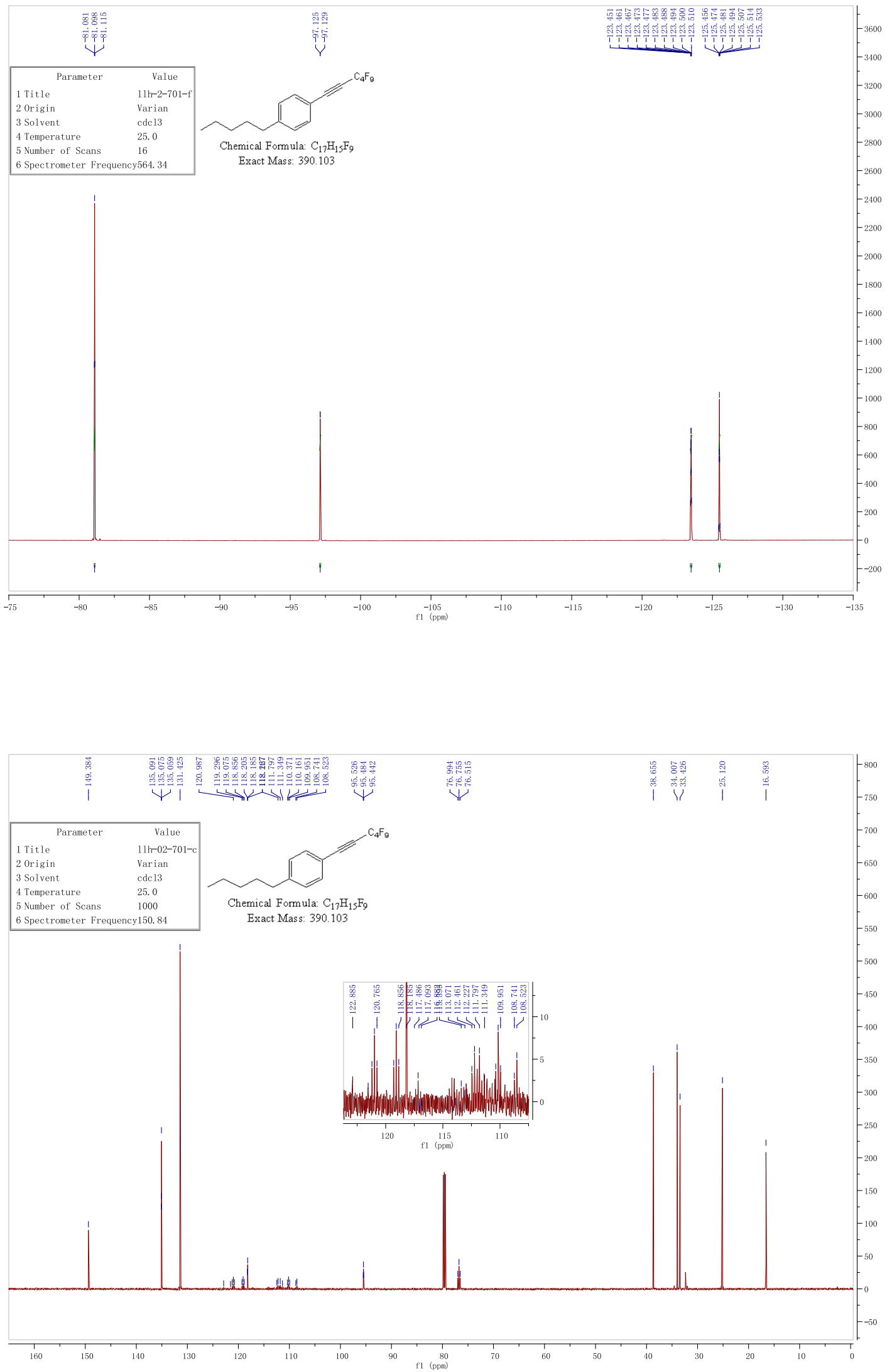
1-(tert-butyl)-4-(perfluorohex-1-yn-1-yl)benzene (4c)
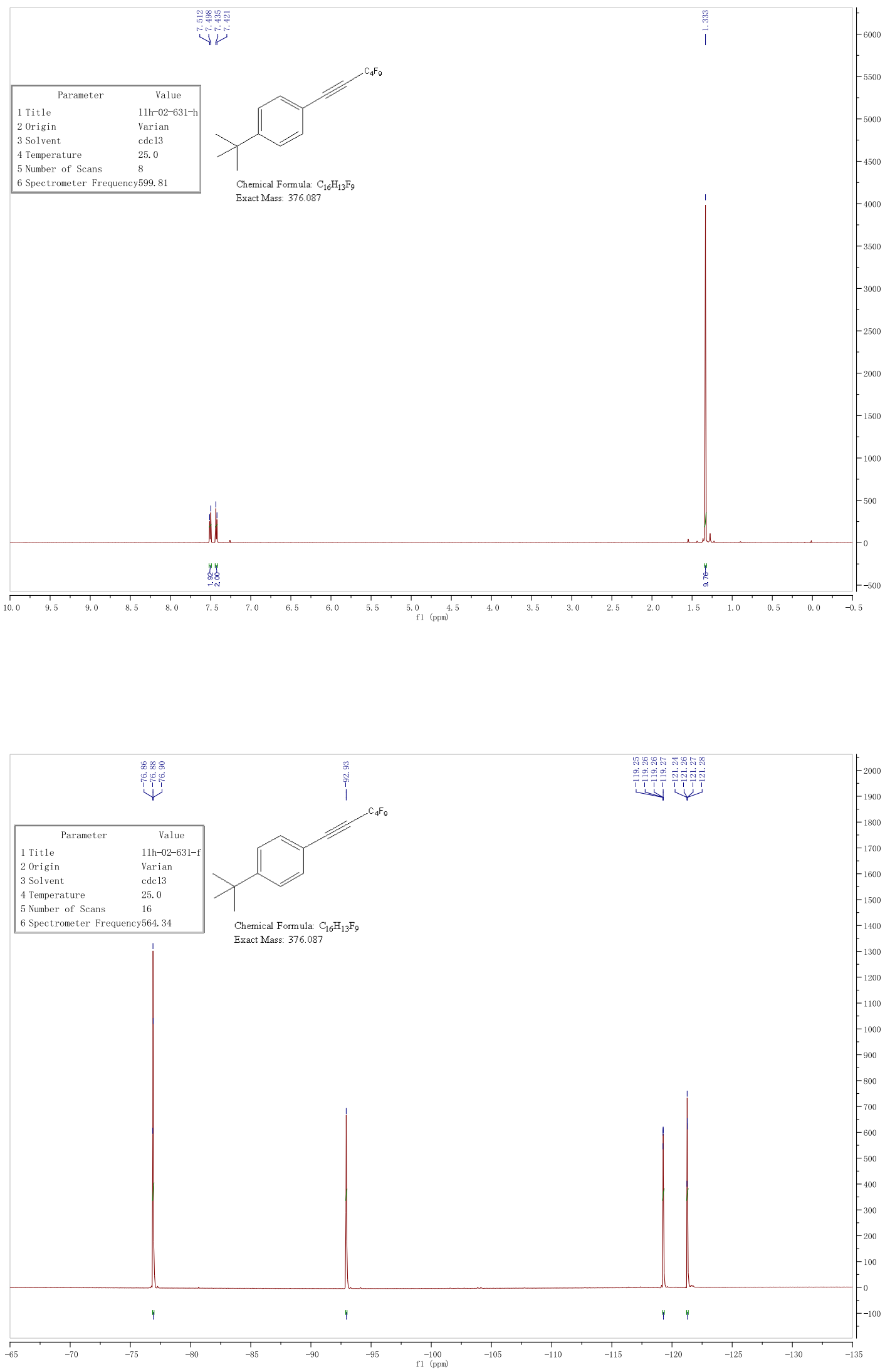


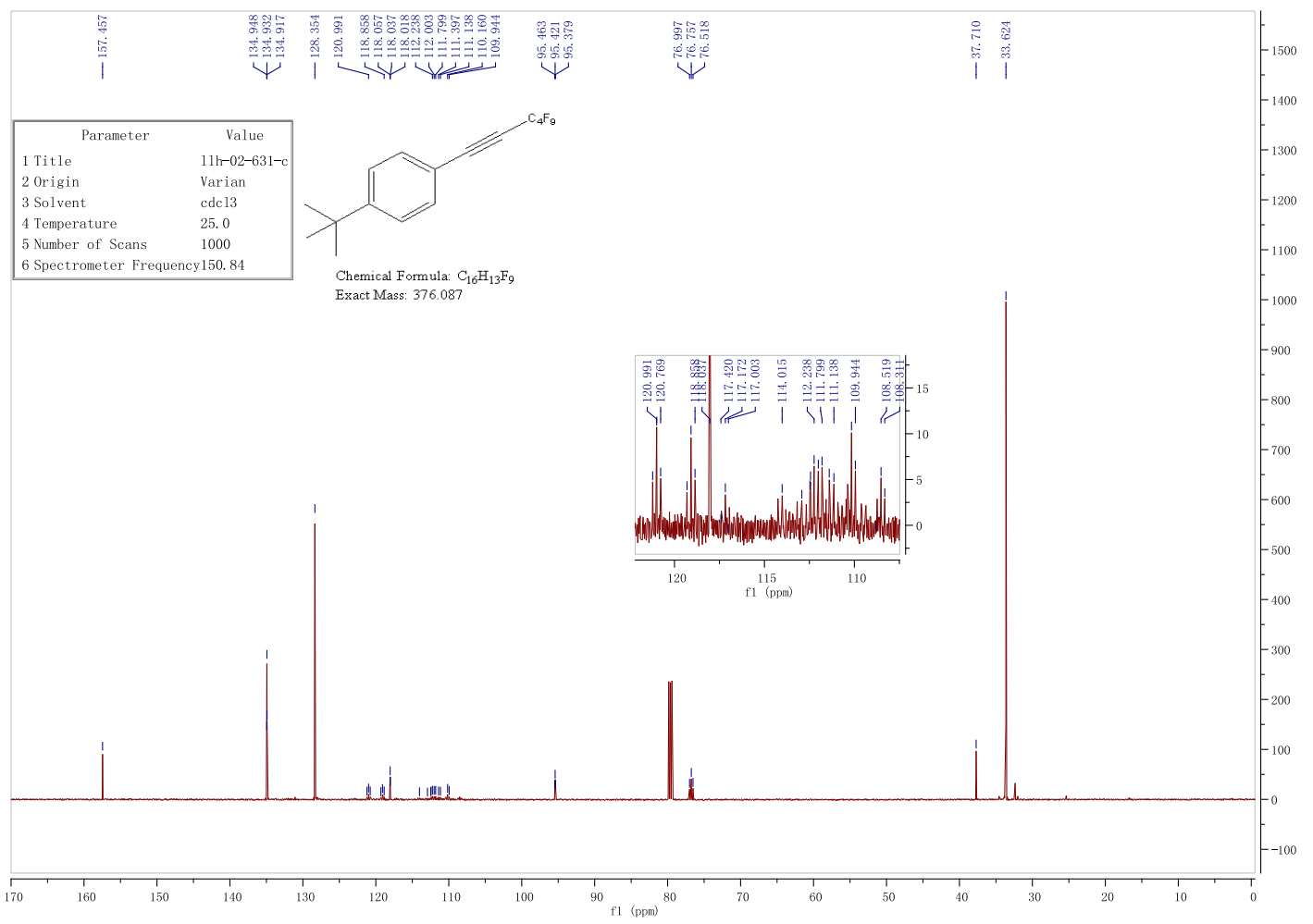

(perfluorohex-1-yn-1-yl)benzene (4d)

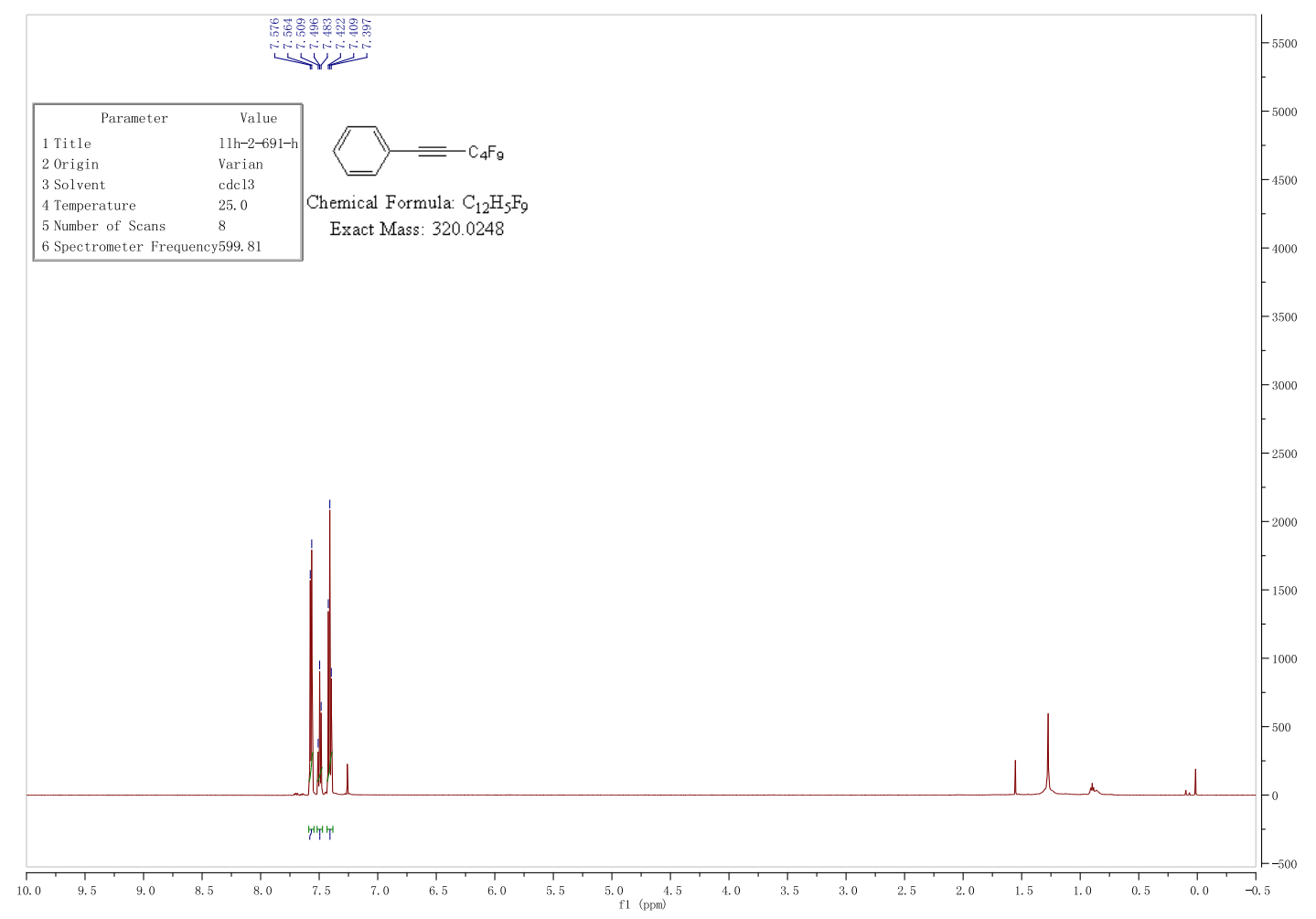




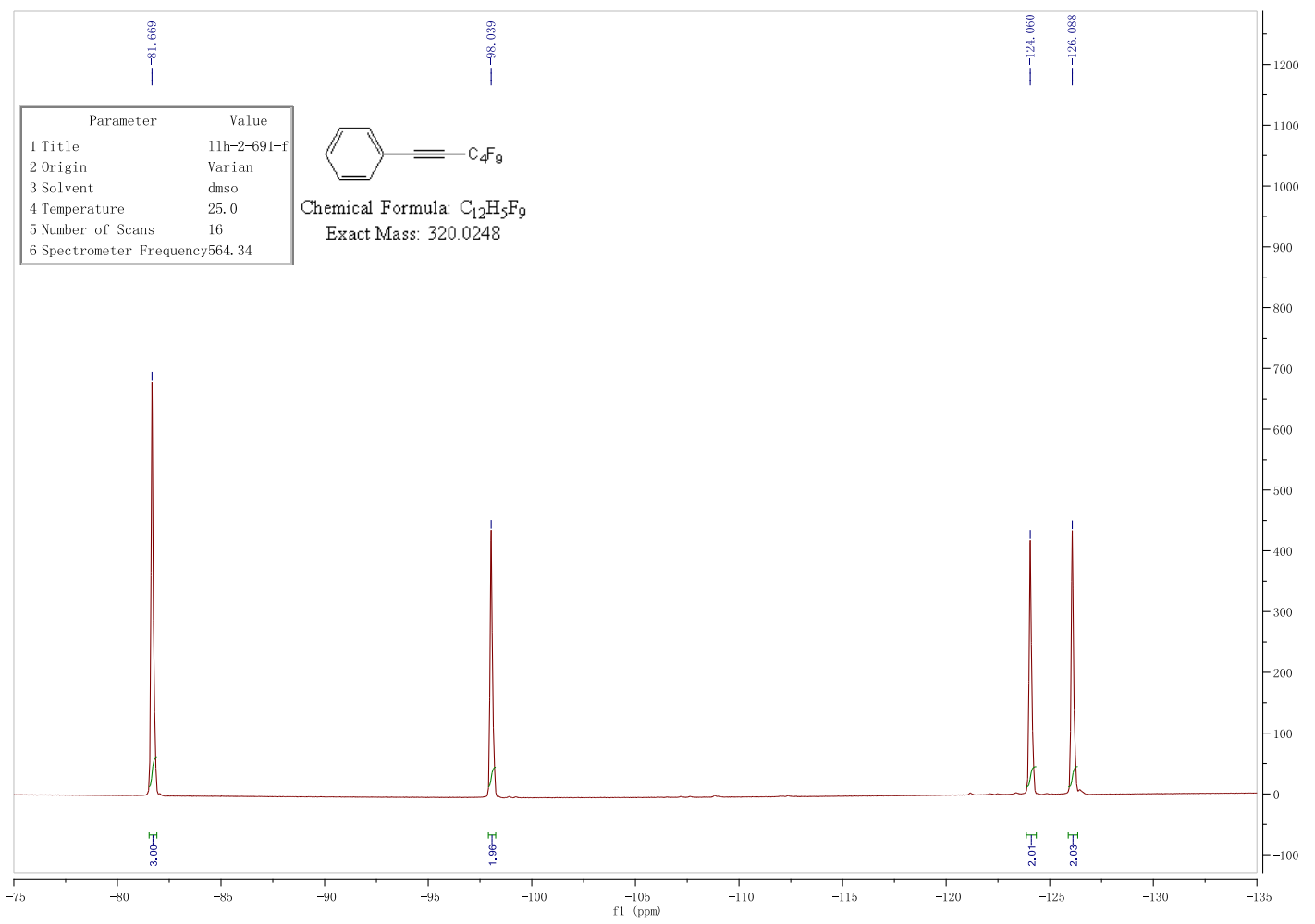

1-methoxy-4-(perfluorohex-1-yn-1-yl)benzene (4e)

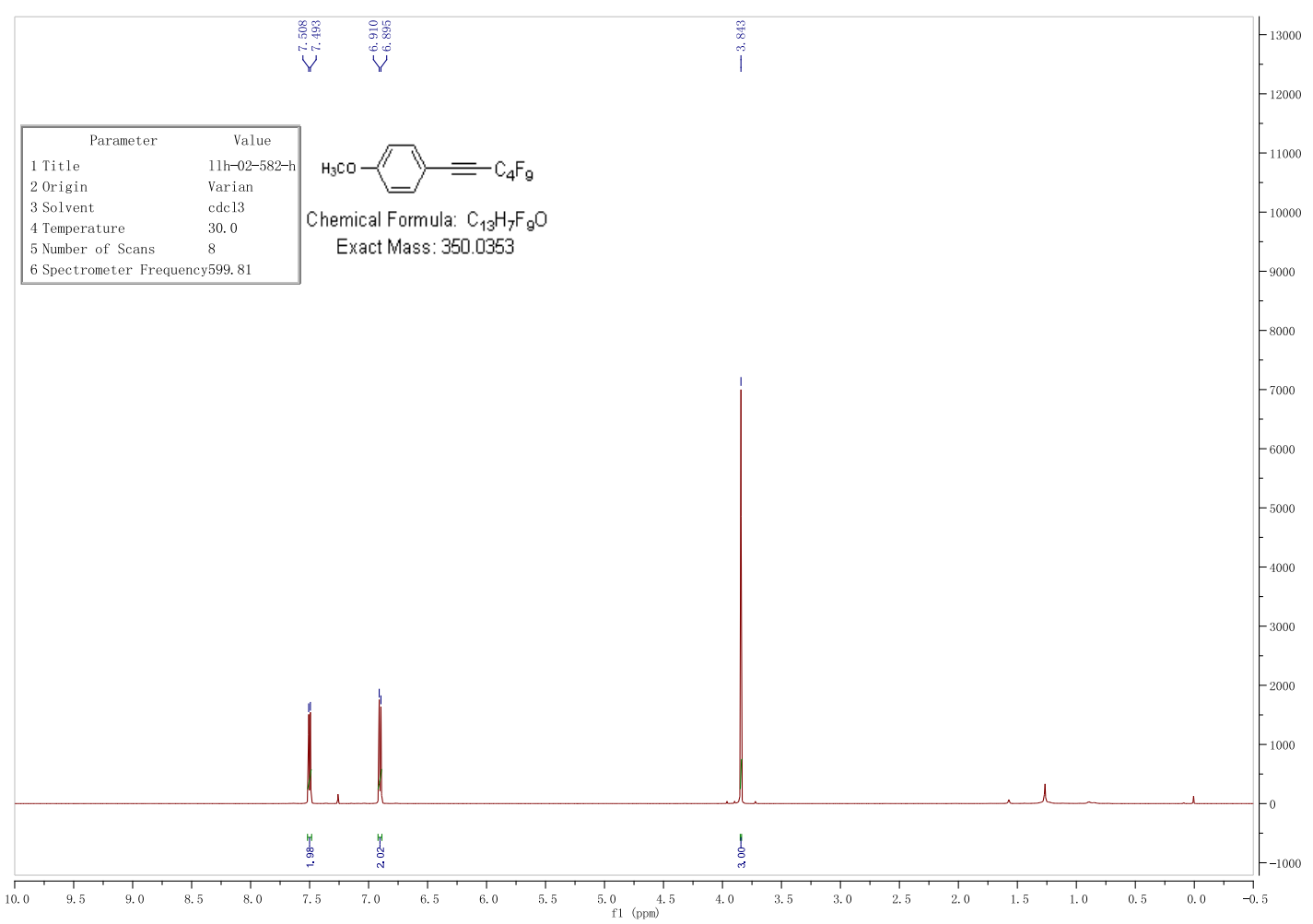



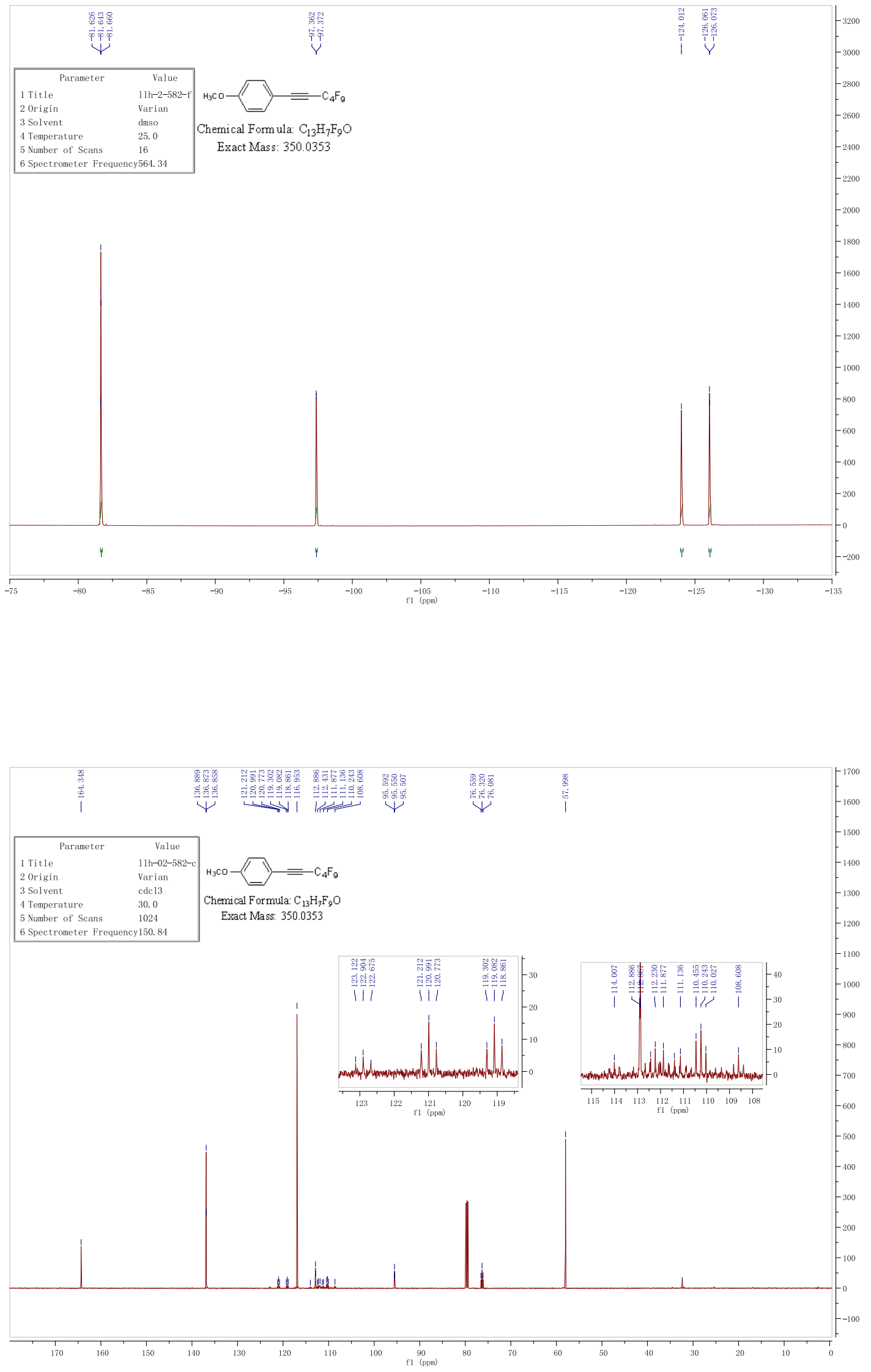
1-(pentyloxy)-4-(perfluorohex-1-yn-1-yl)benzene (4f)
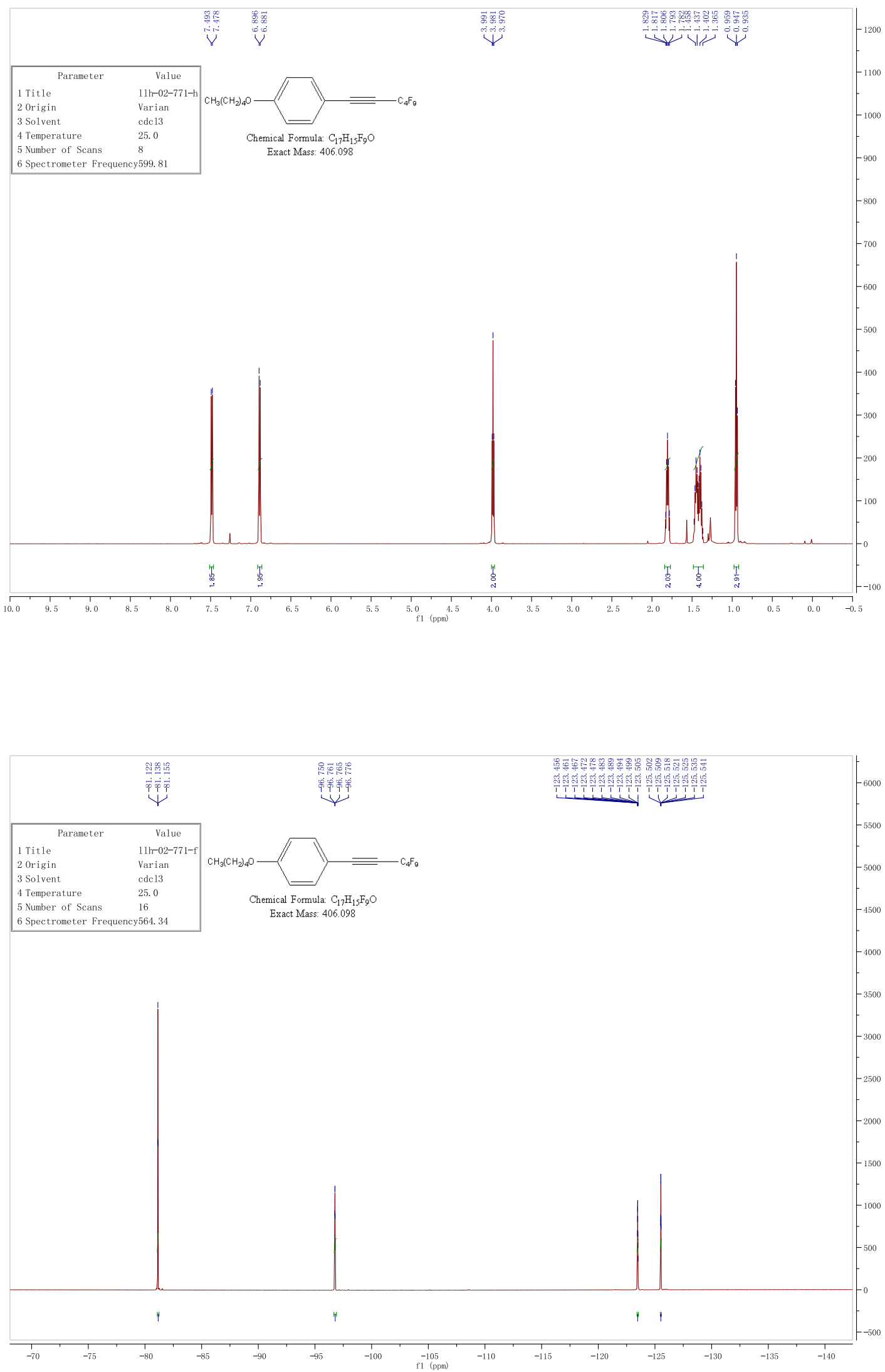


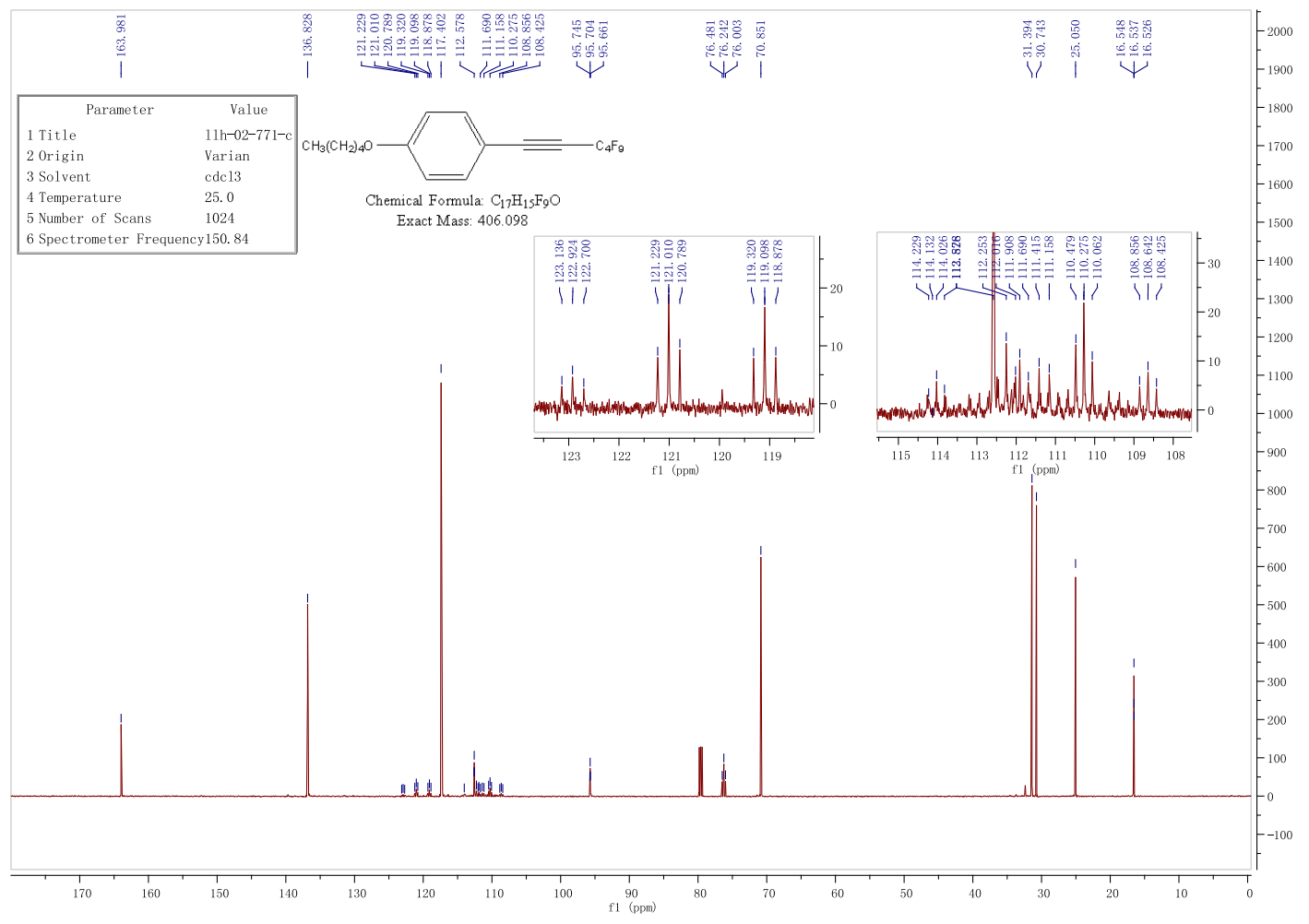

1,3-dimethoxy-5-(perfluorohex-1-yn-1-yl)benzene (4g)

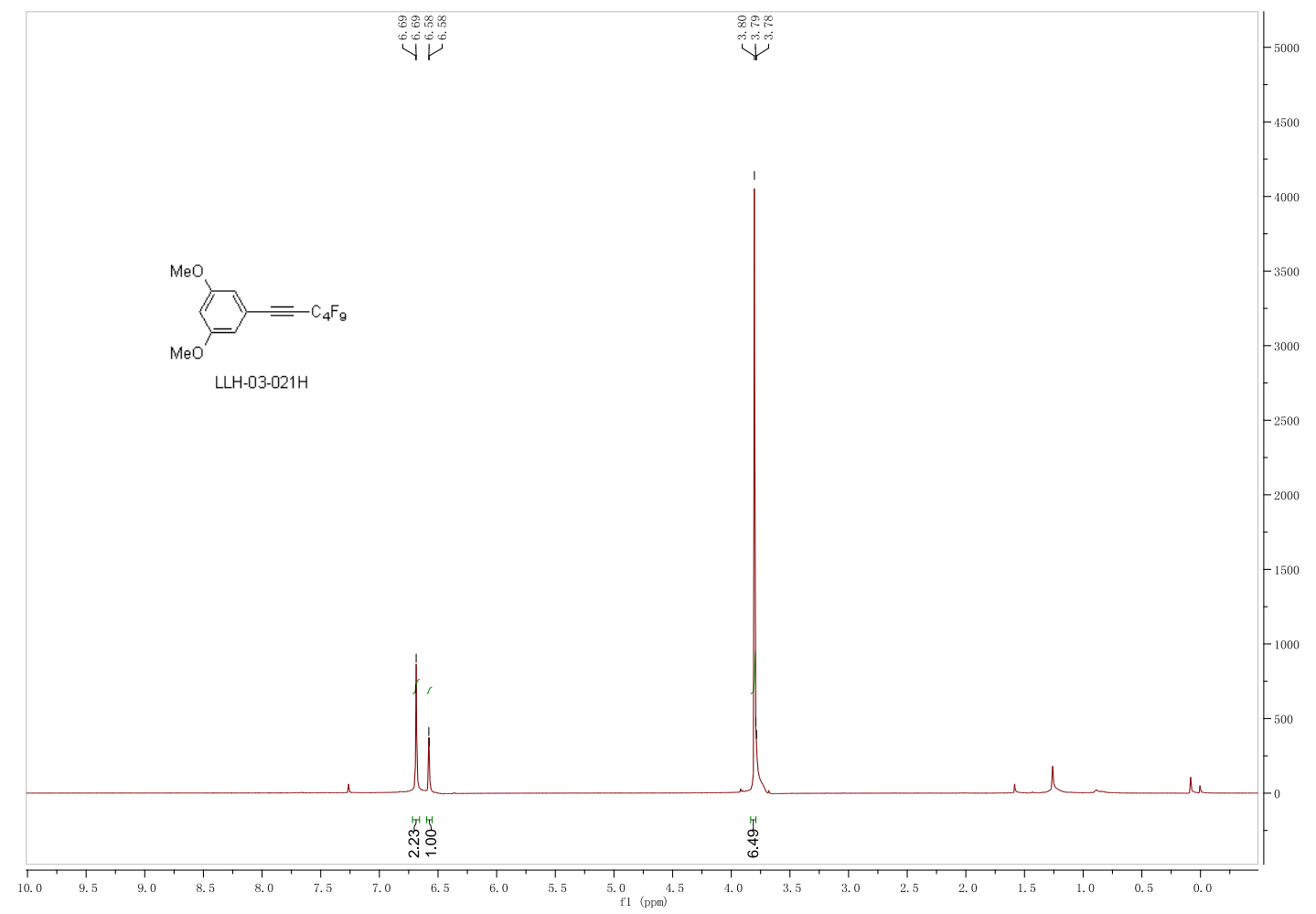



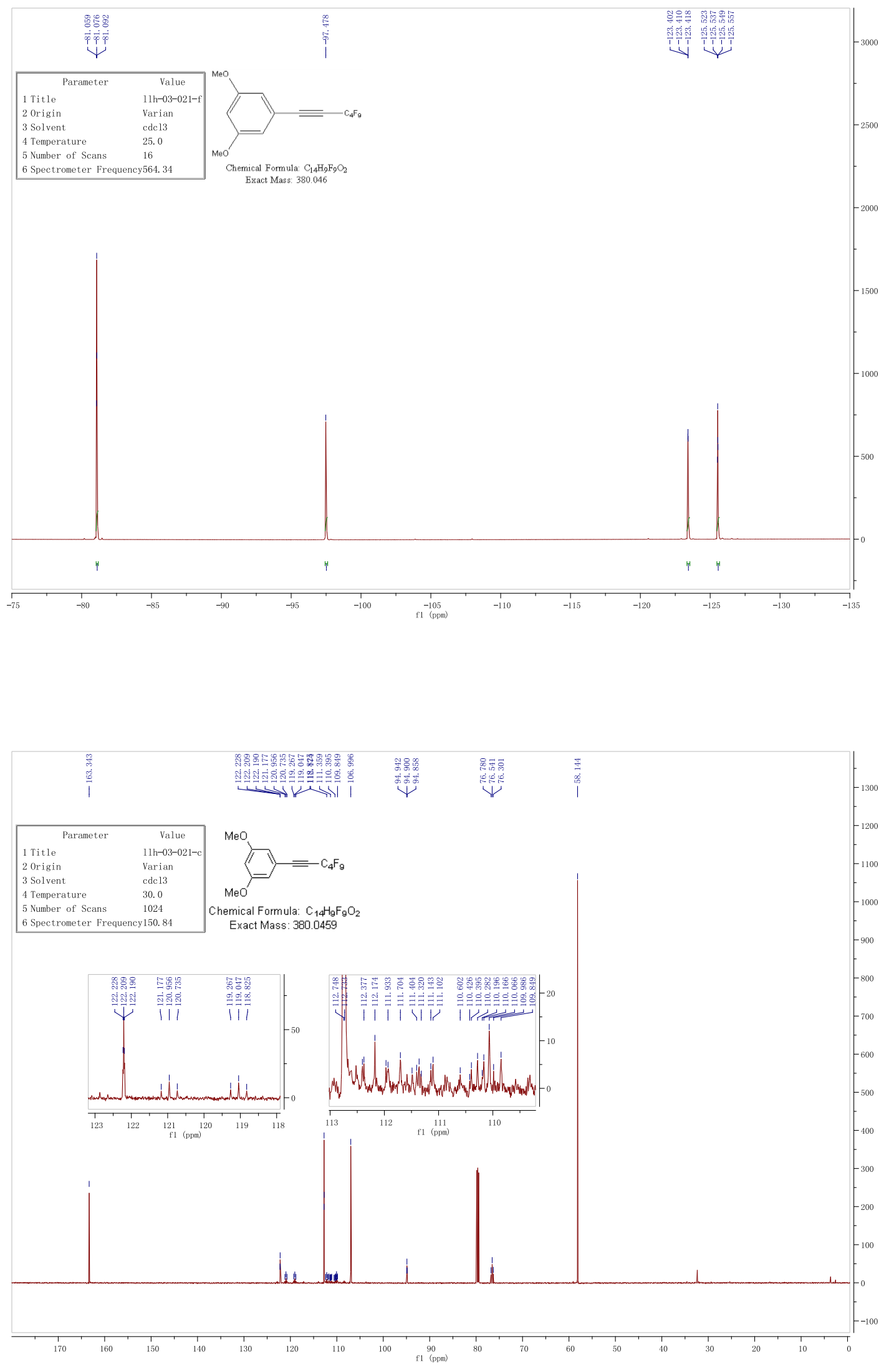
4-(perfluorohex-1-yn-1-yl)-1,1'-biphenyl (4h)
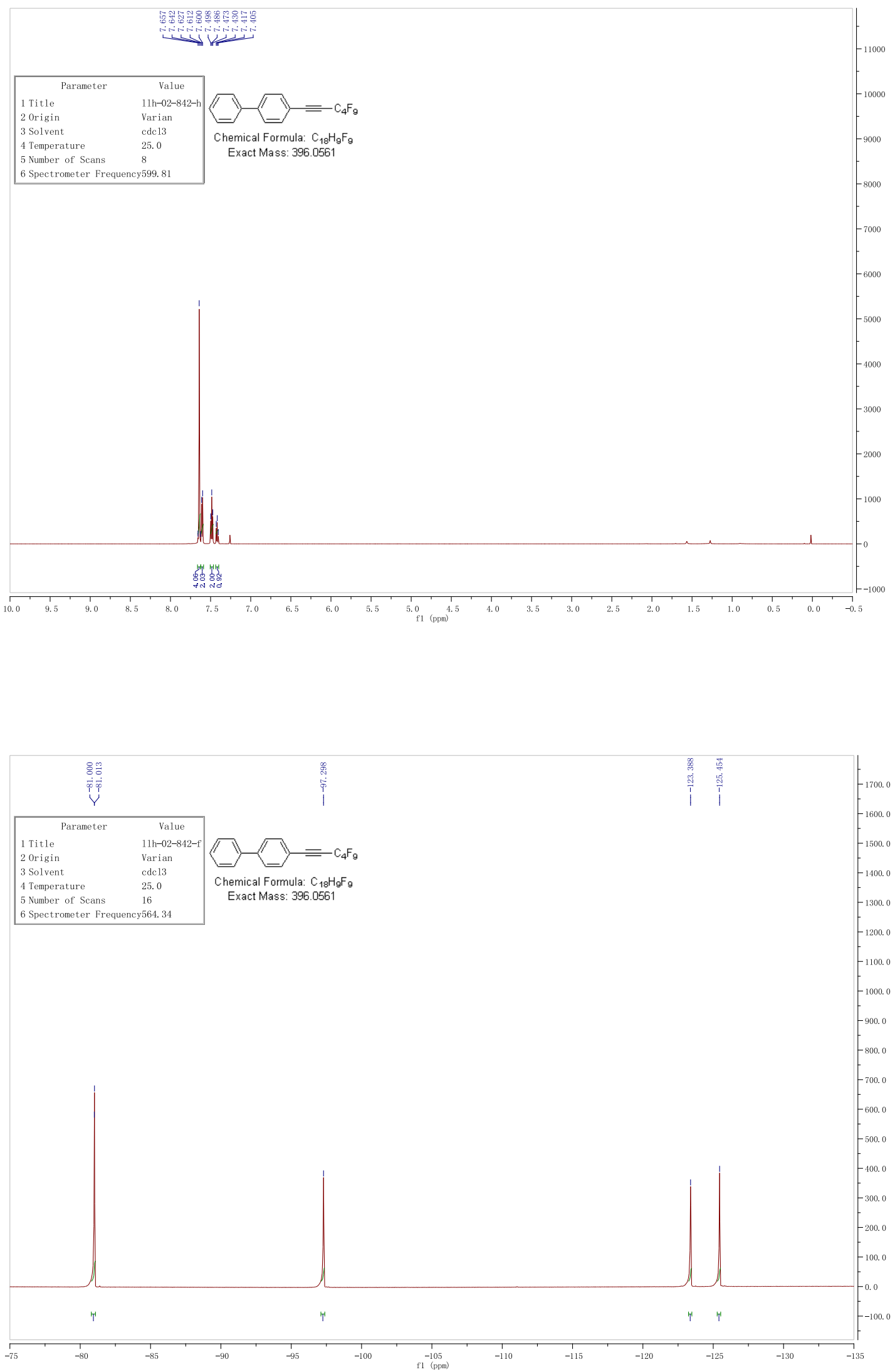


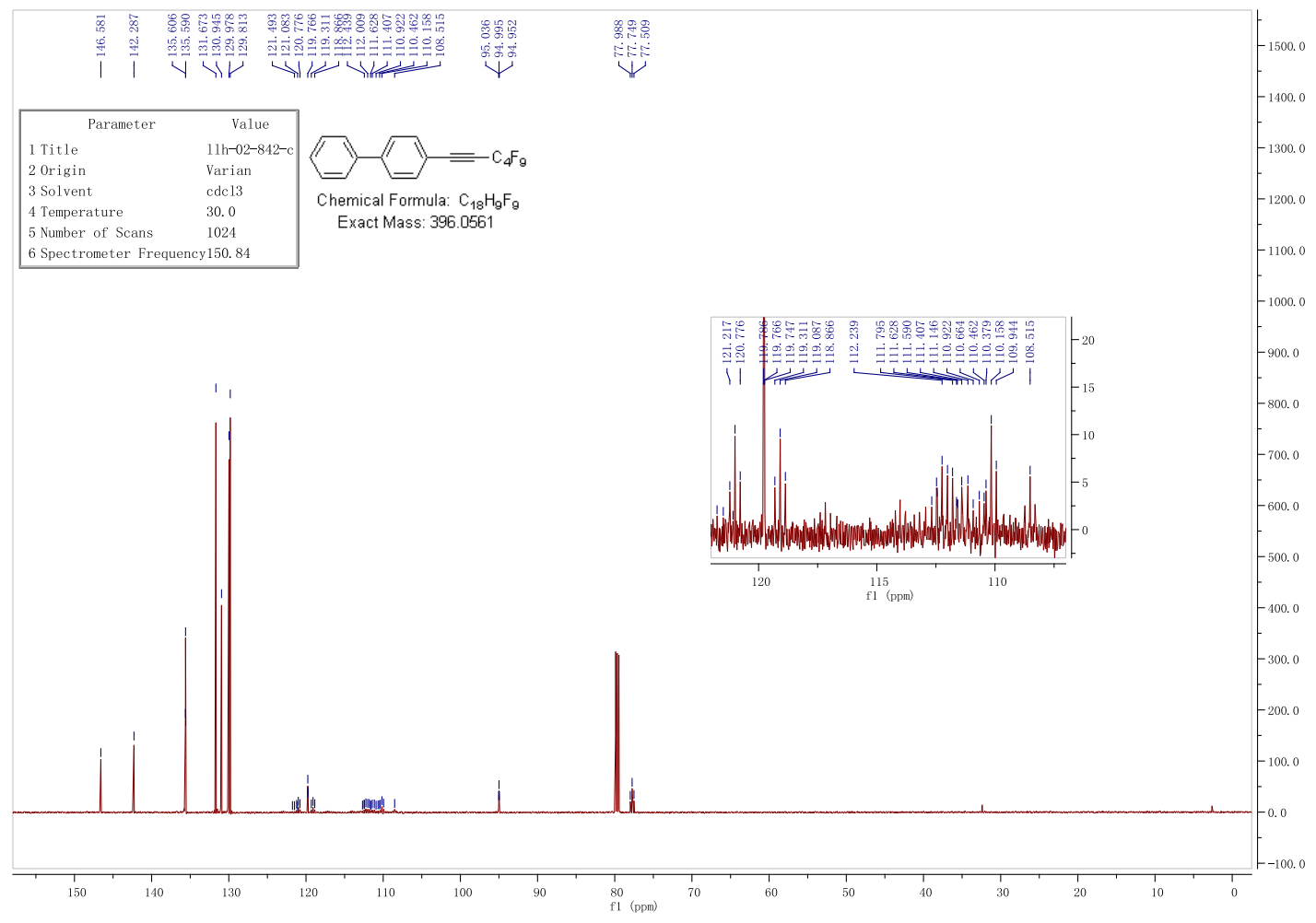

2-(perfluorohex-1-yn-1-yl)naphthalene (4i)

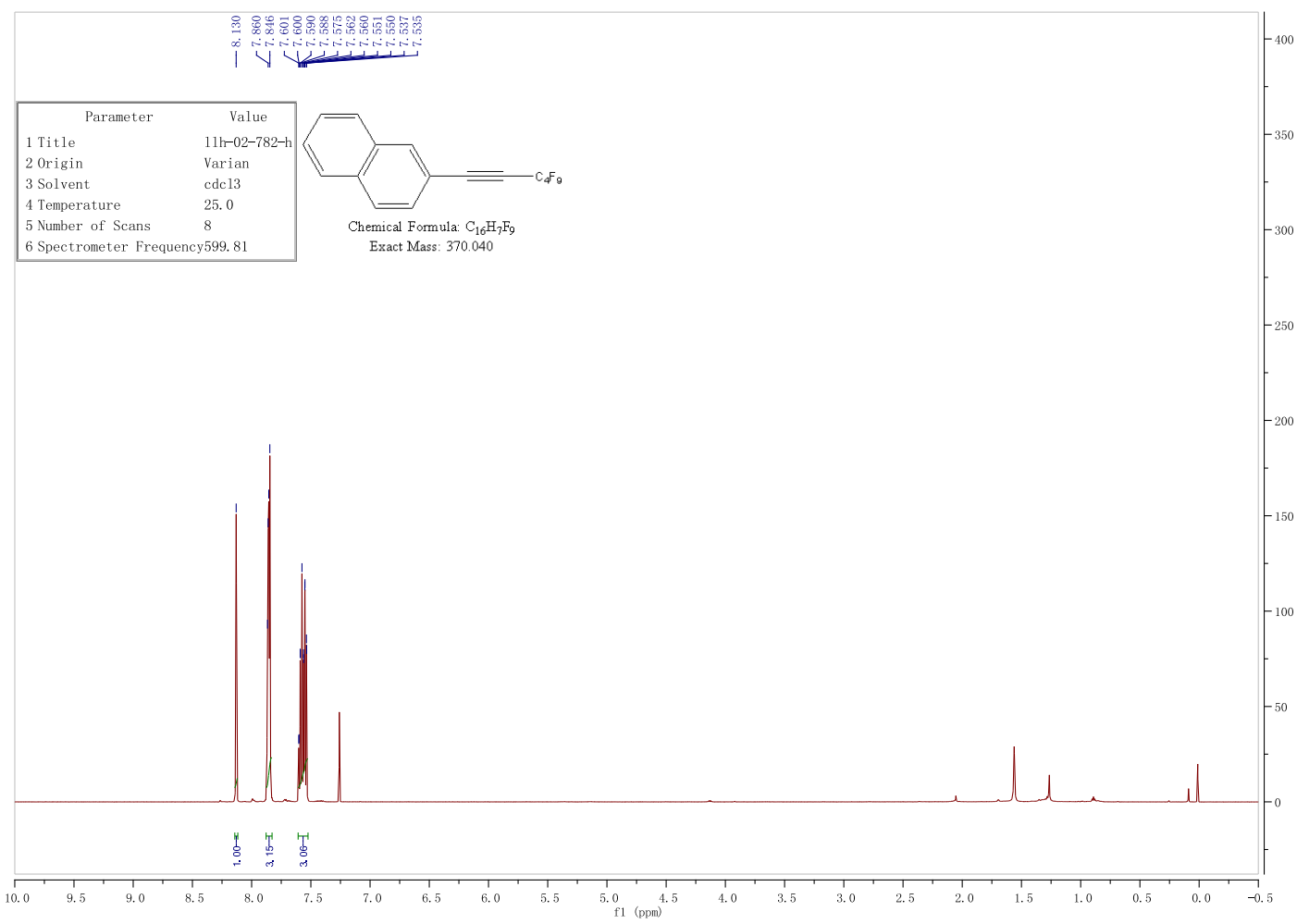



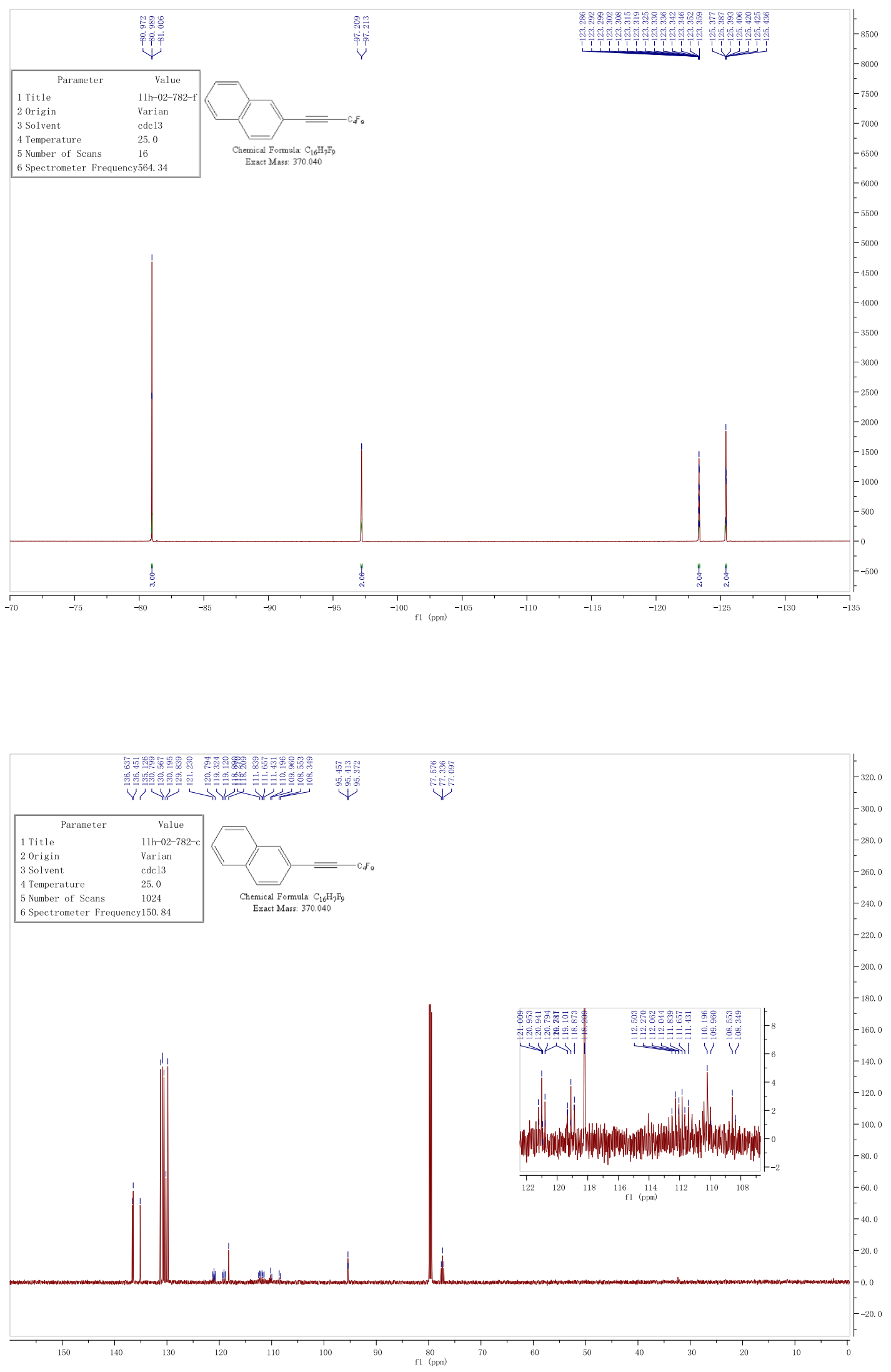
1-chloro-4-(perfluorohex-1-yn-1-yl)benzene (4j)
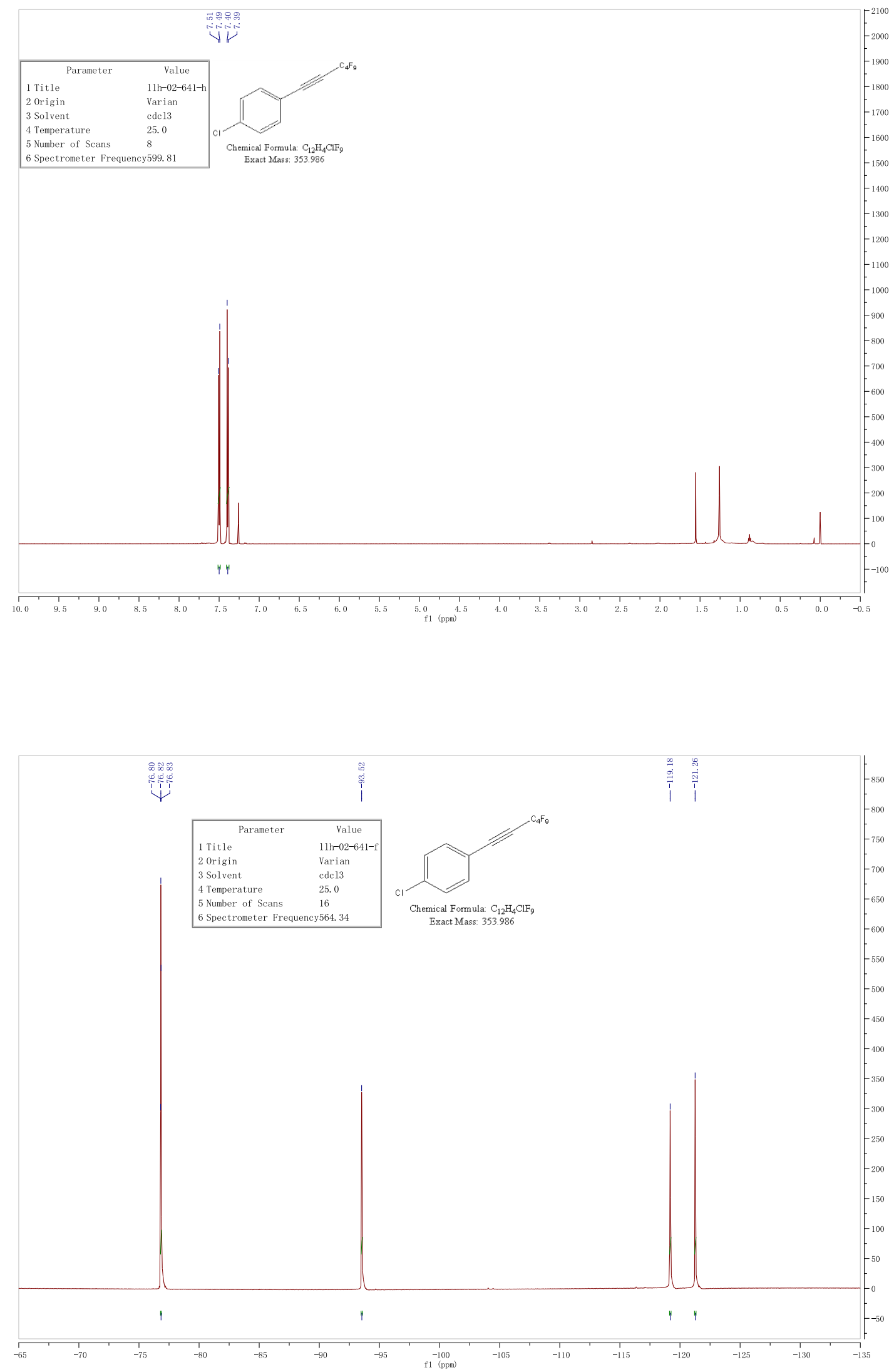


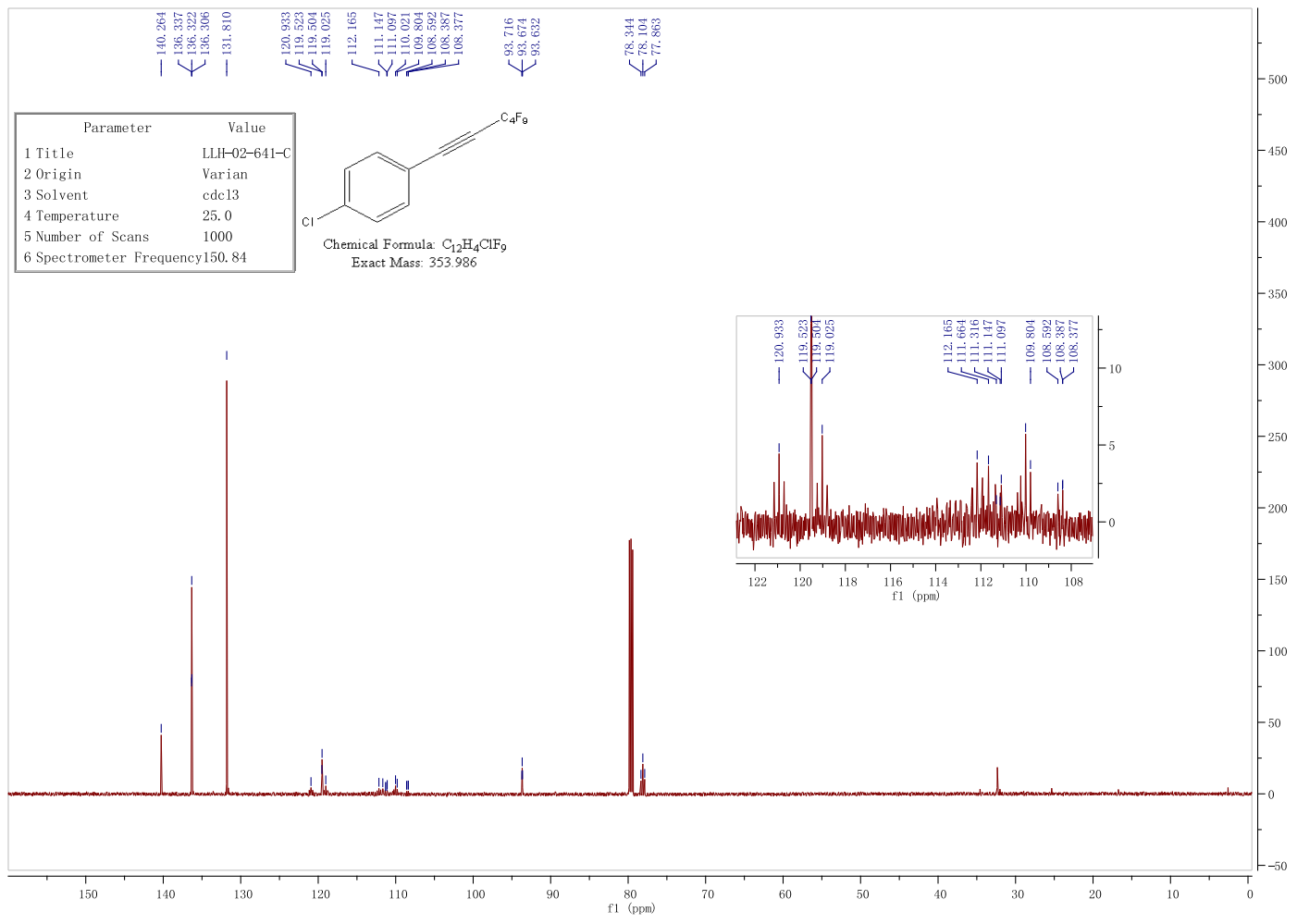

1-fluoro-4-(perfluorohex-1-yn-1-yl)benzene (4l)

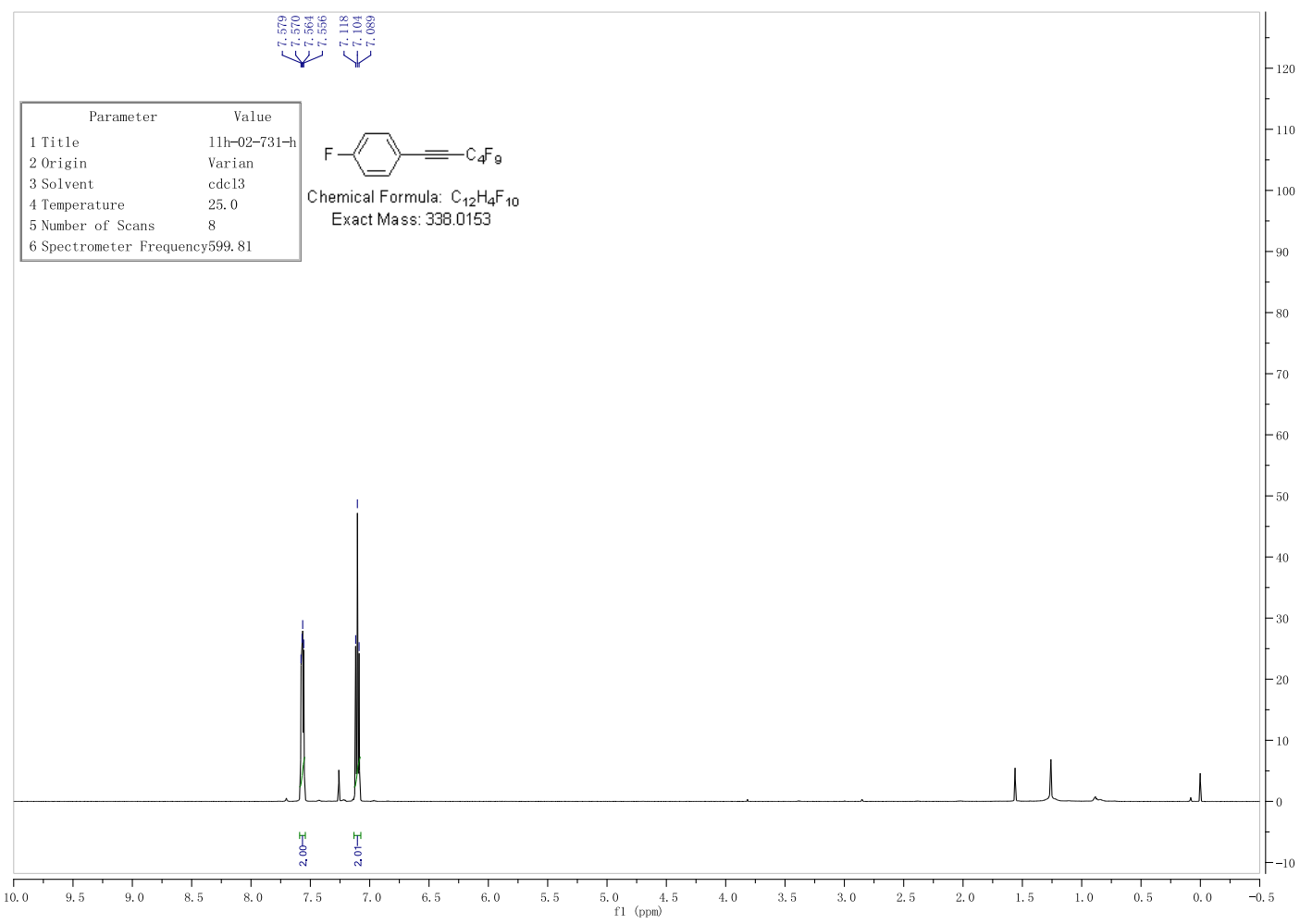



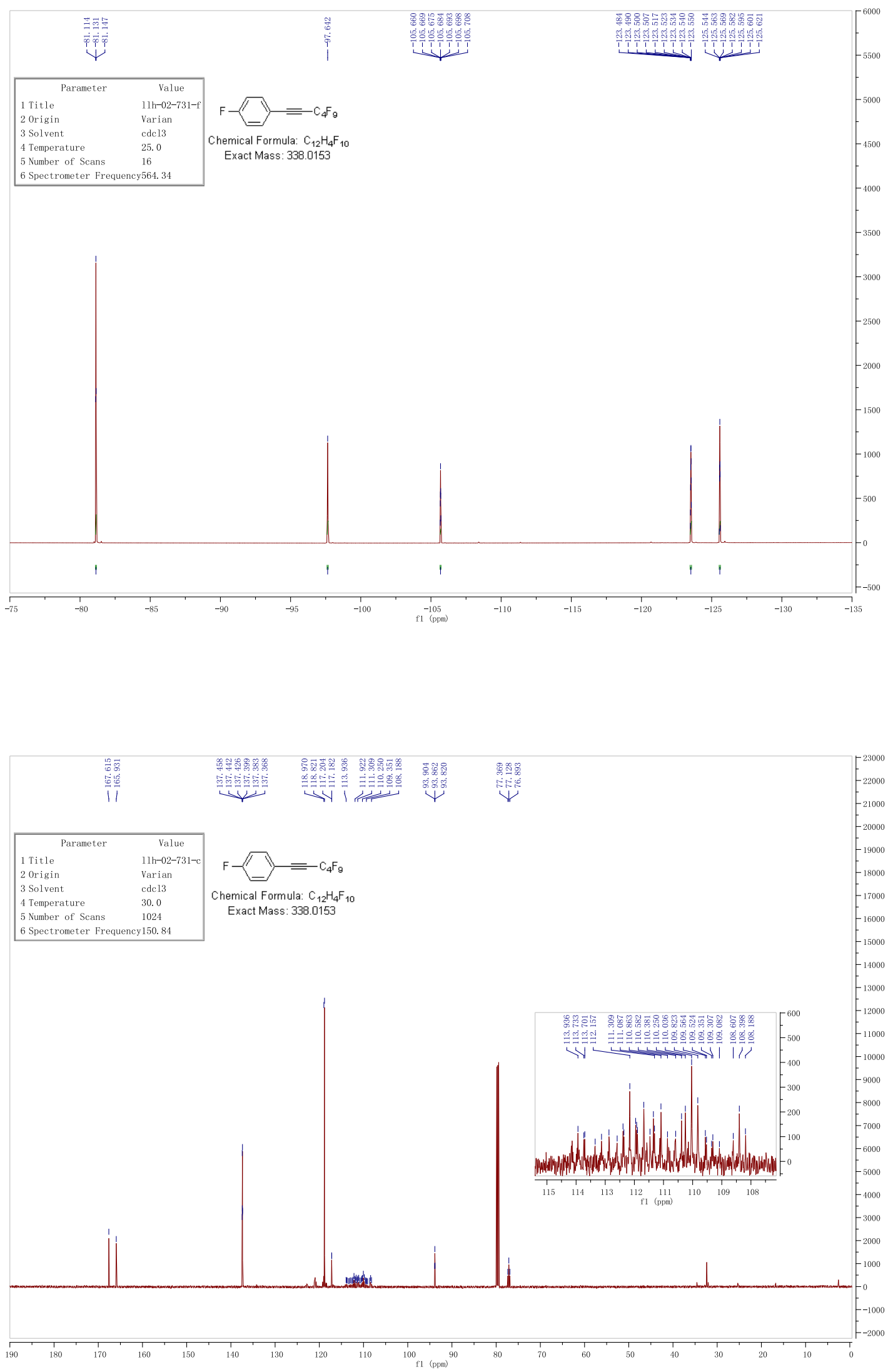
3-(Perfluorohex-1-yn-1-yl)pyridine (4l)
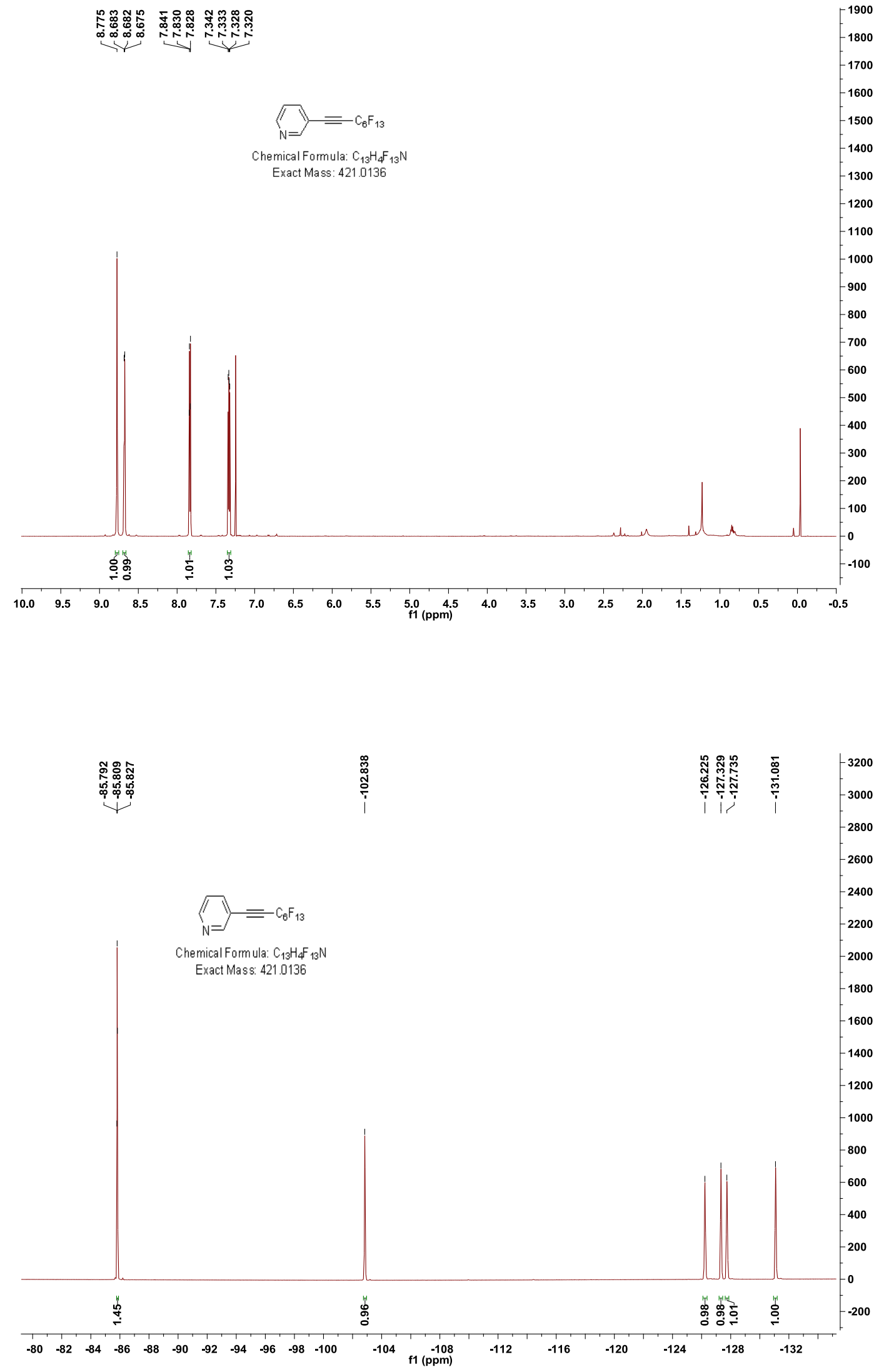


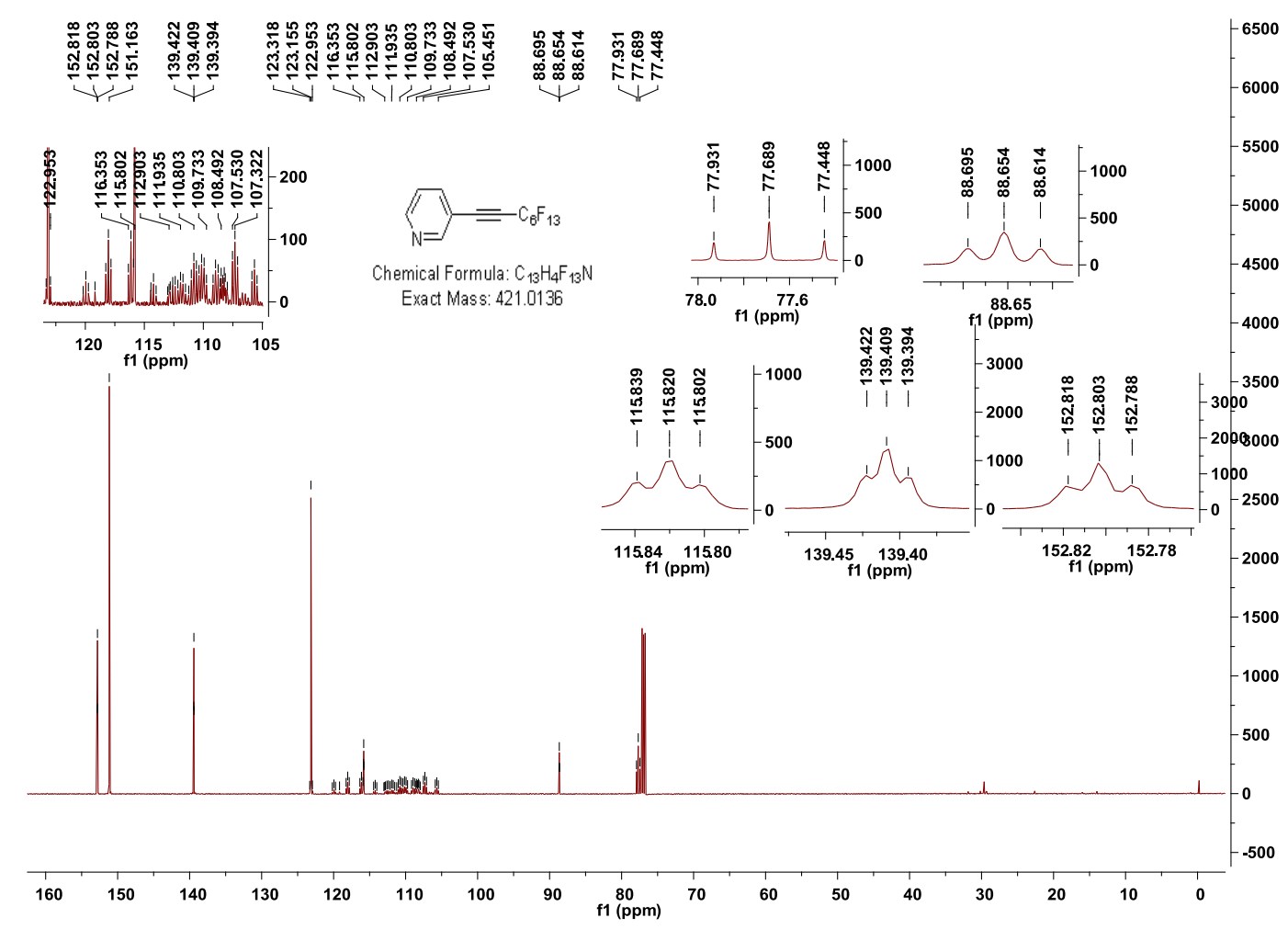

3-(Perfluorohex-1-yn-1-yl)thiophene(4m)

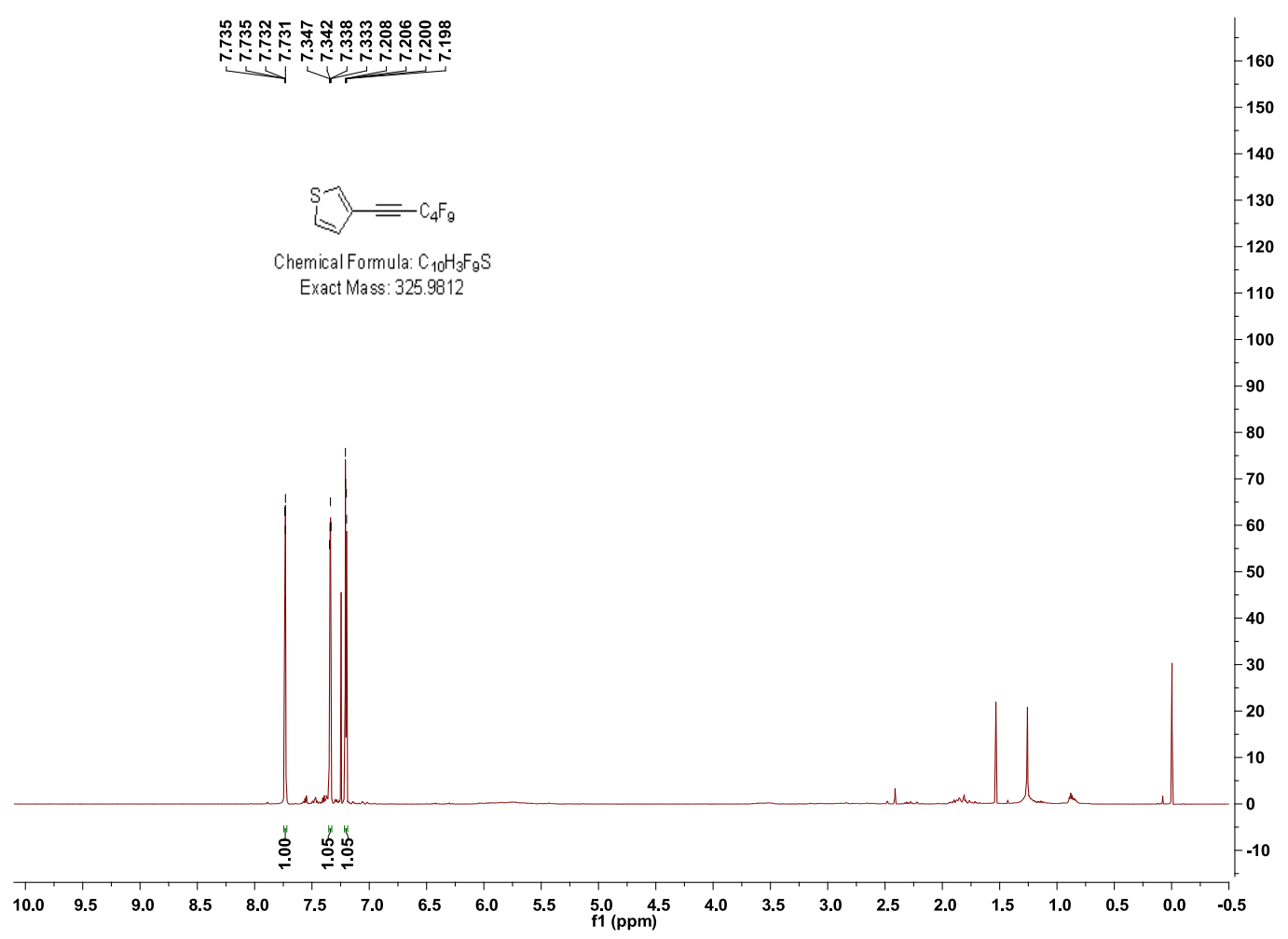



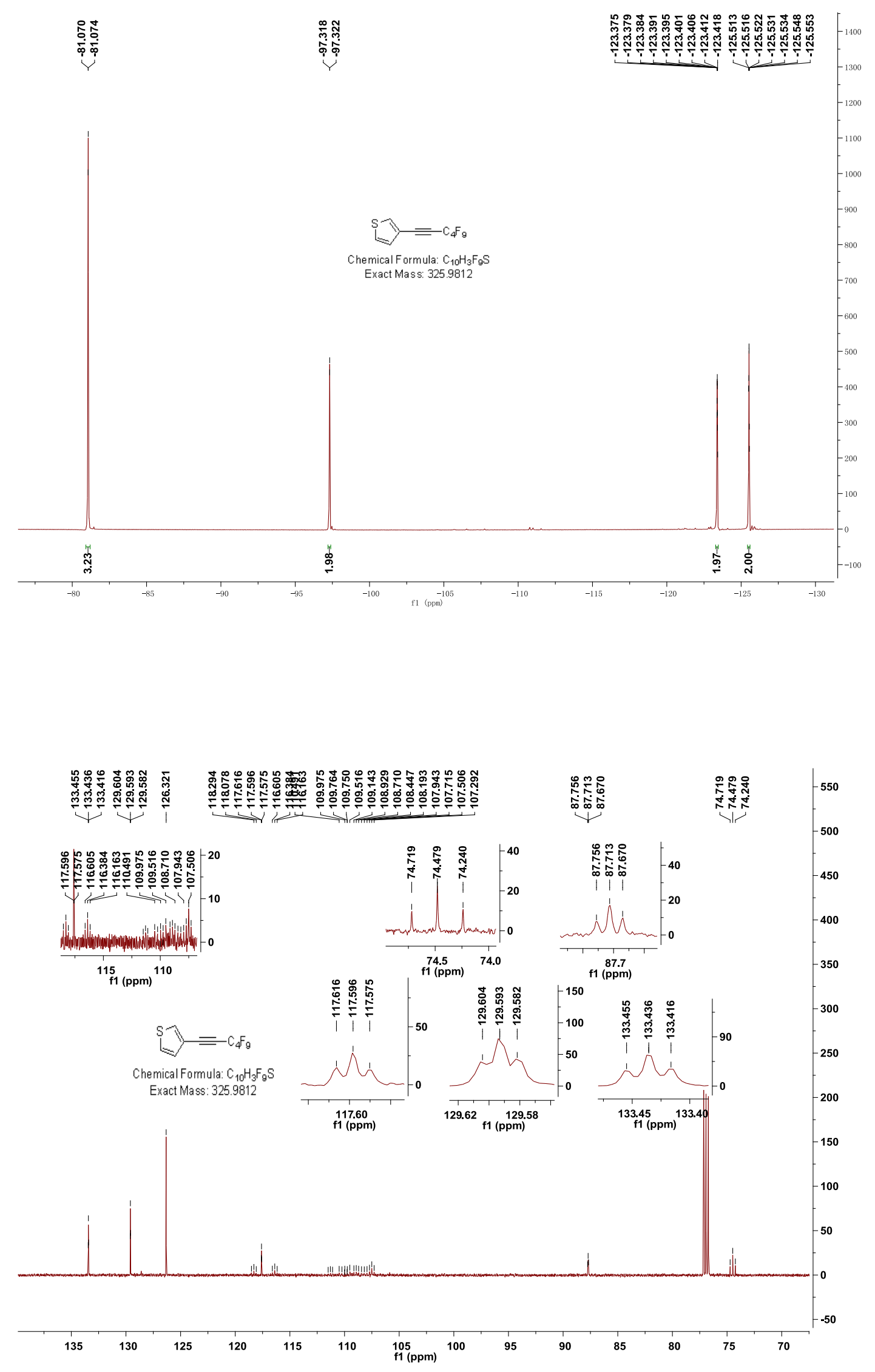
Methyl 4-(perfluorohex-1-yn-1-yl)benzoate (4n)
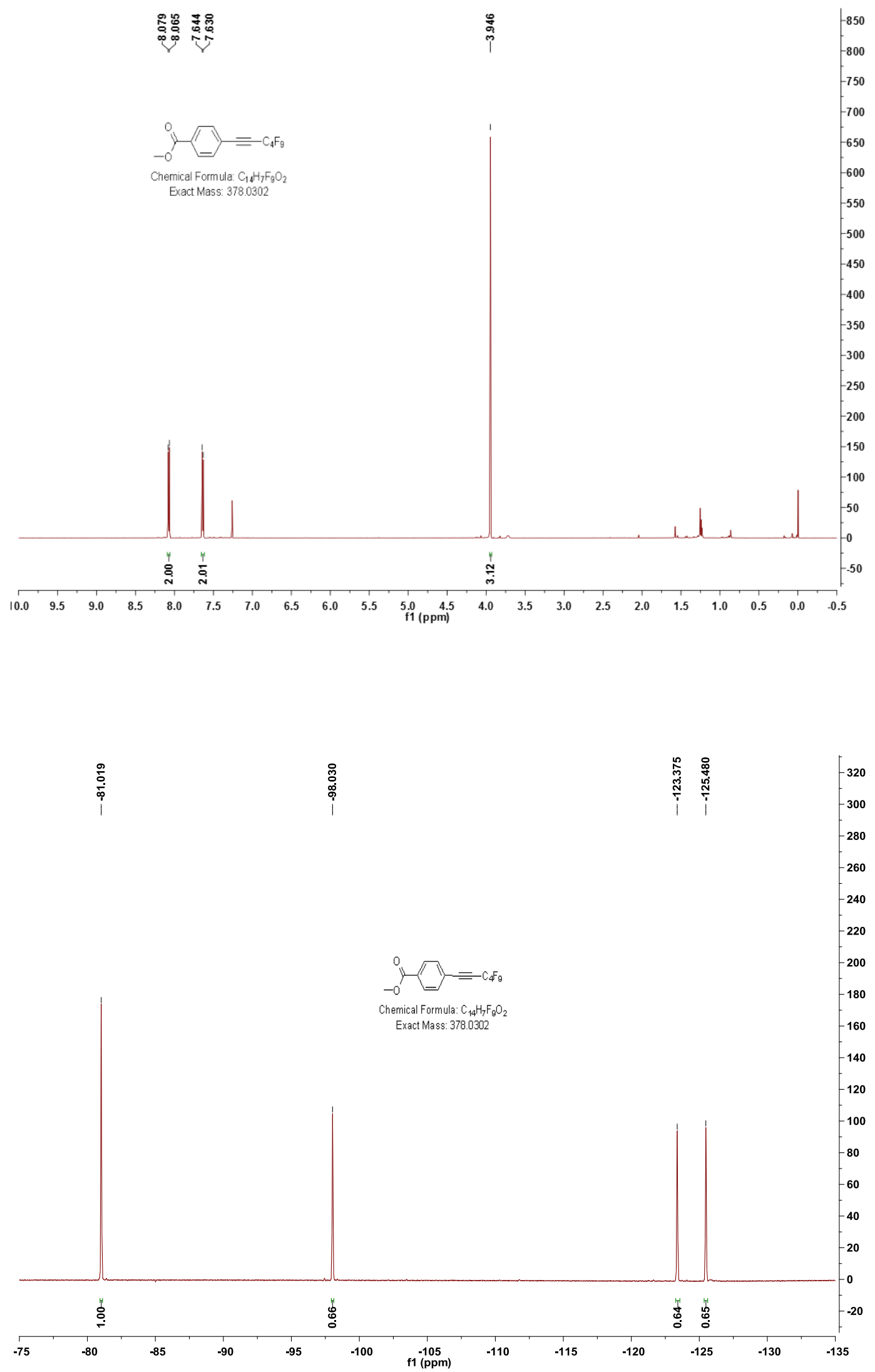


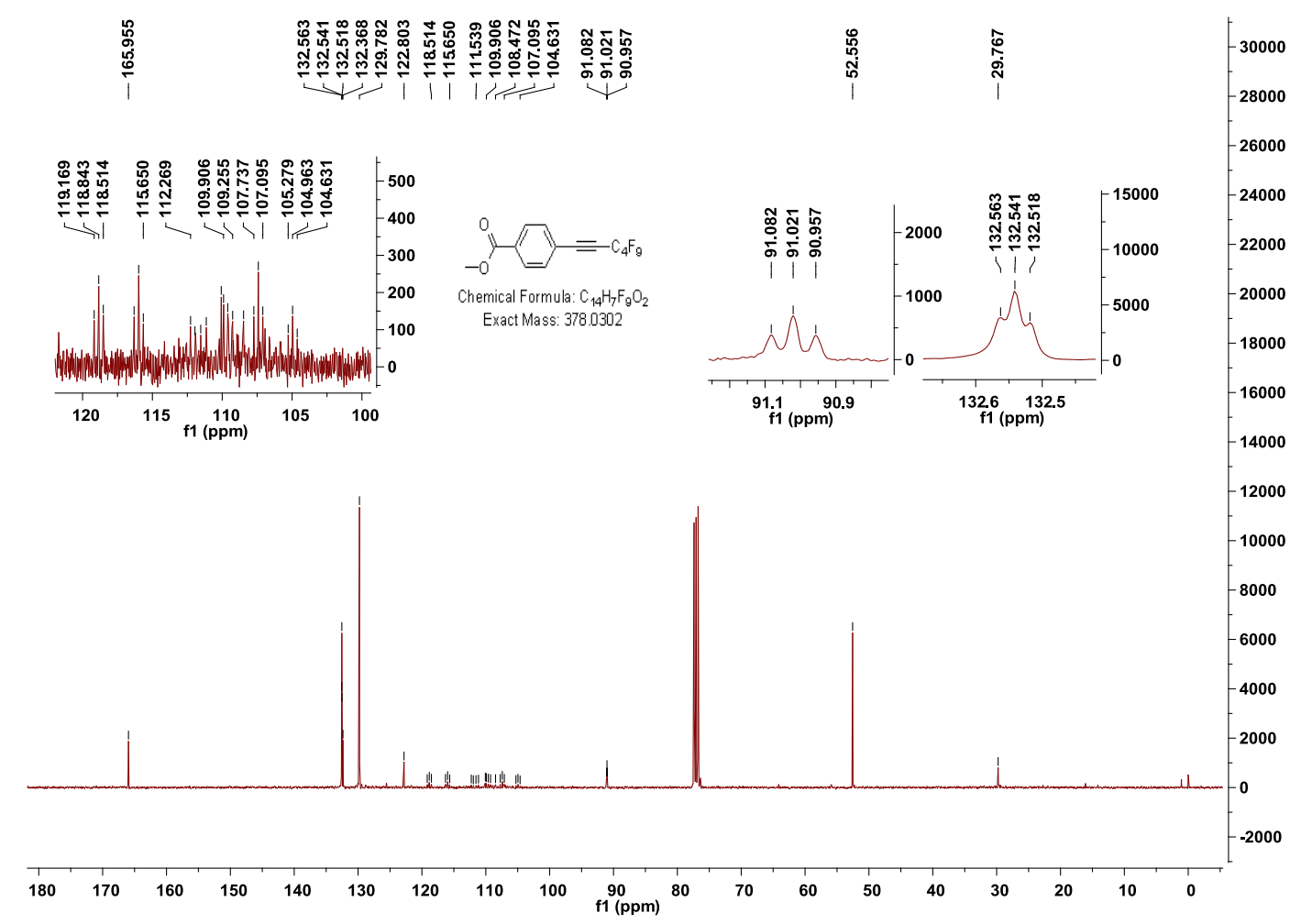

\section{1,1,1,2,2,3,3,4,4-Nonafluorohexadec-5-yne (4p)}

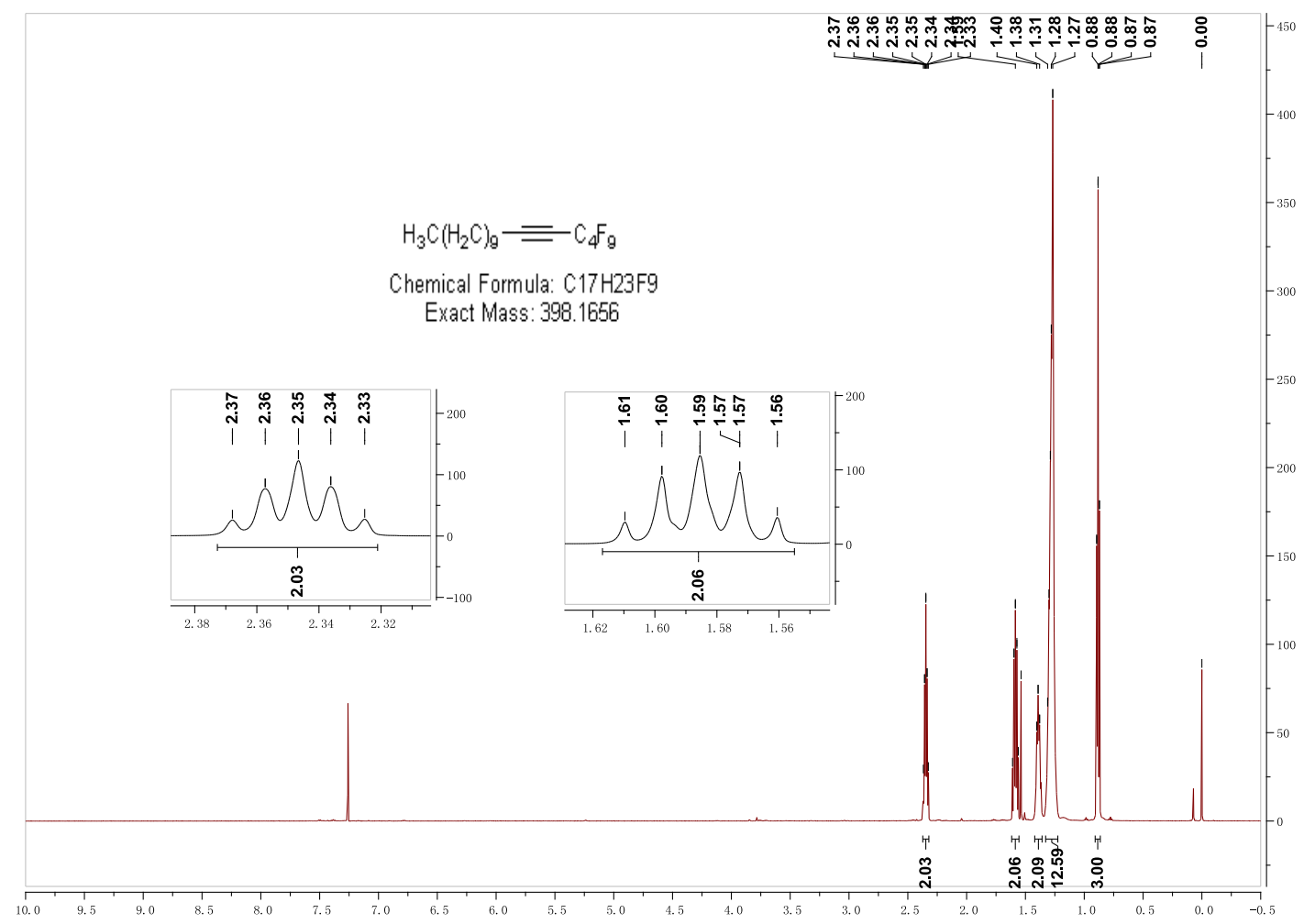



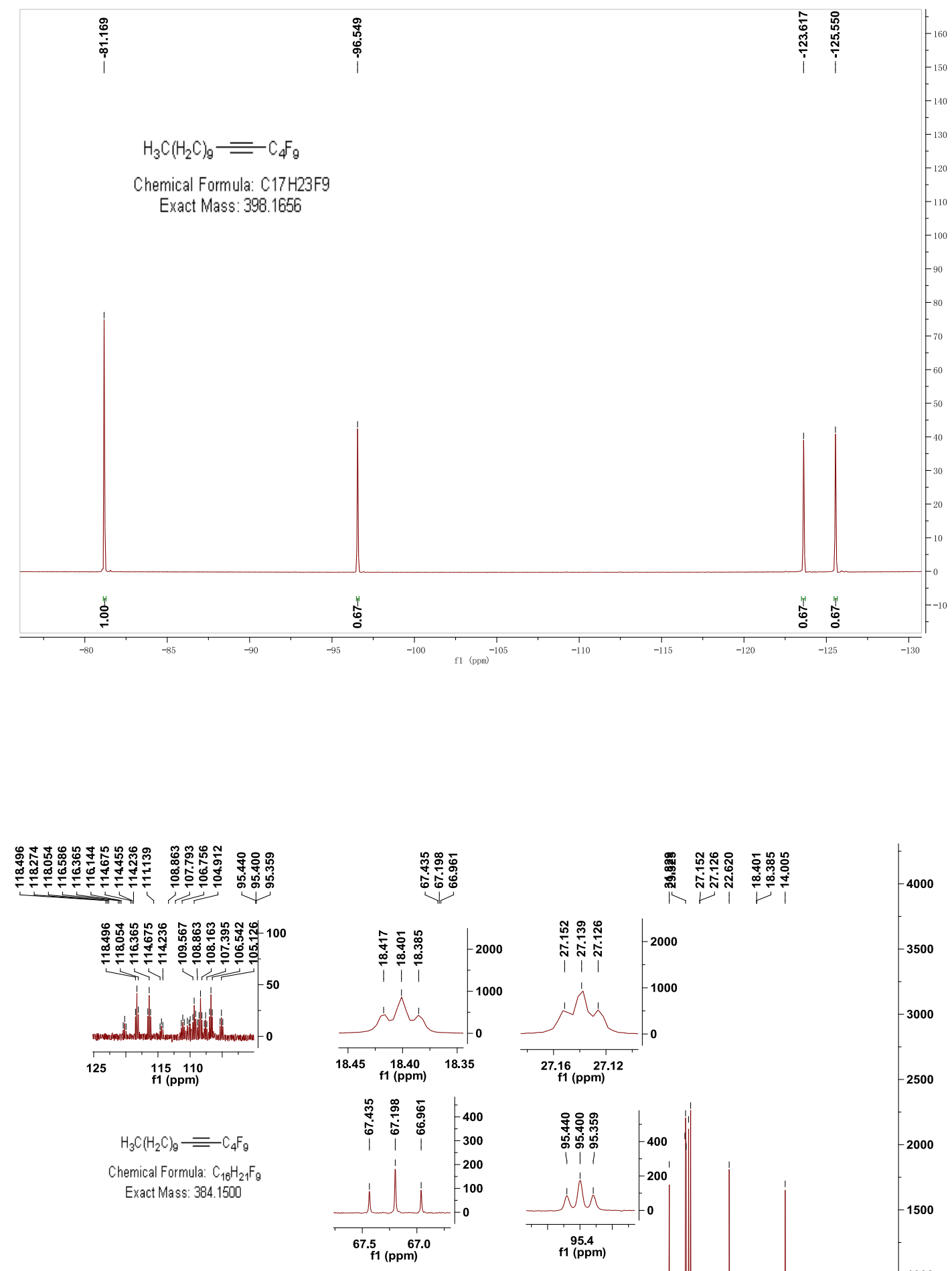

$\mathrm{H}_{3} \mathrm{C}\left(\mathrm{H}_{2} \mathrm{C}\right)_{9}=\mathrm{C}_{4} \mathrm{~F}_{9}$

Chemical Formula: $\mathrm{C}_{16} \mathrm{H}_{21} \mathrm{~F}_{9}$

Exact Mass: 384.1500

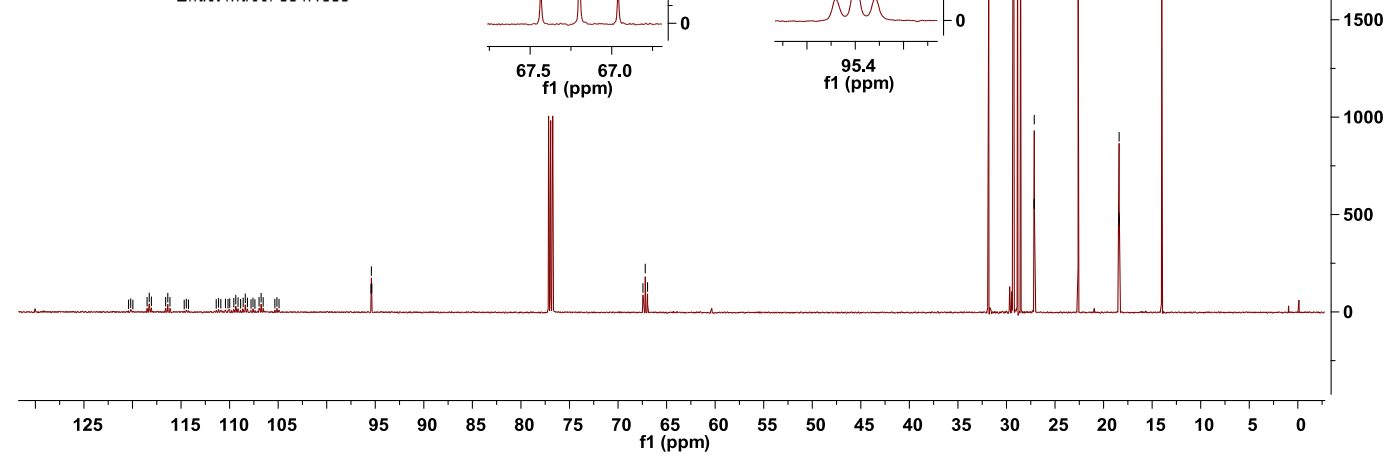


1-(perfluoropent-1-yn-1-yl)-4-propylbenzene (3a)
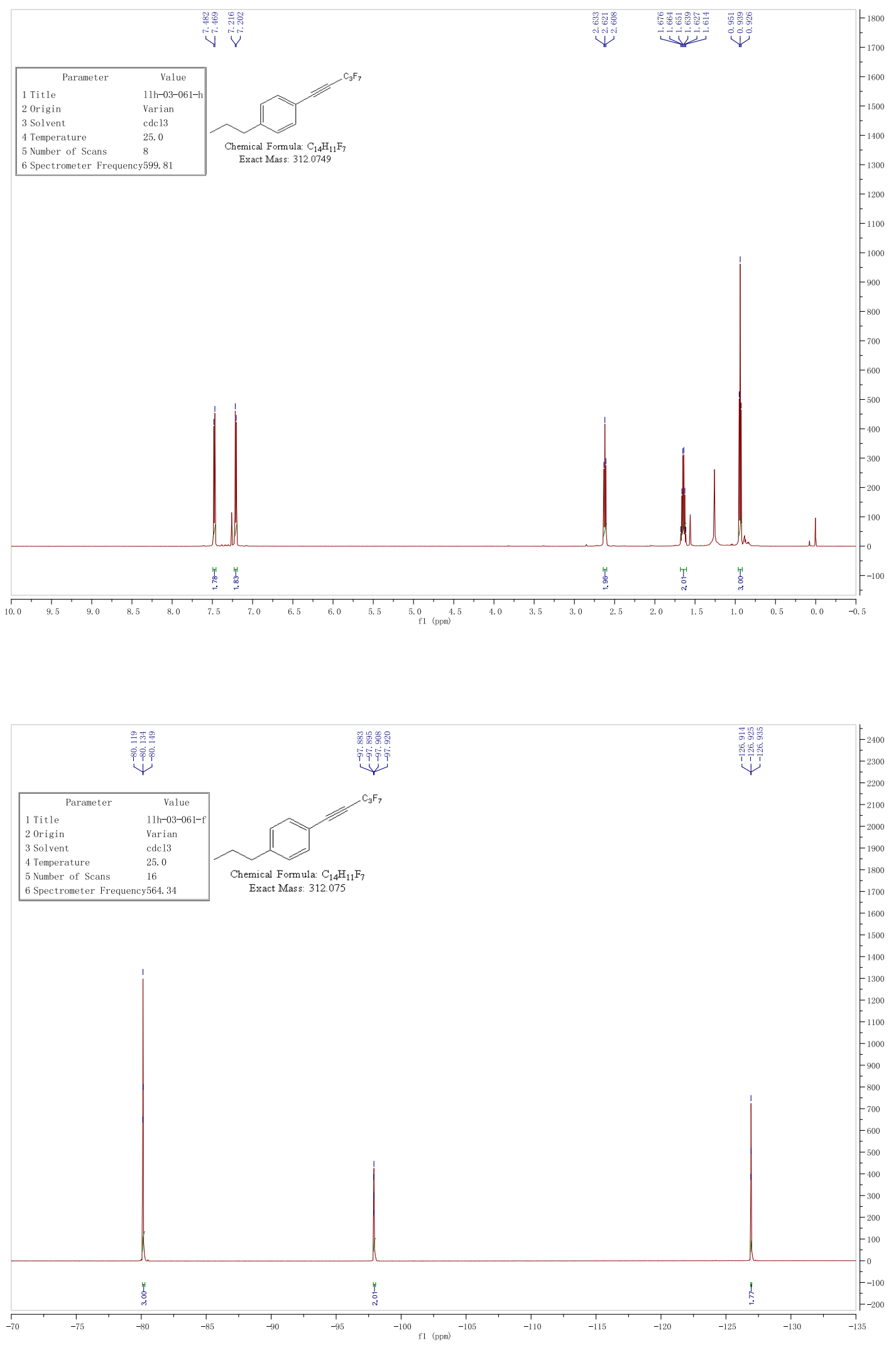


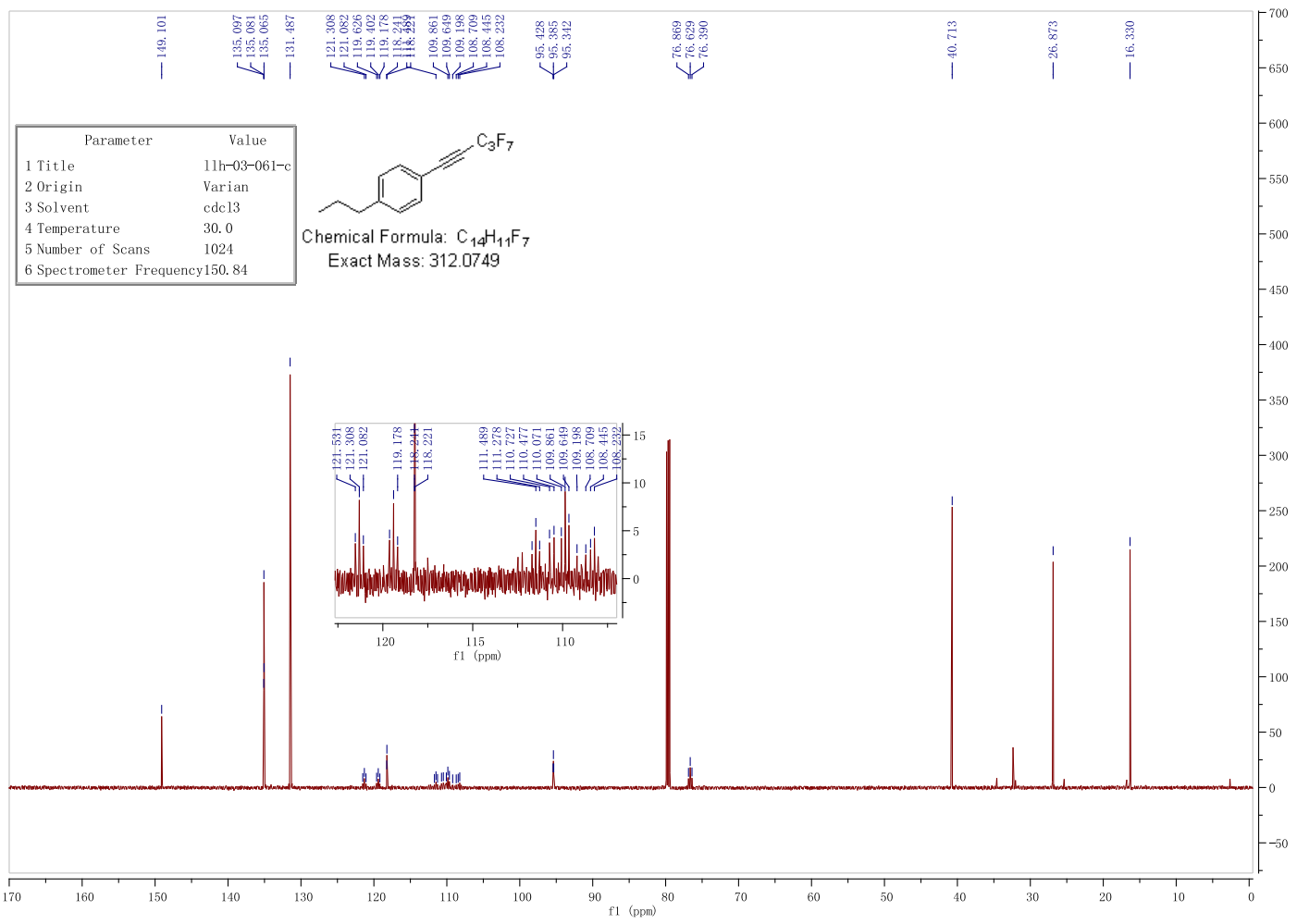

1-(tert-butyl)-4-(perfluoropent-1-yn-1-yl)benzene (3c)

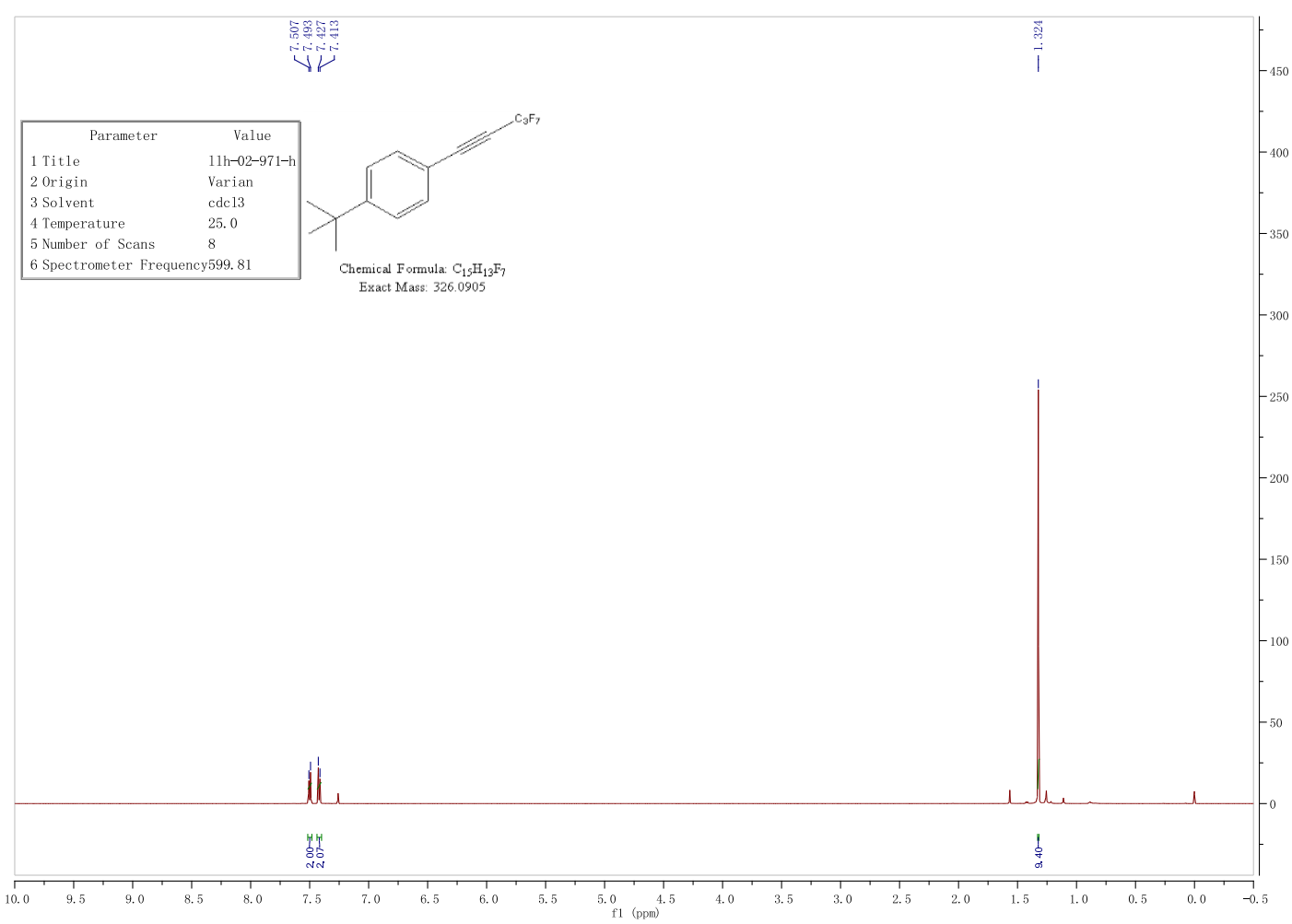



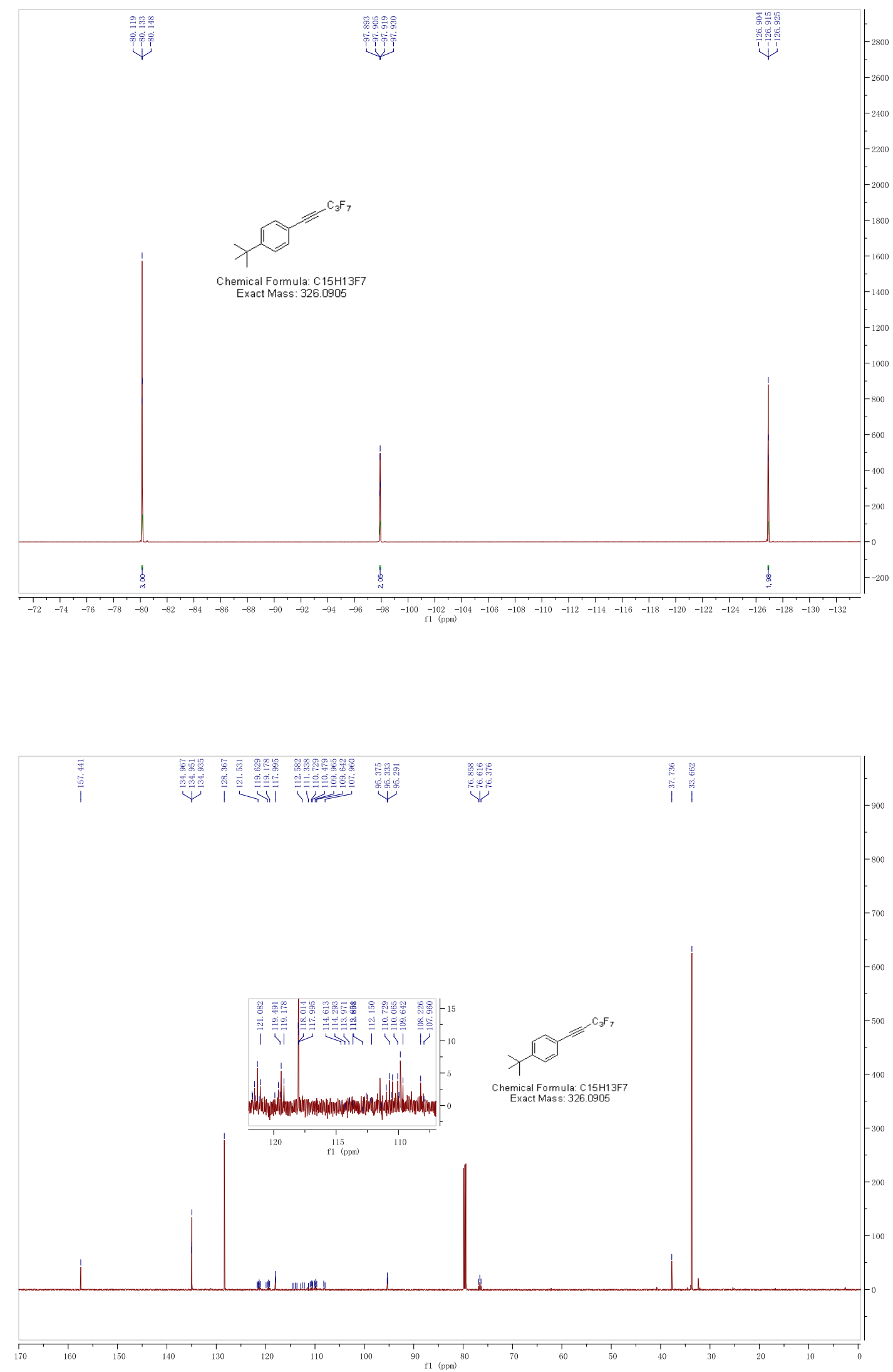
1-(perfluorooct-1-yn-1-yl)-4-propylbenzene (5a)
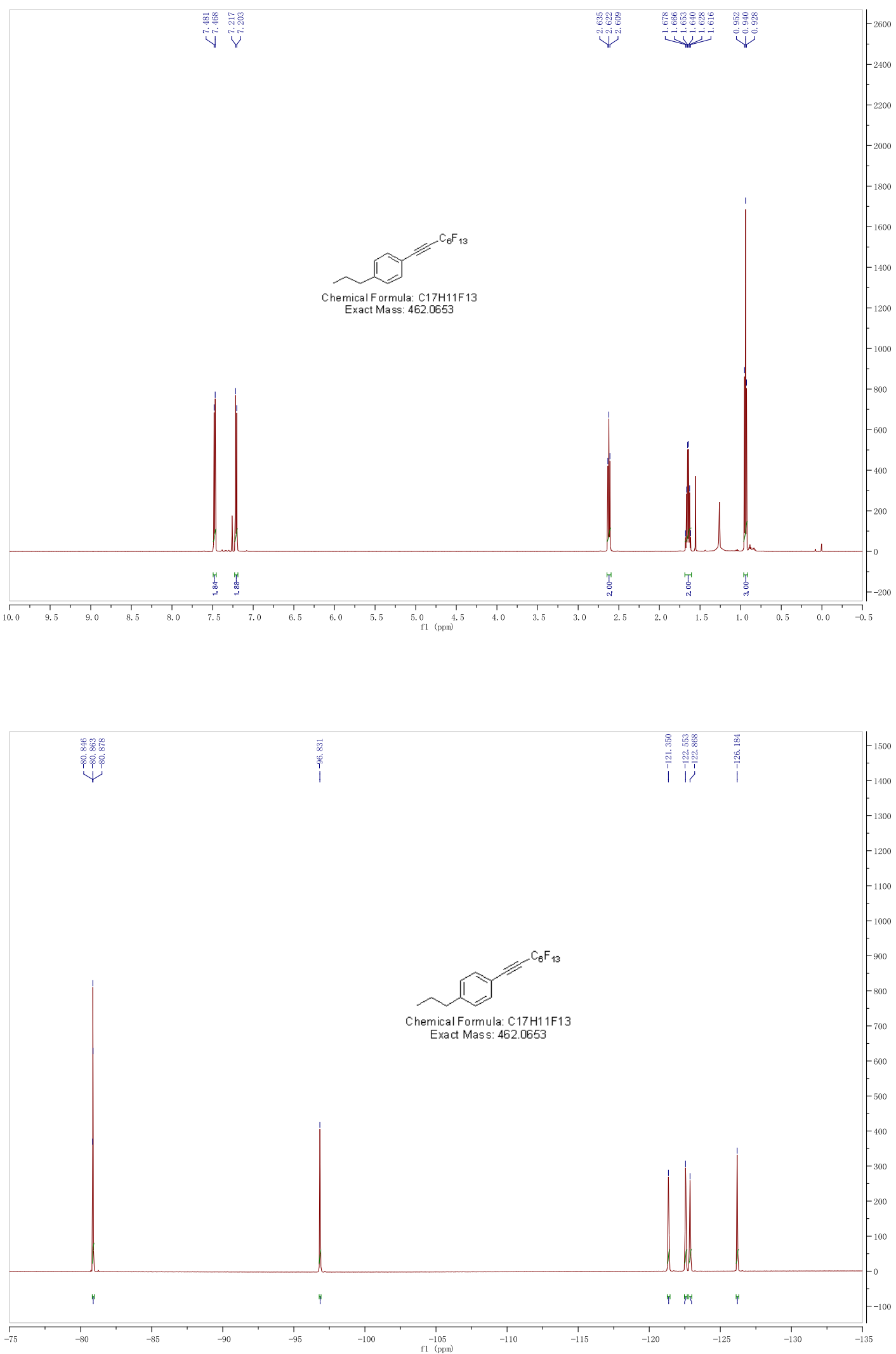


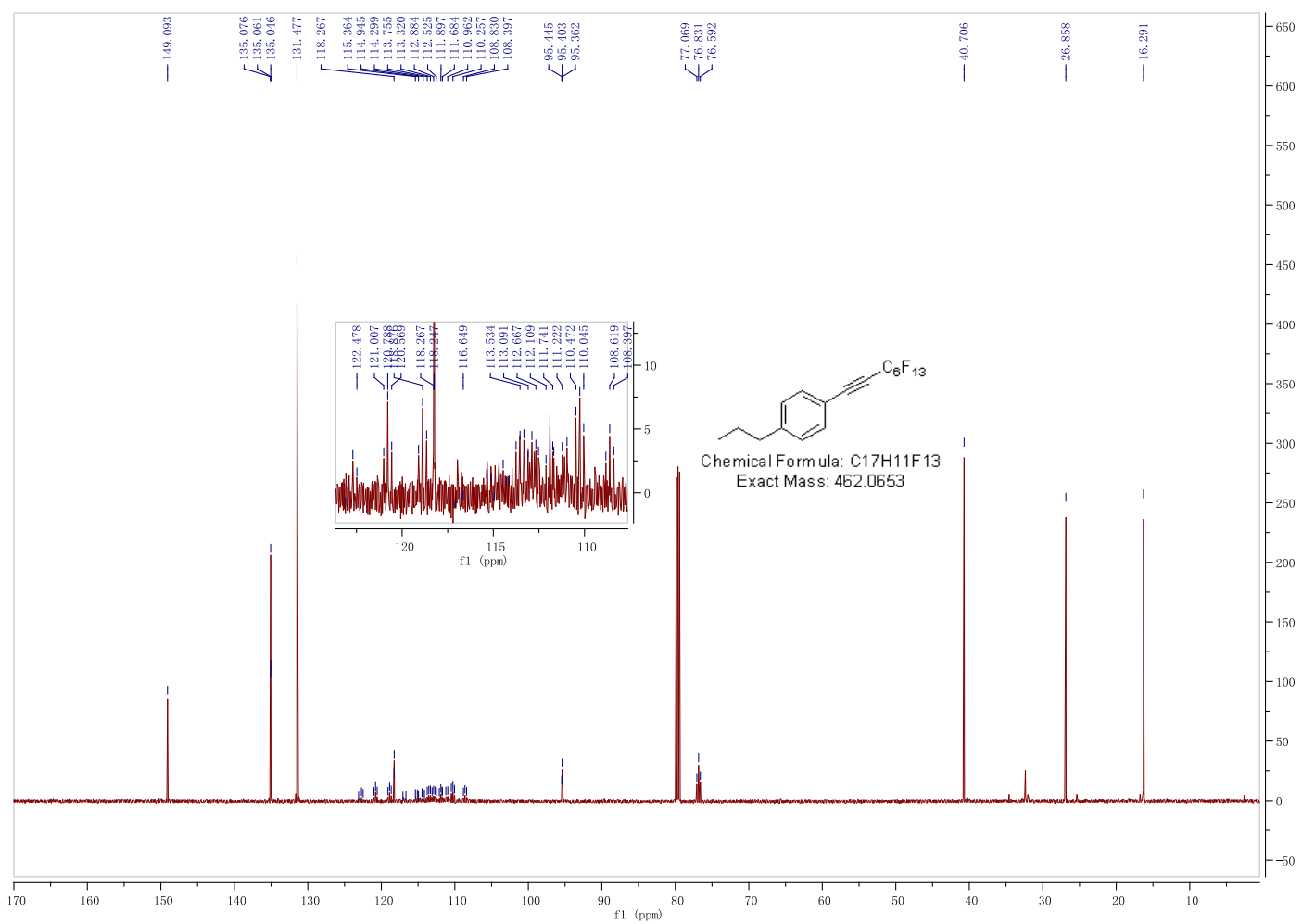

1-pentyl-4-(perfluorooct-1-yn-1-yl)benzene (5b)

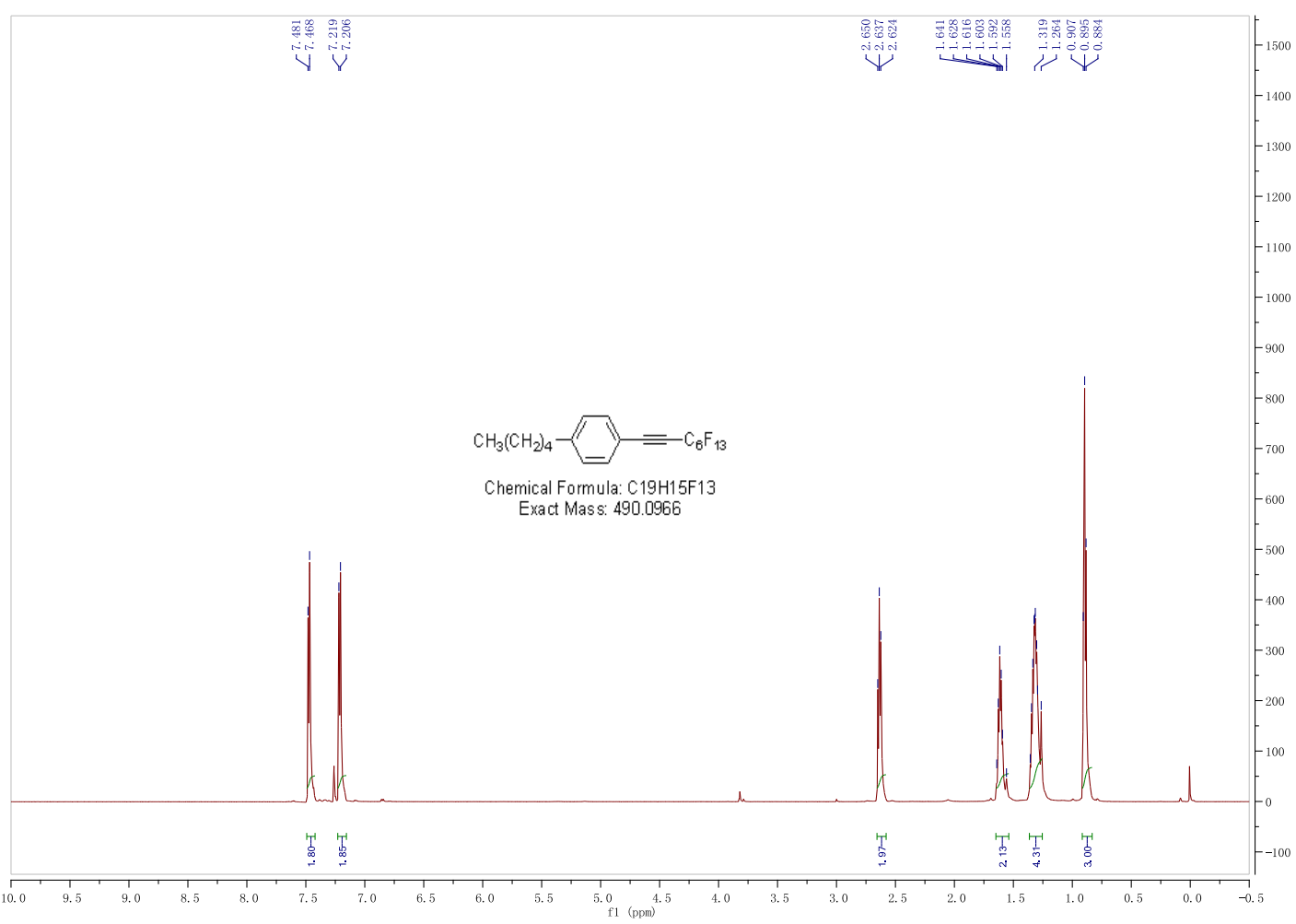



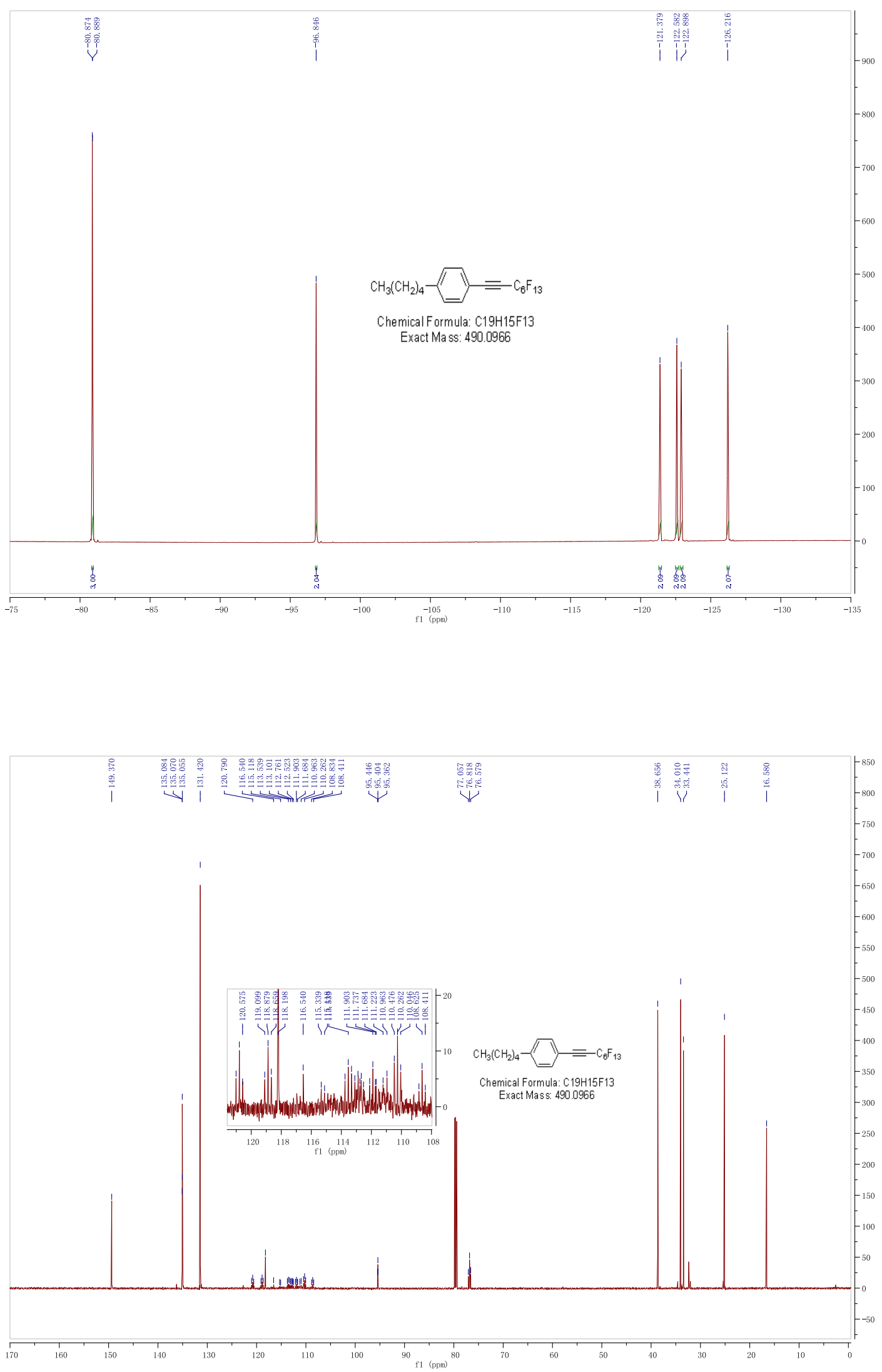
1-(tert-butyl)-4-(perfluorooct-1-yn-1-yl)benzene (5c)
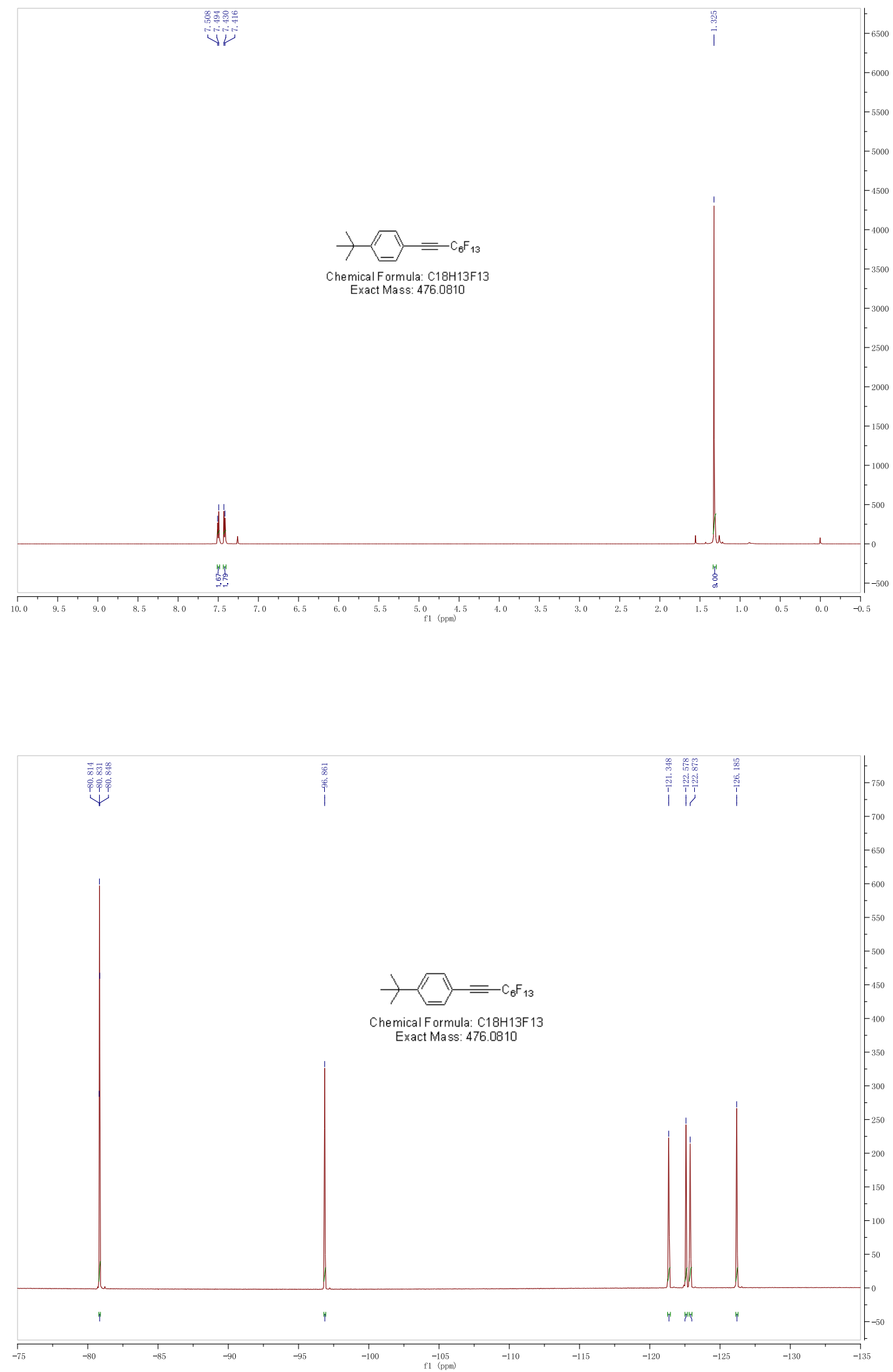


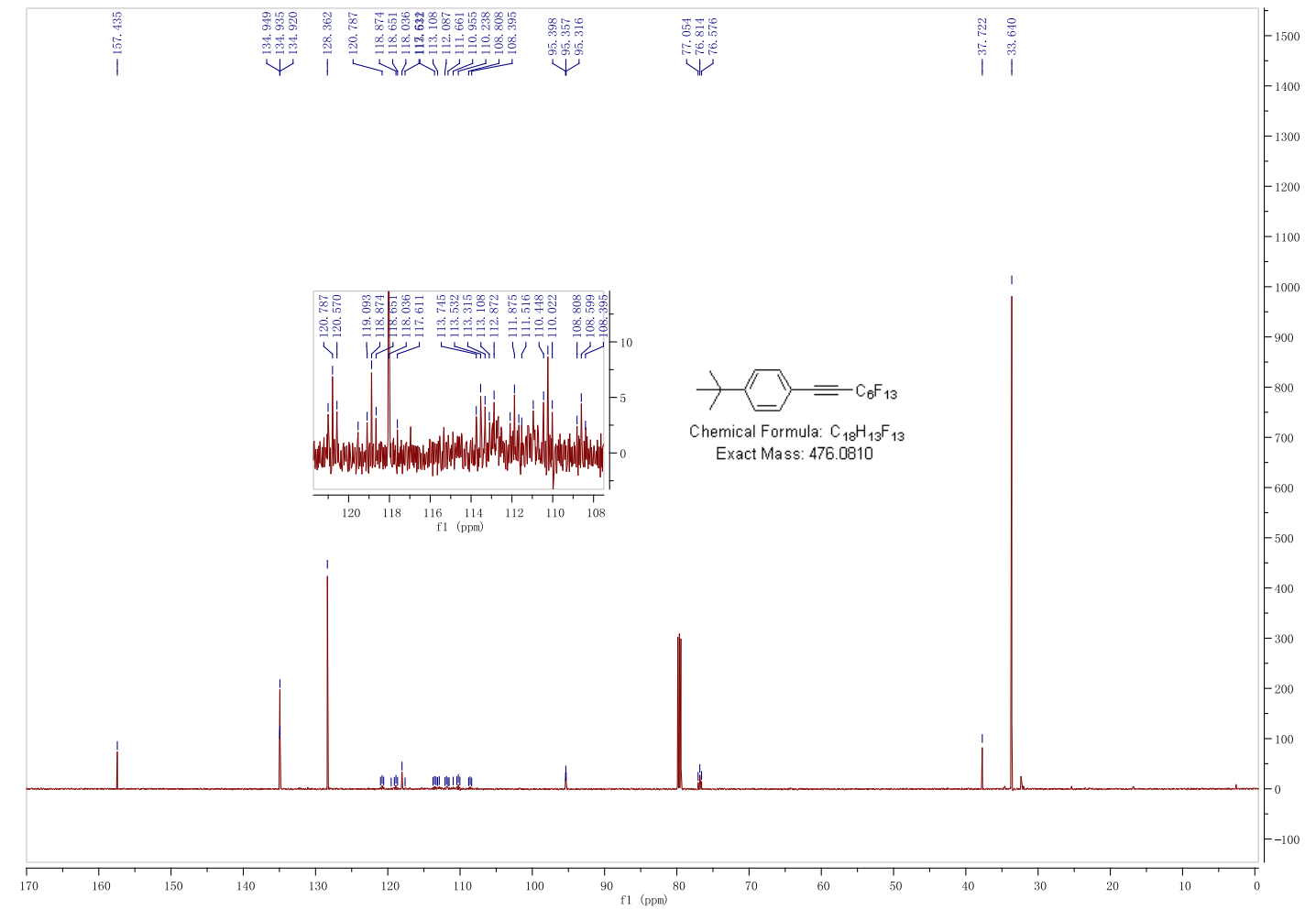

(perfluorooct-1-yn-1-yl)benzene (5d)

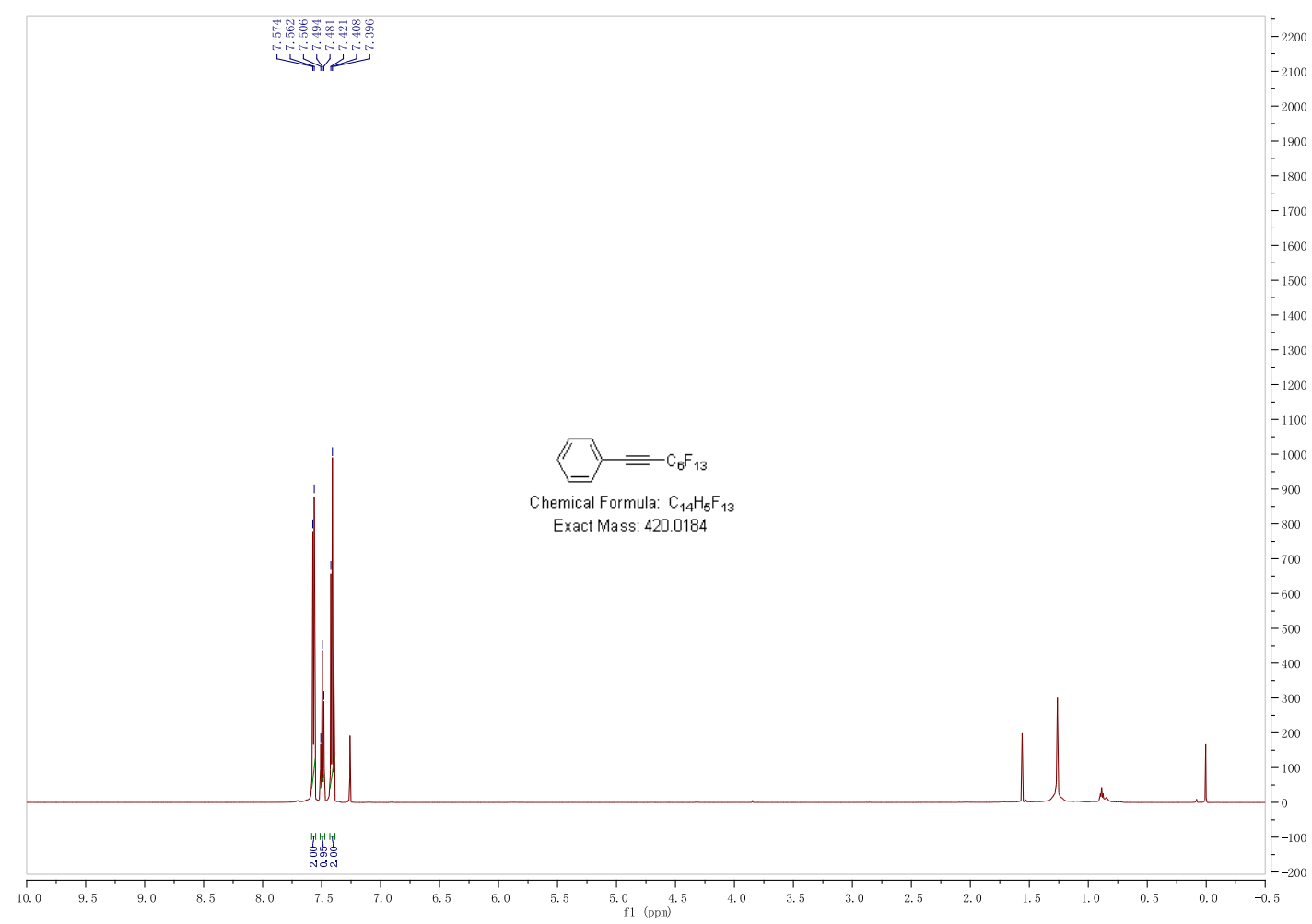




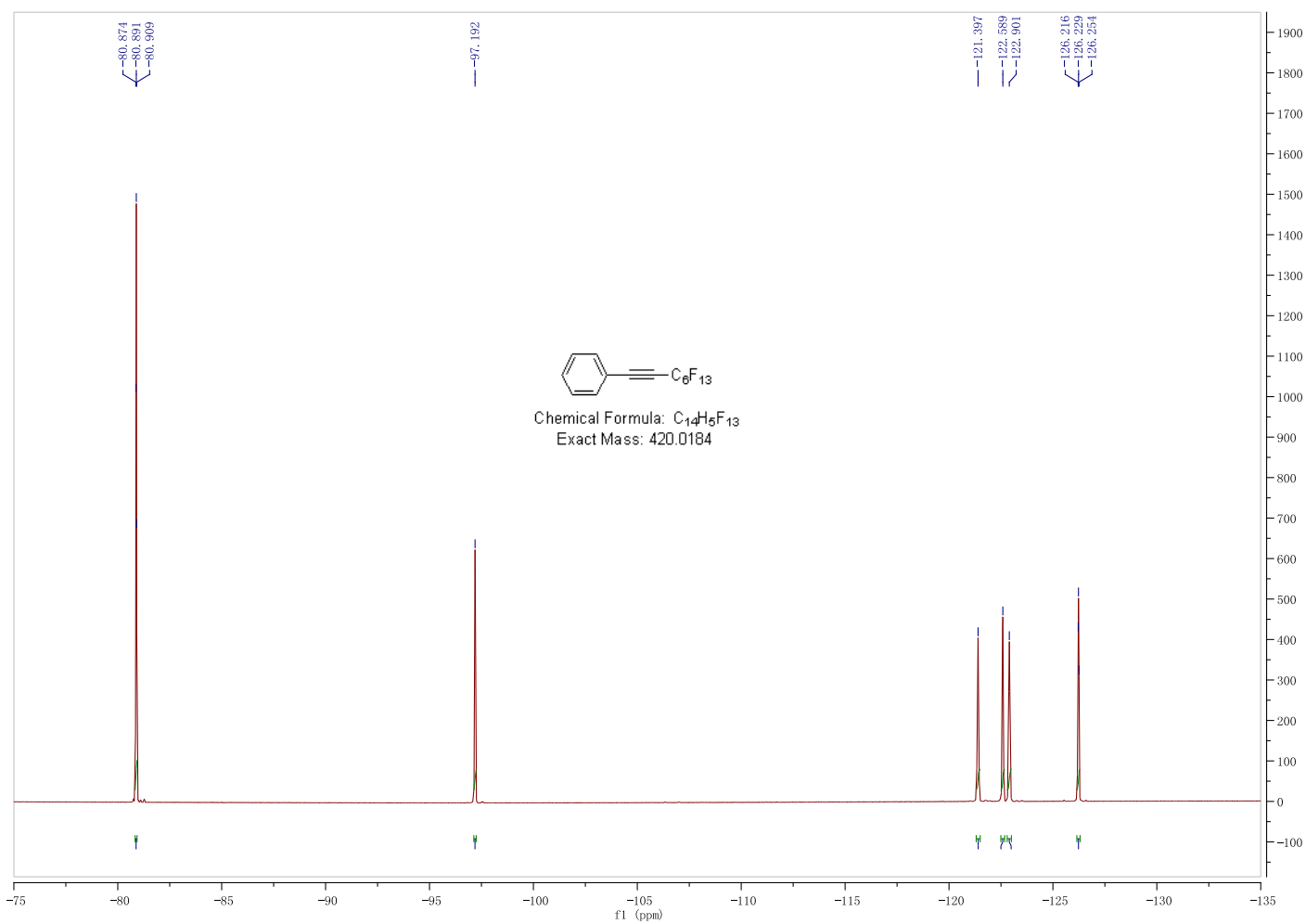

1-methoxy-4-(perfluorooct-1-yn-1-yl)benzene (5e)

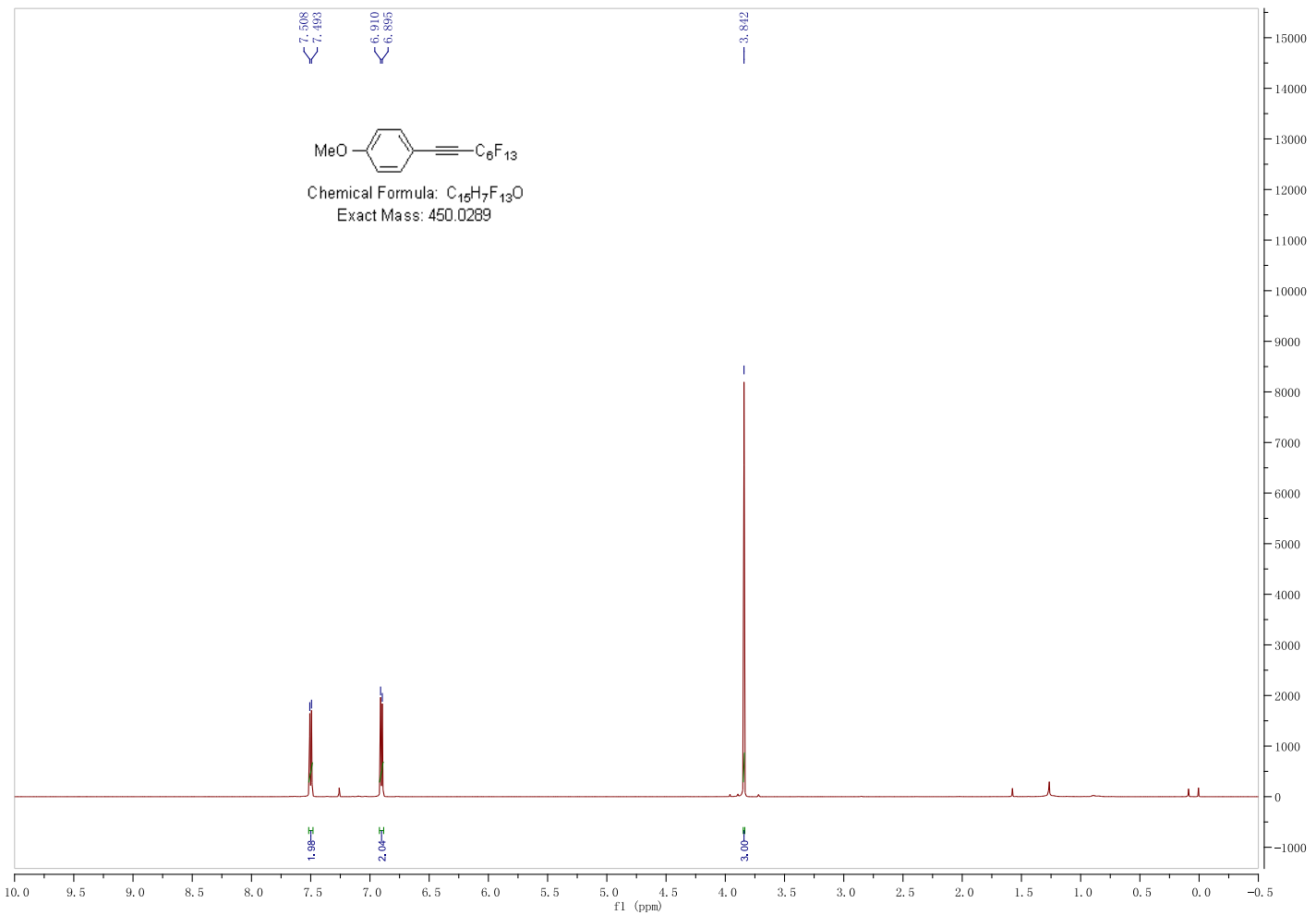



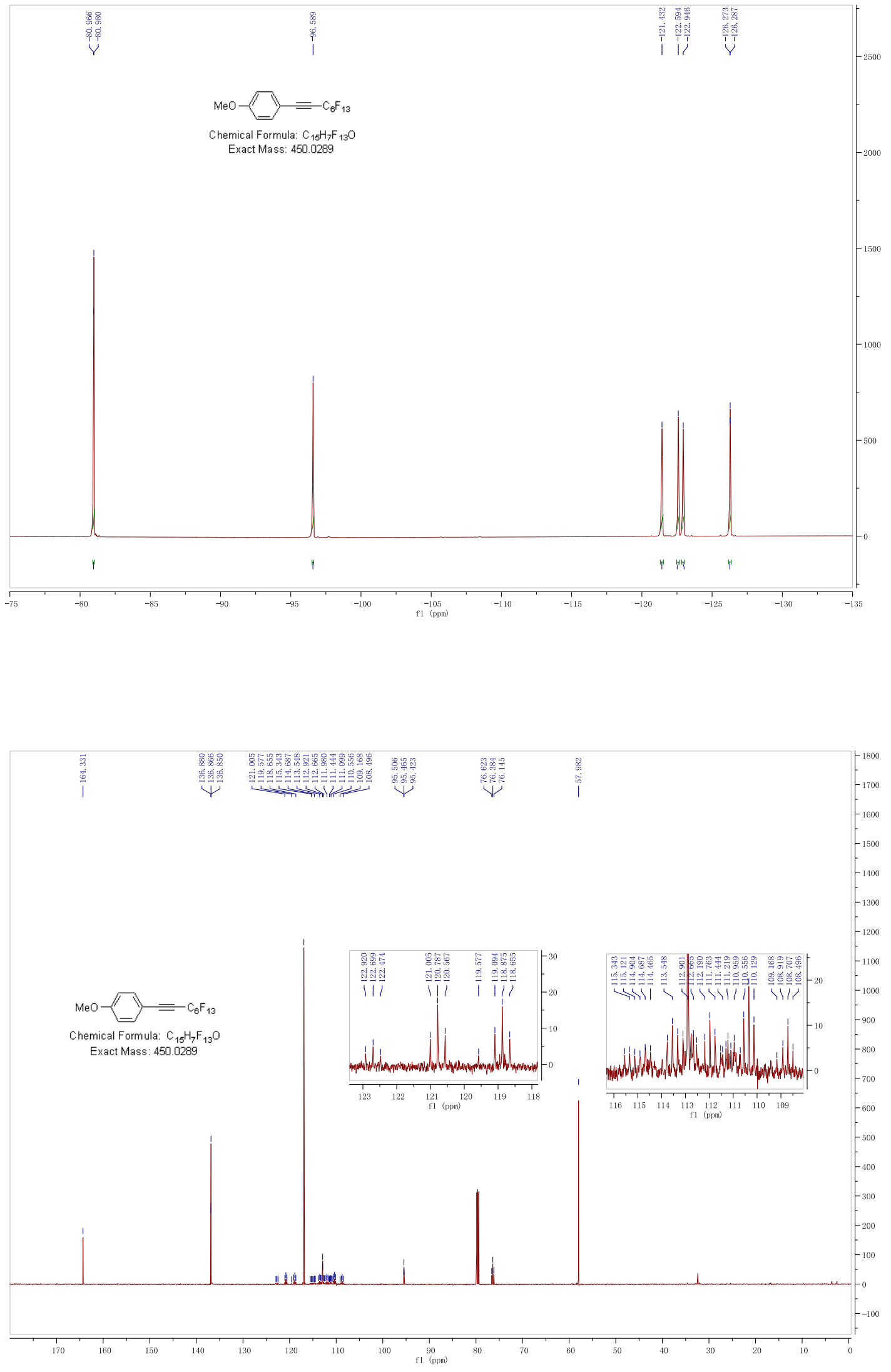
1-(pentyloxy)-4-(perfluorooct-1-yn-1-yl)benzene (5f)
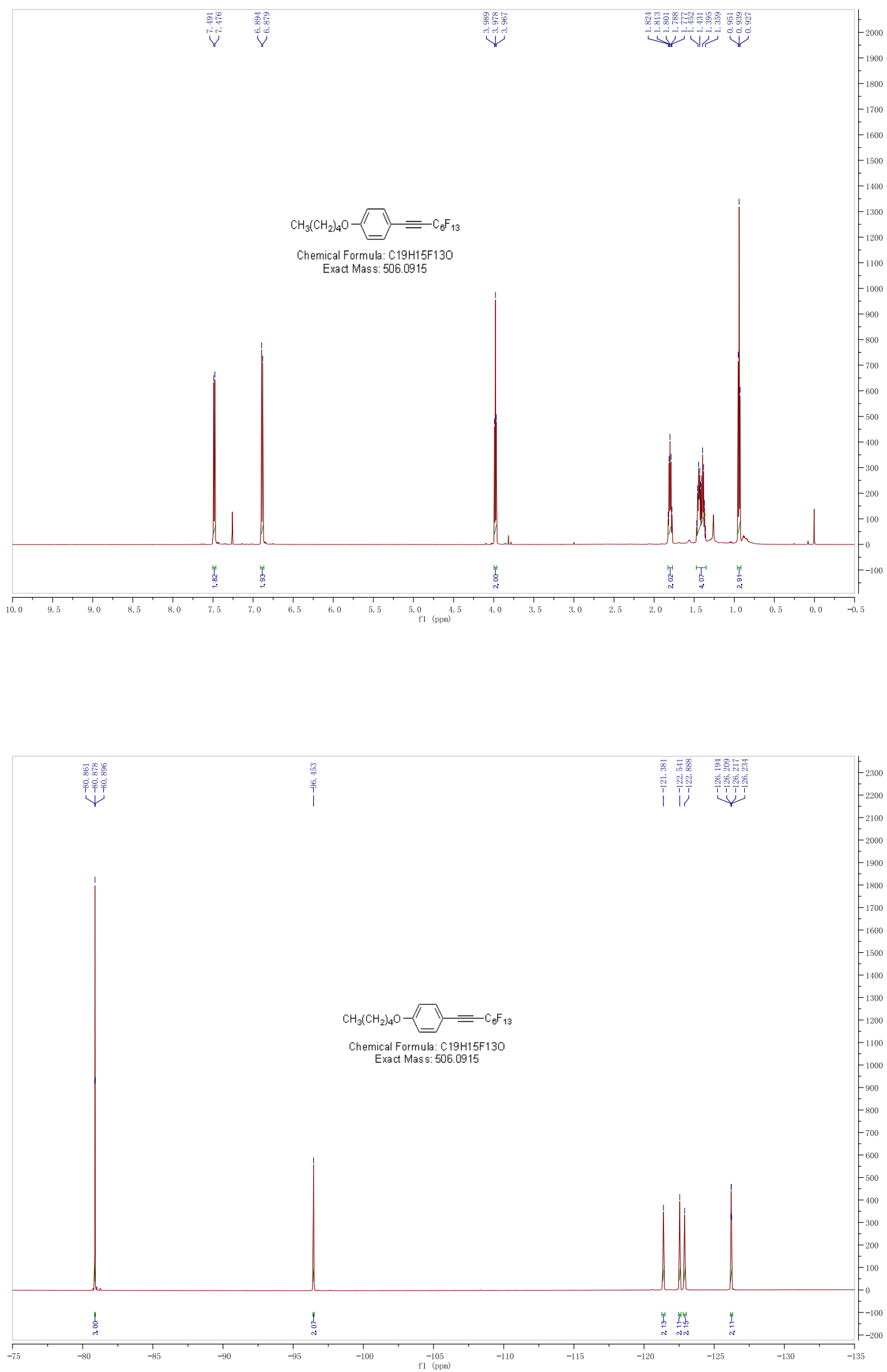


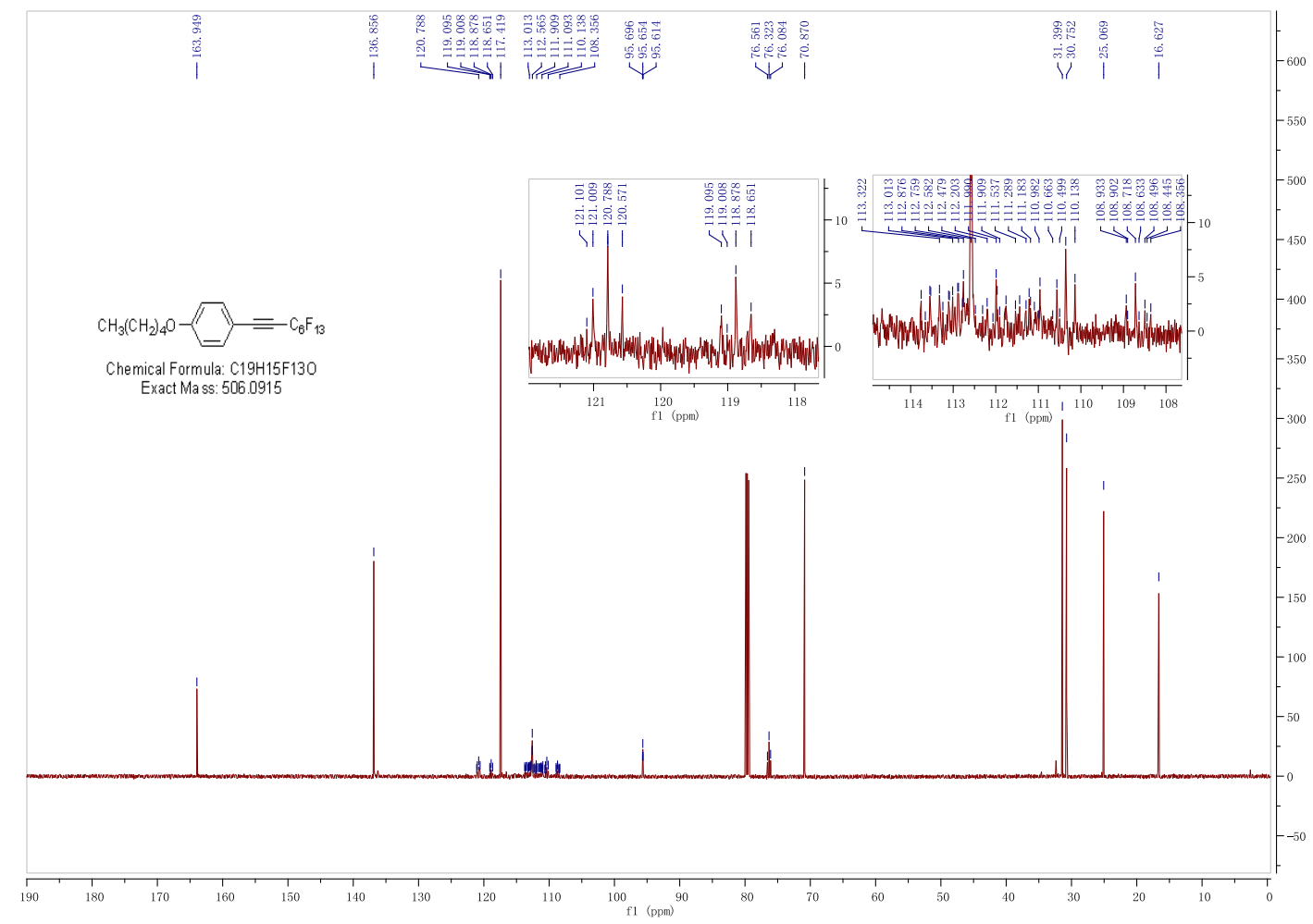

1,3-dimethoxy-5-(perfluorooct-1-yn-1-yl)benzene (5g)

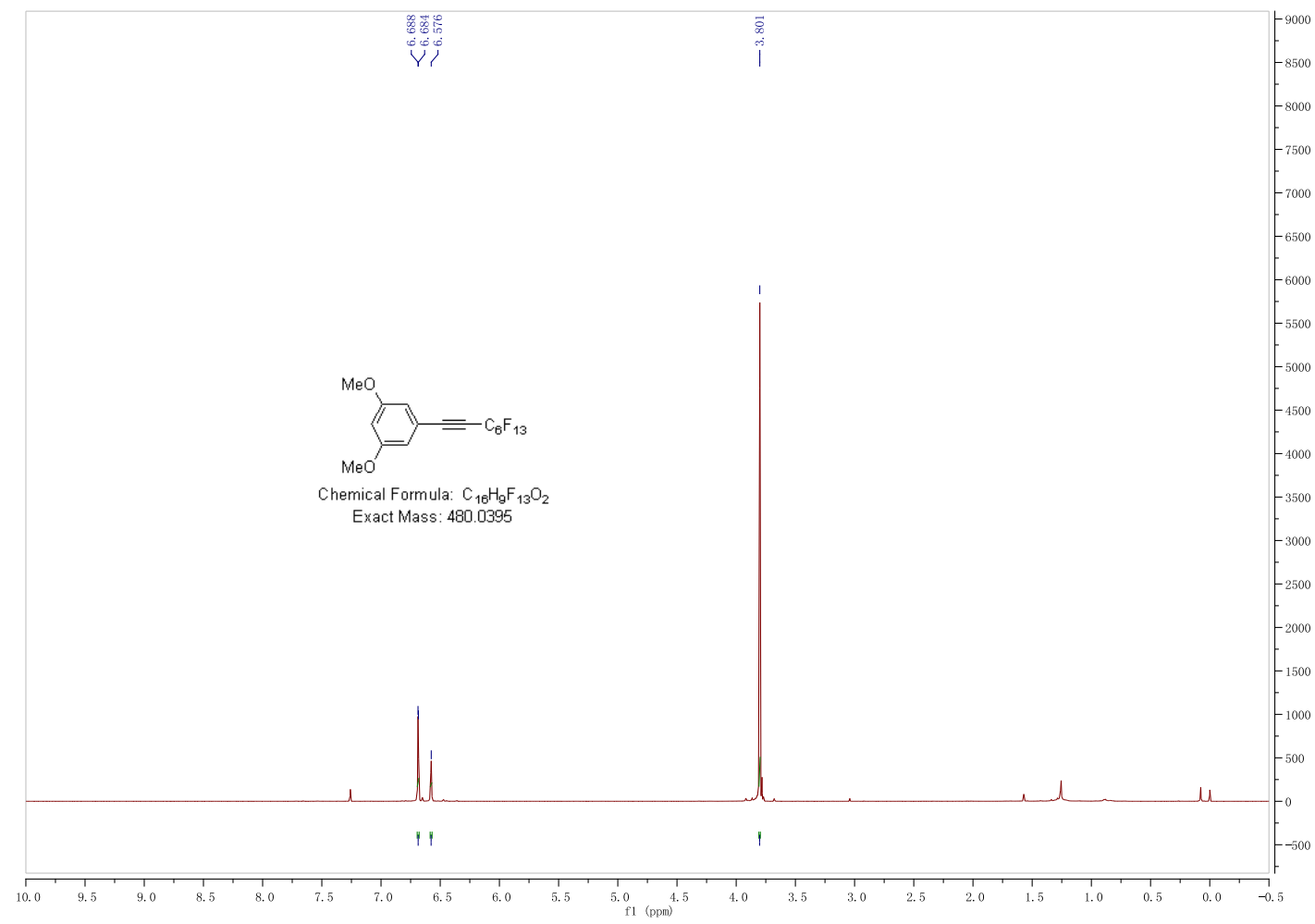



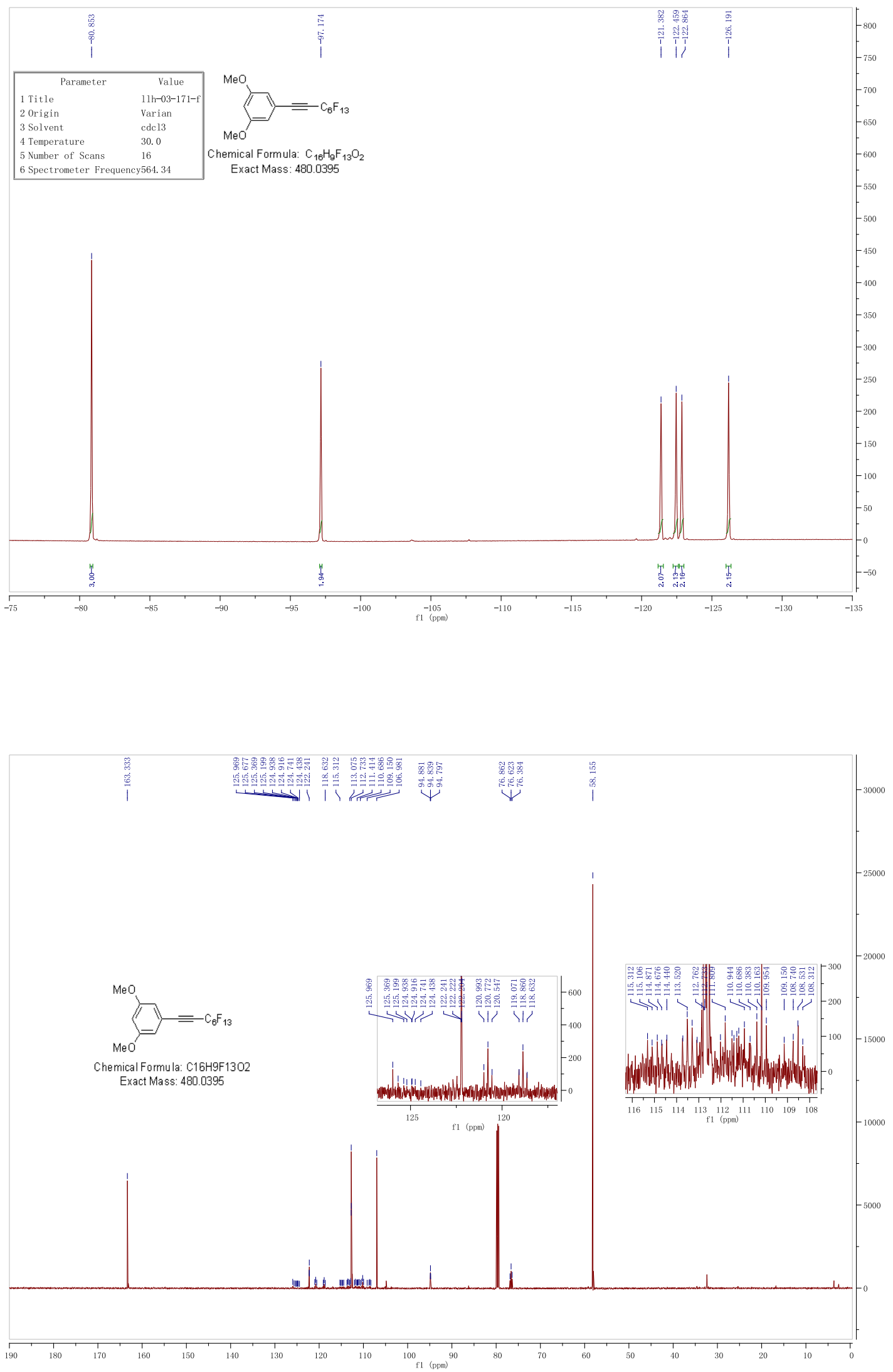
4-(perfluorooct-1-yn-1-yl)-1,1'-biphenyl (5h)
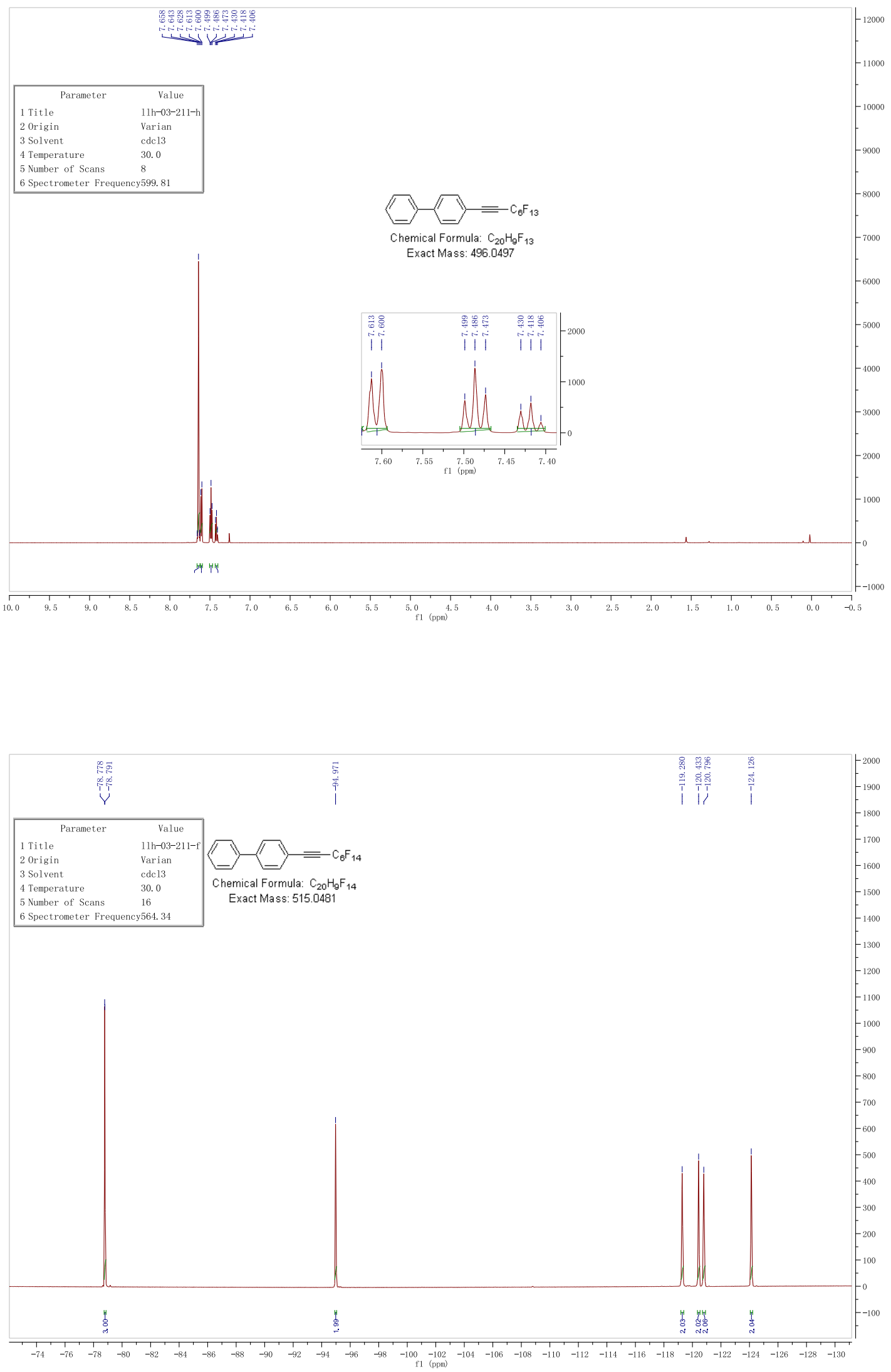


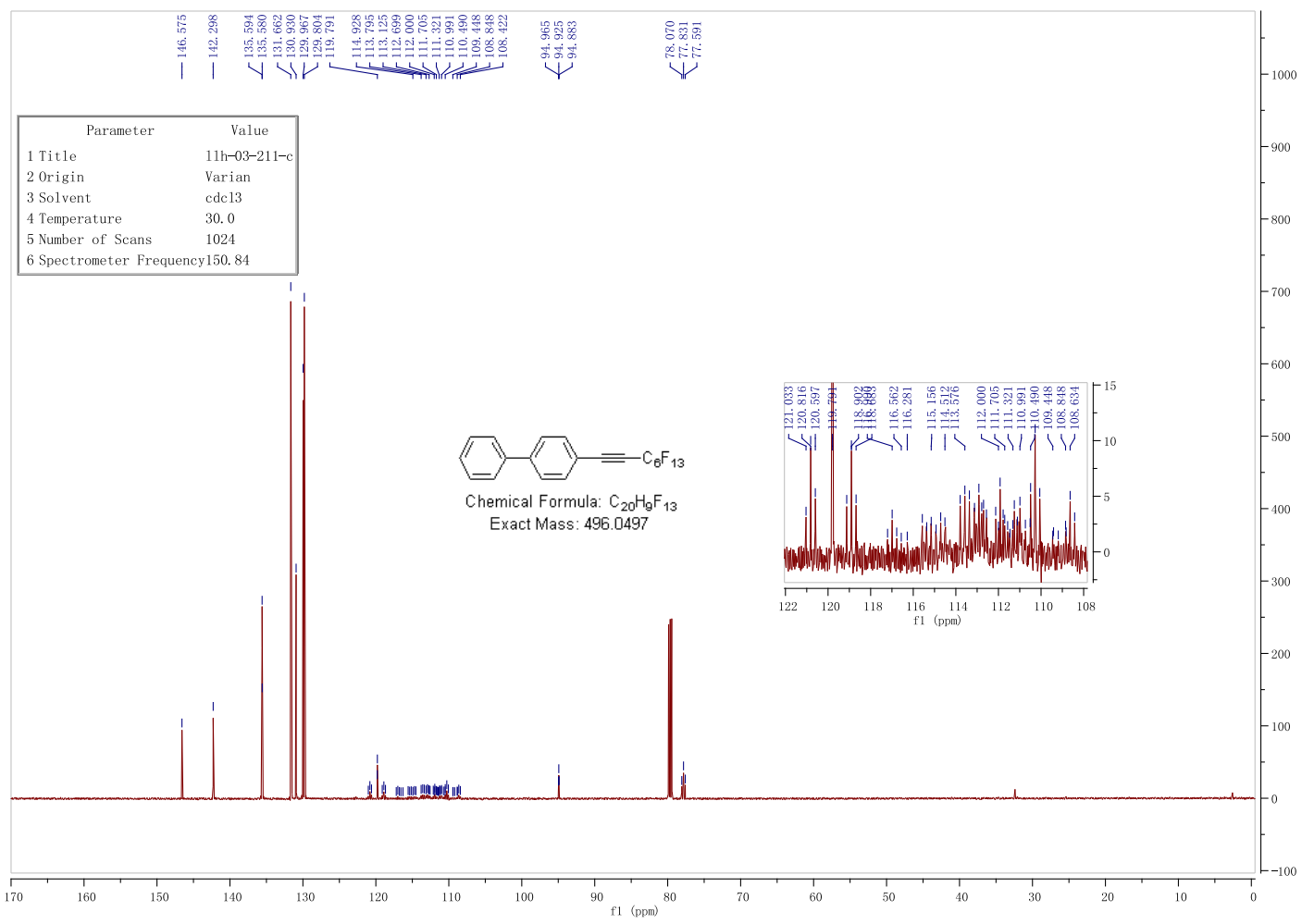

2-(perfluorooct-1-yn-1-yl)naphthalene (5i)

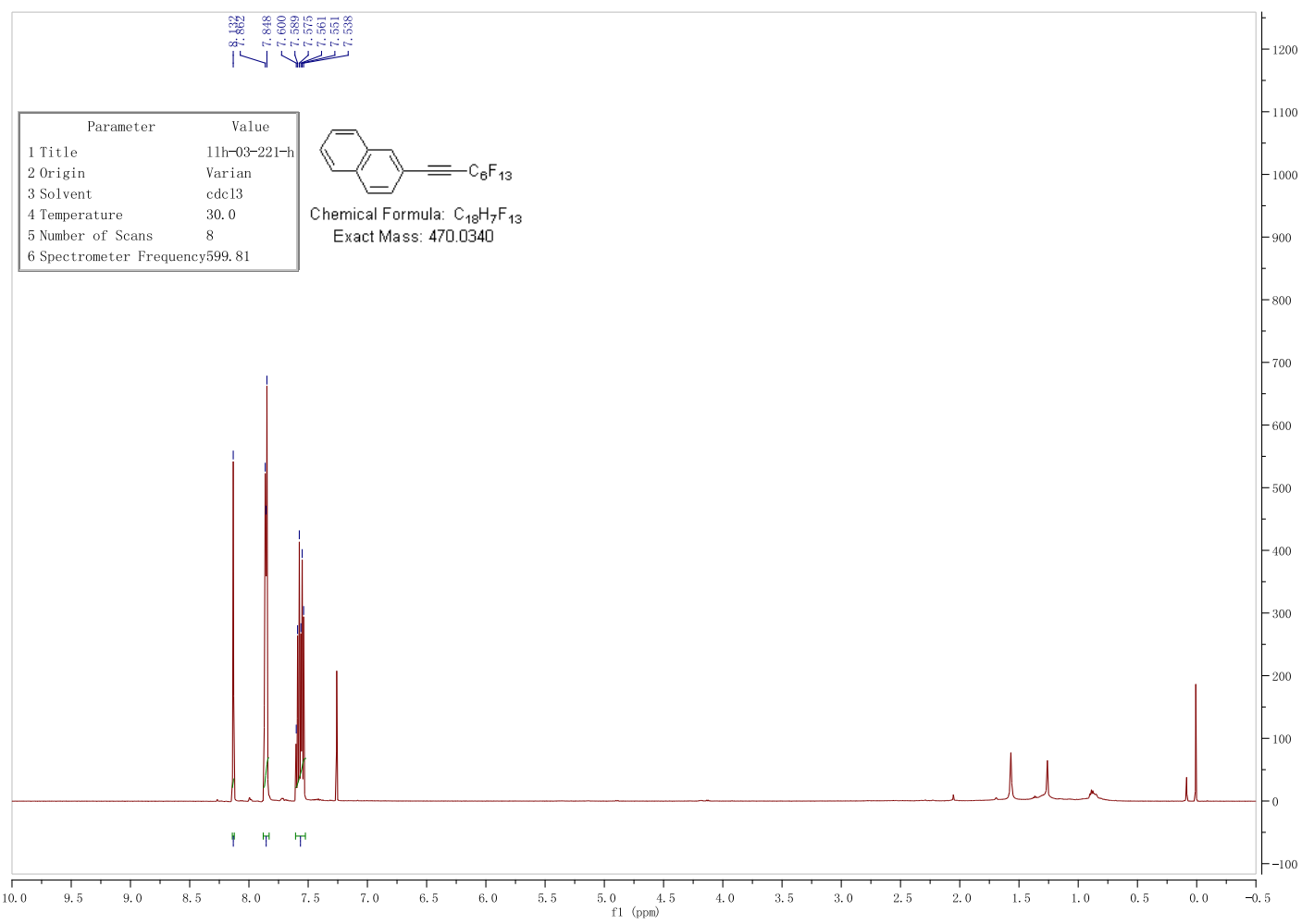



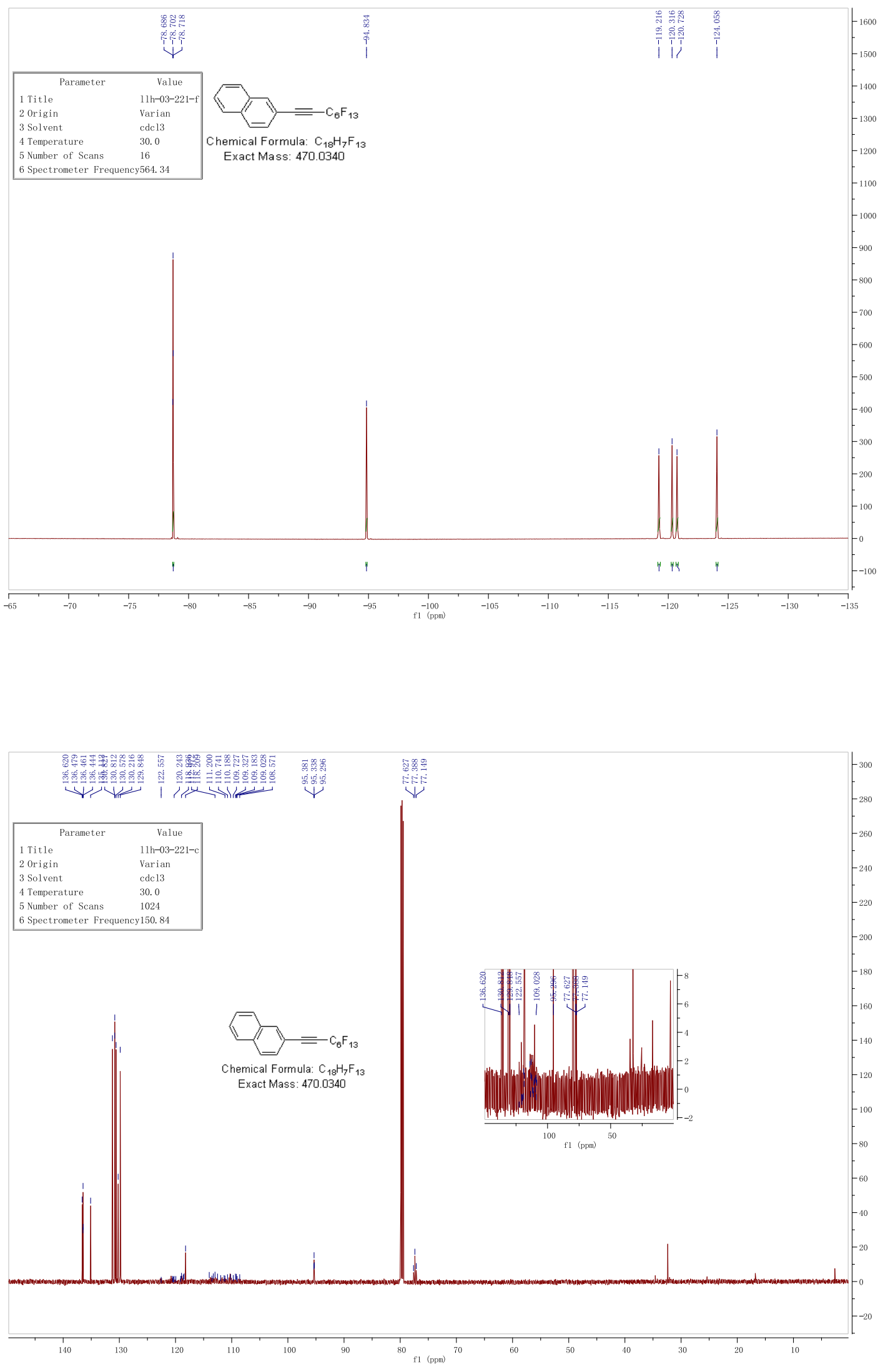
1-chloro-4-(perfluorooct-1-yn-1-yl)benzene (5j)
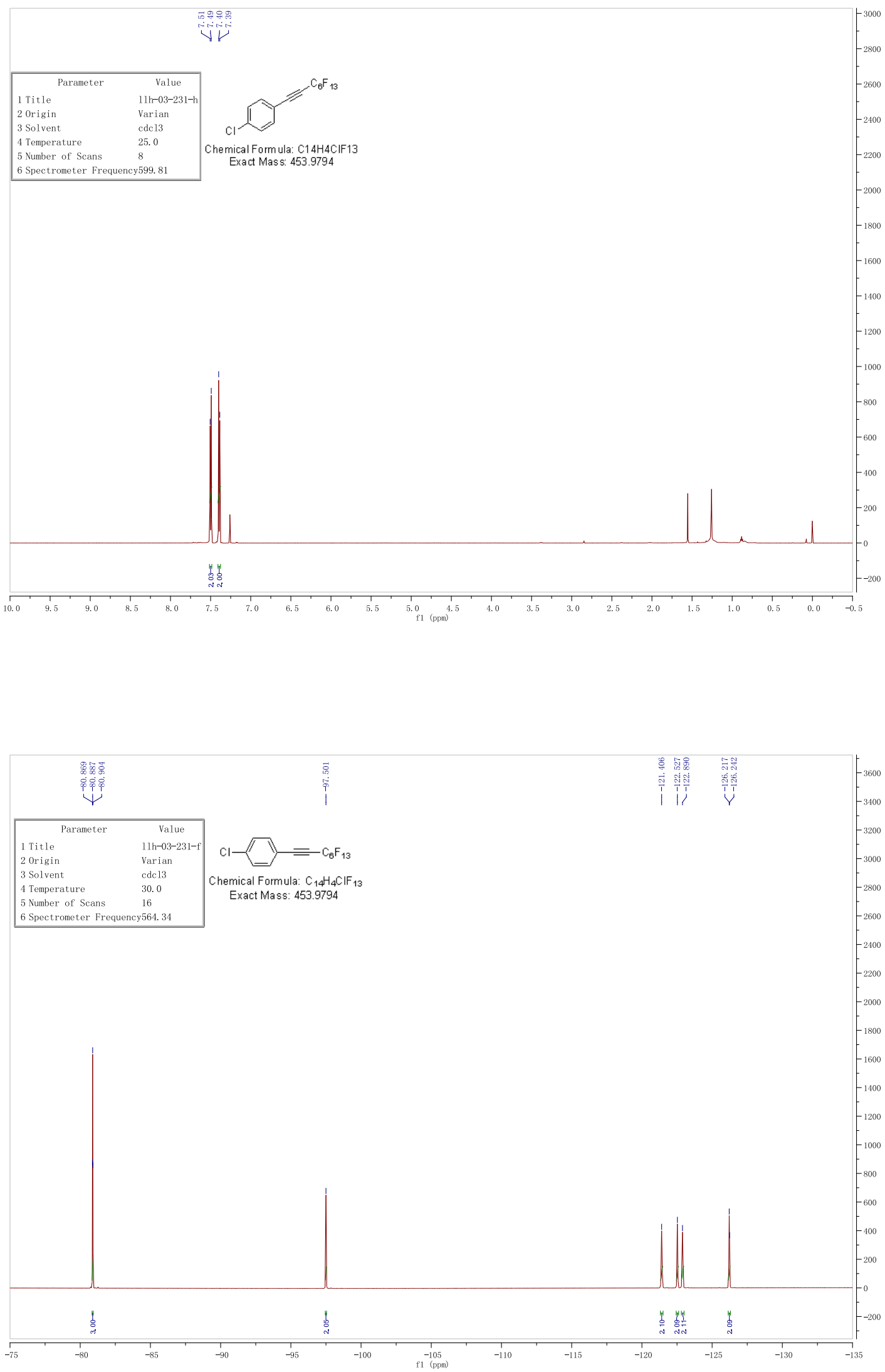


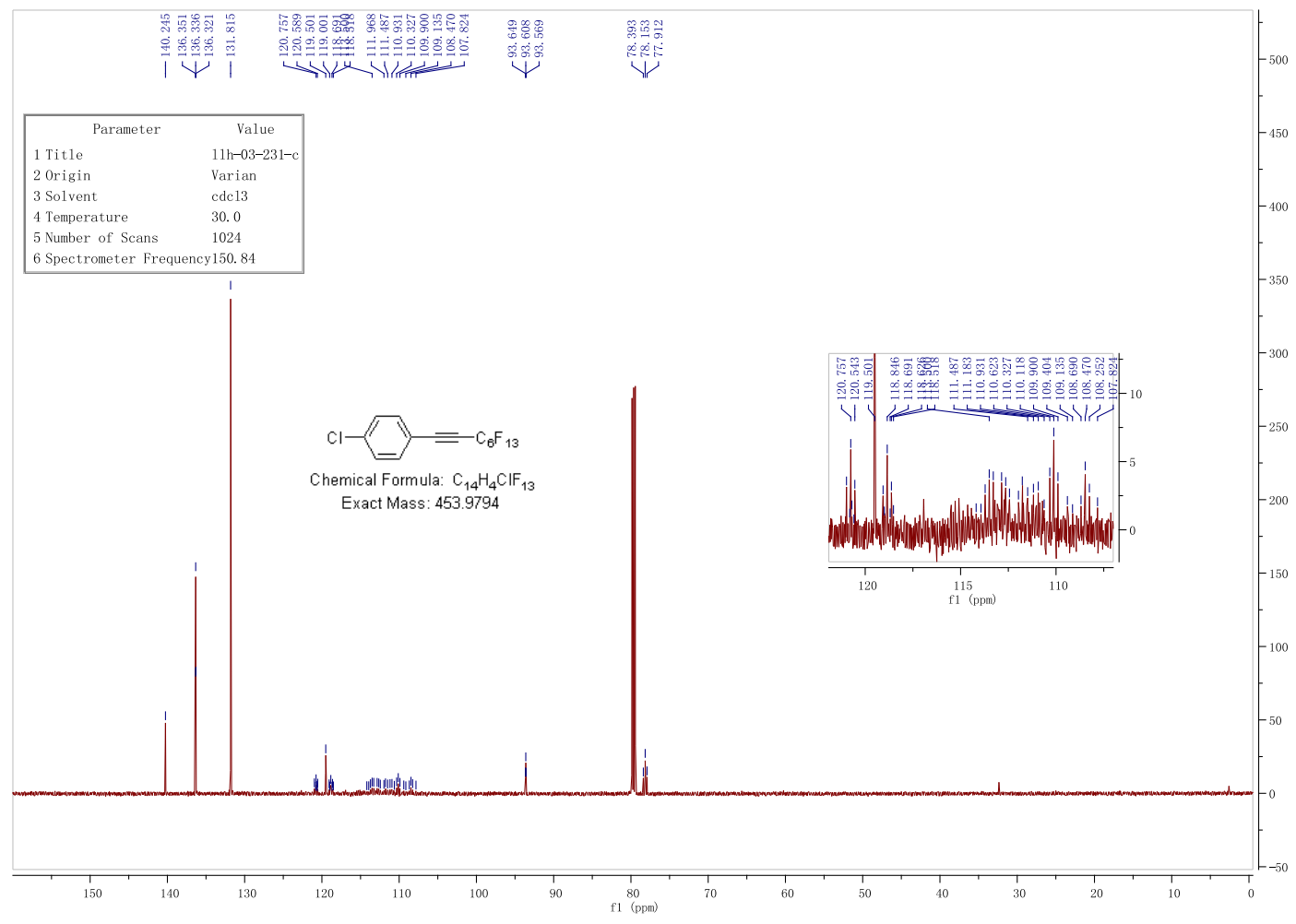

1-fluoro-4-(perfluorooct-1-yn-1-yl)benzene (5k)

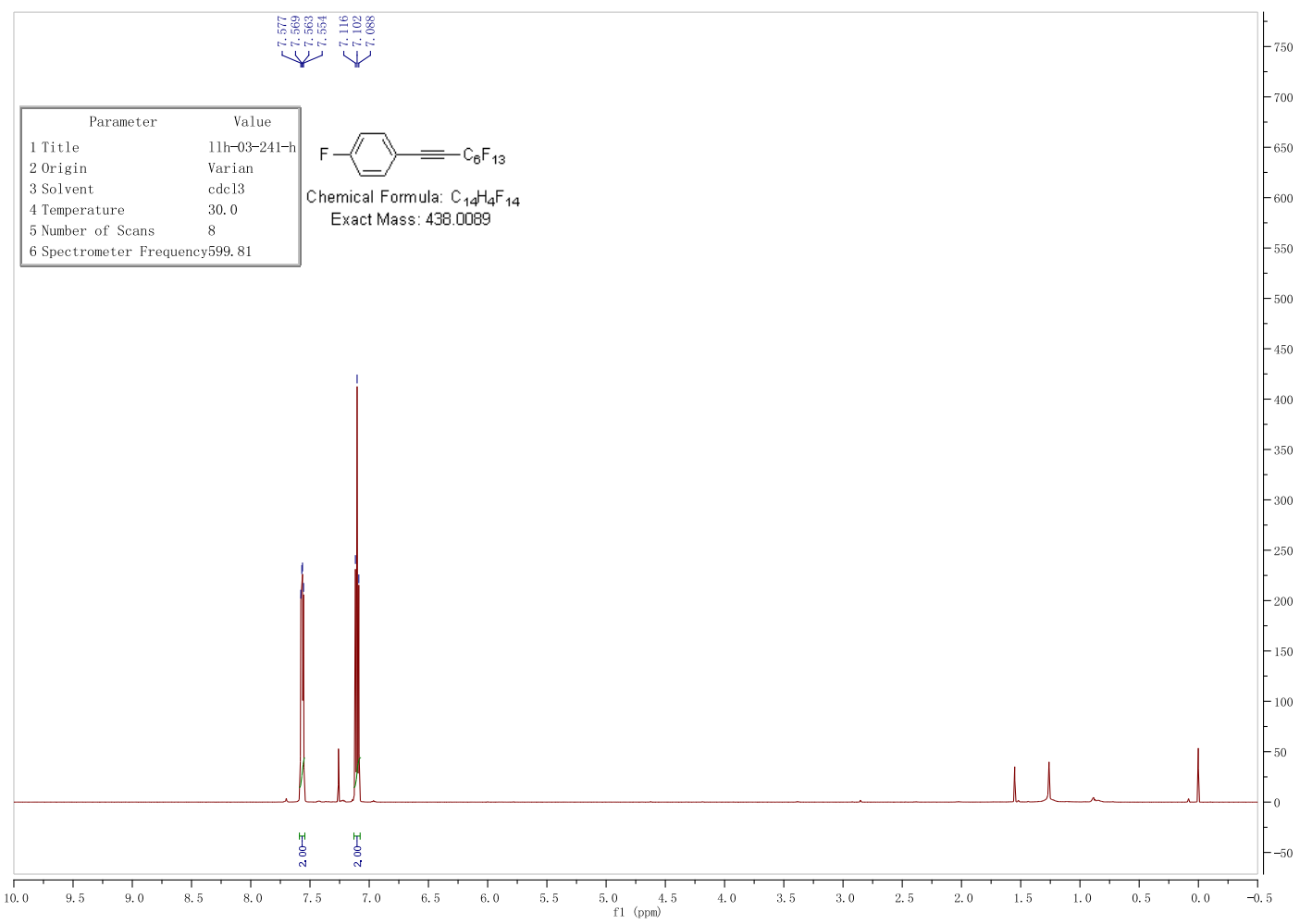



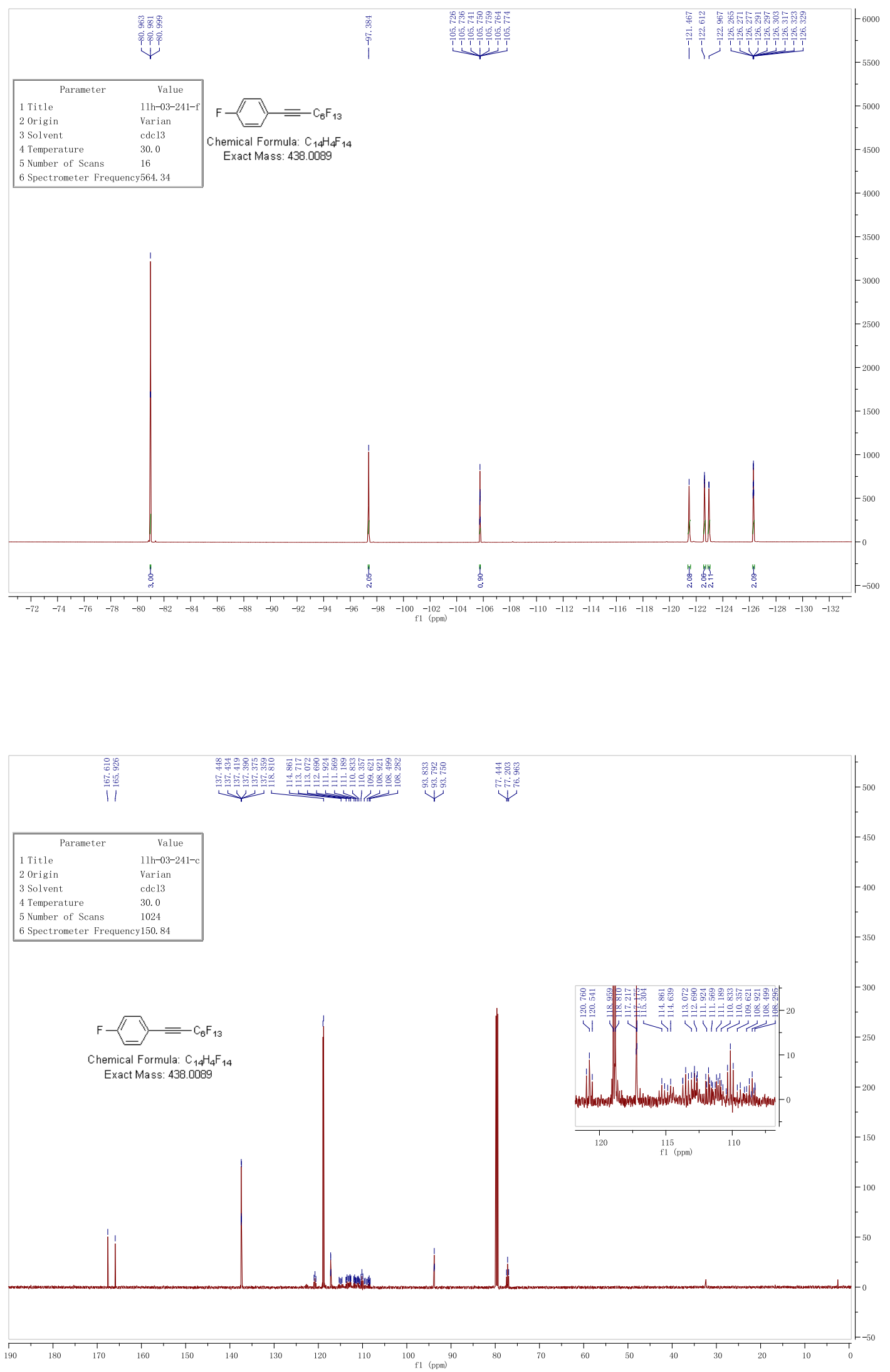
3-(Perfluorohex-1-yn-1-yl)pyridine (5l)
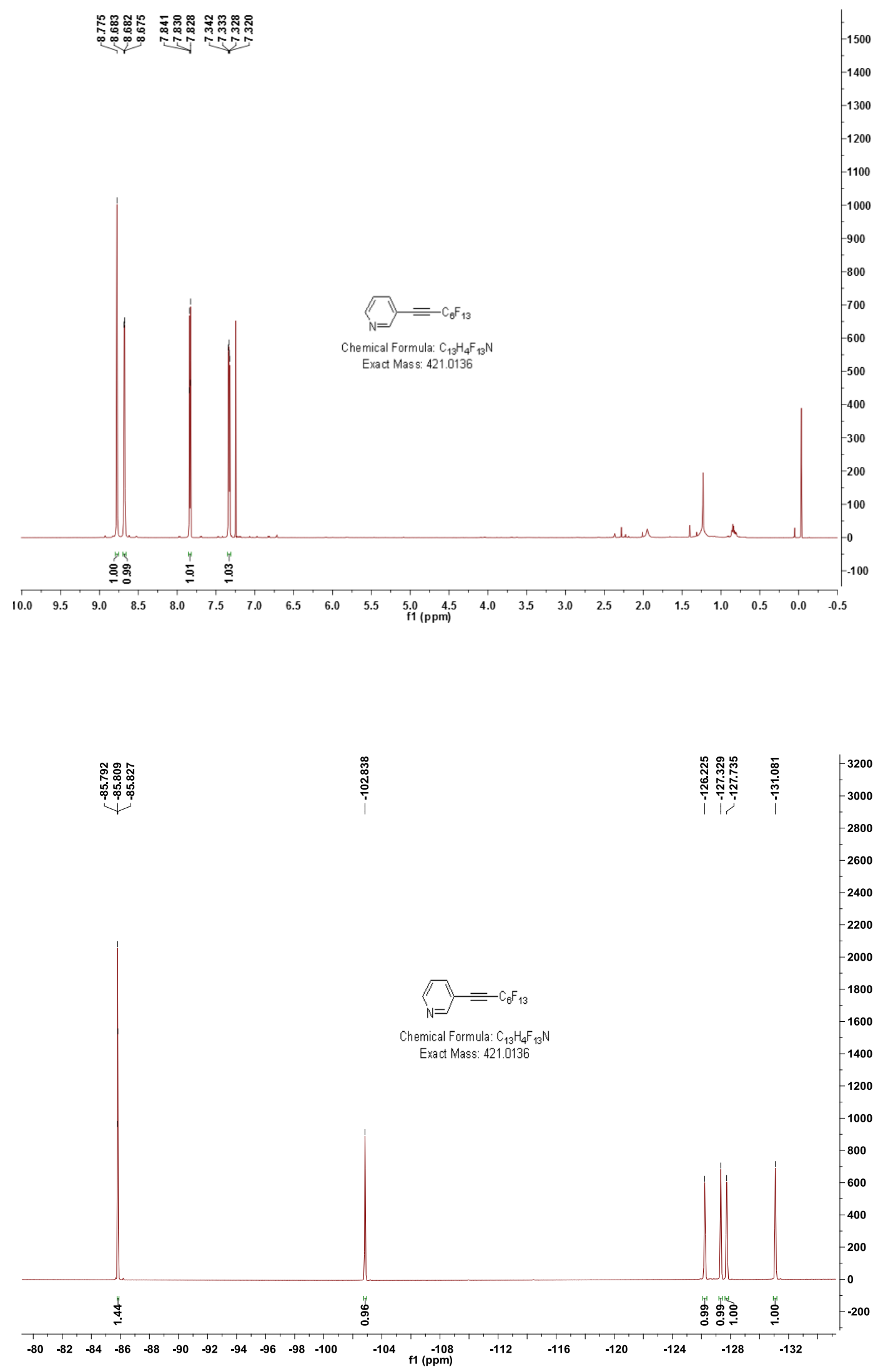


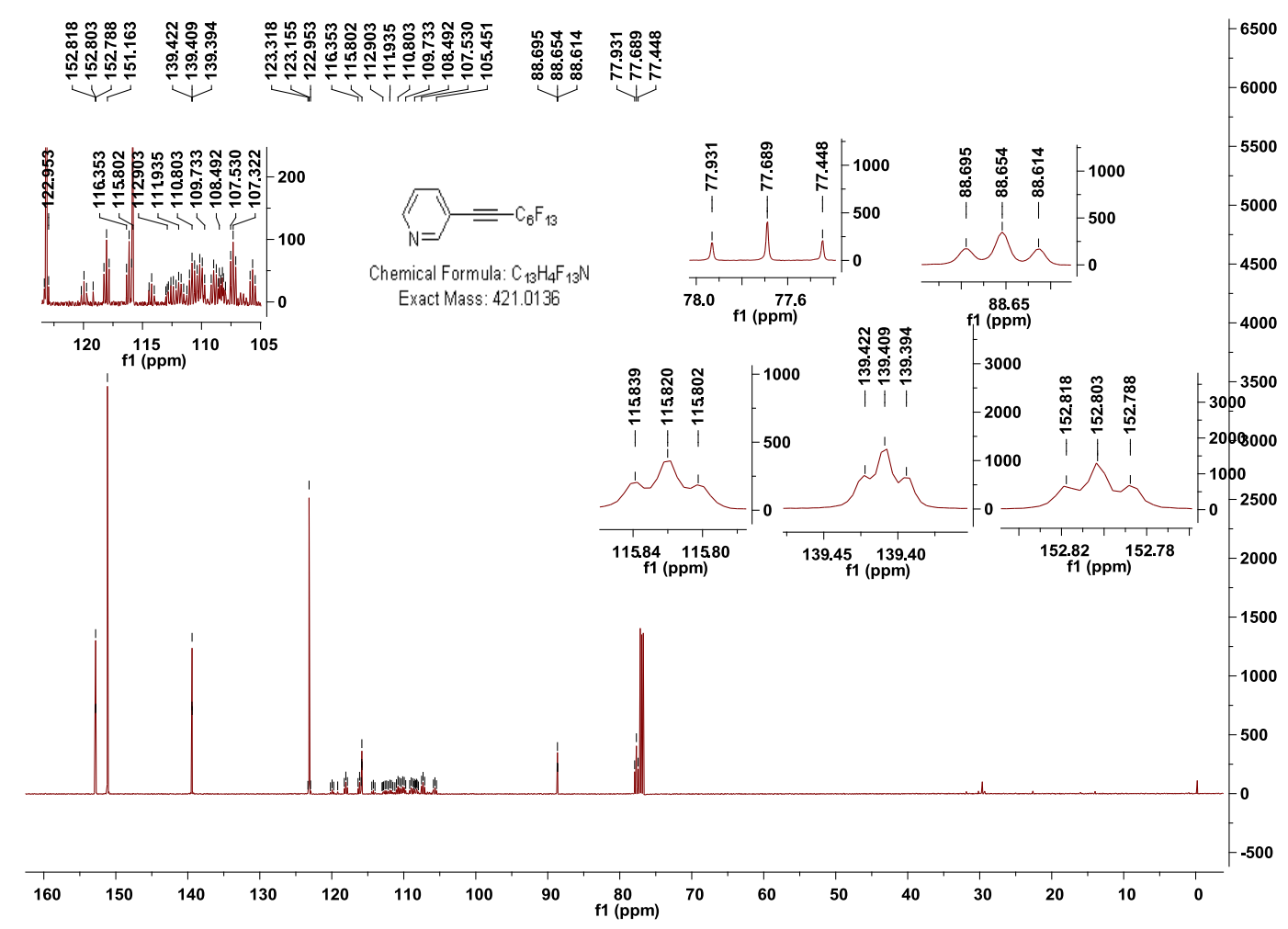

3-(Perfluorooct-1-yn-1-yl)thiophene (5m)

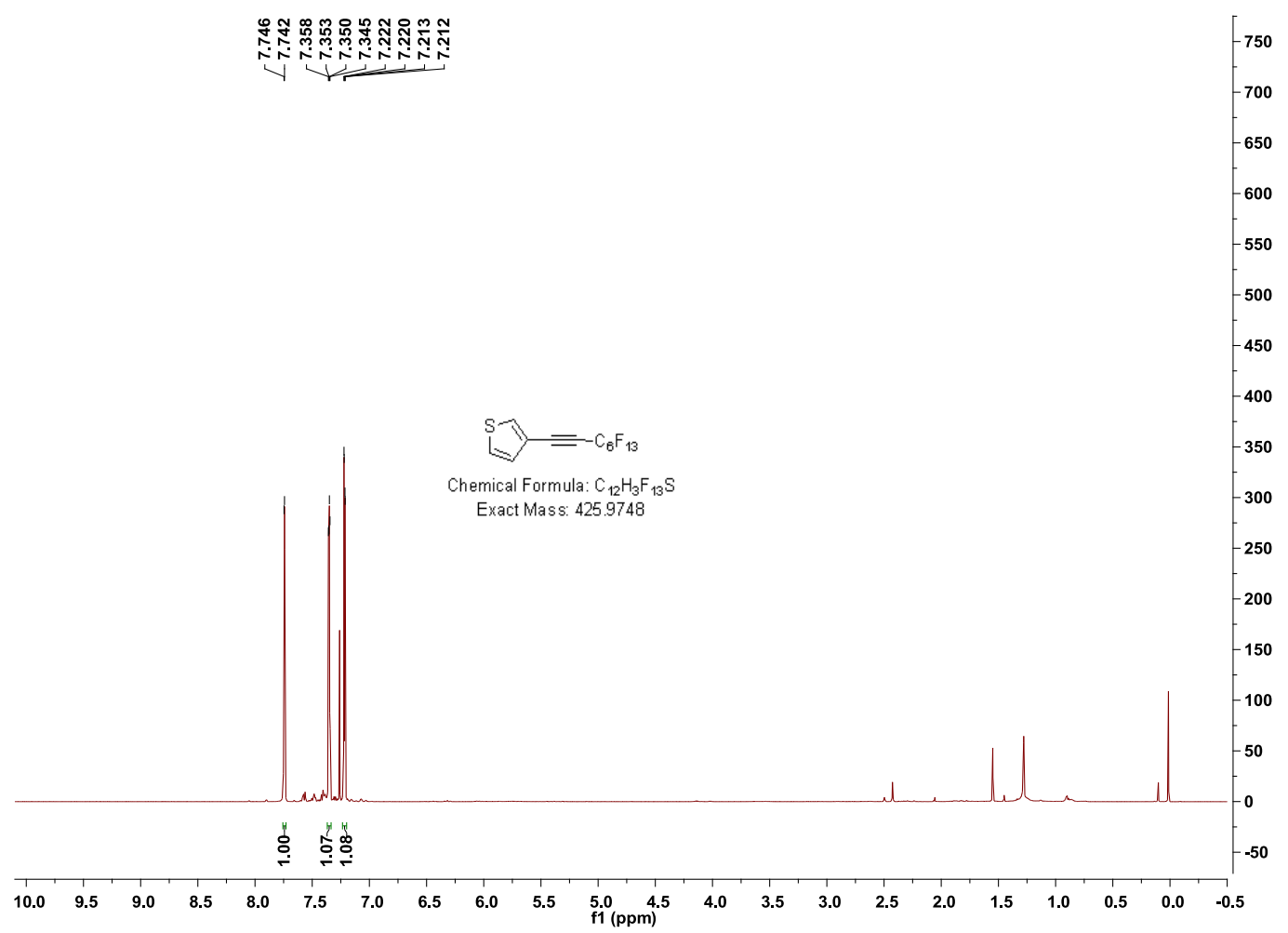



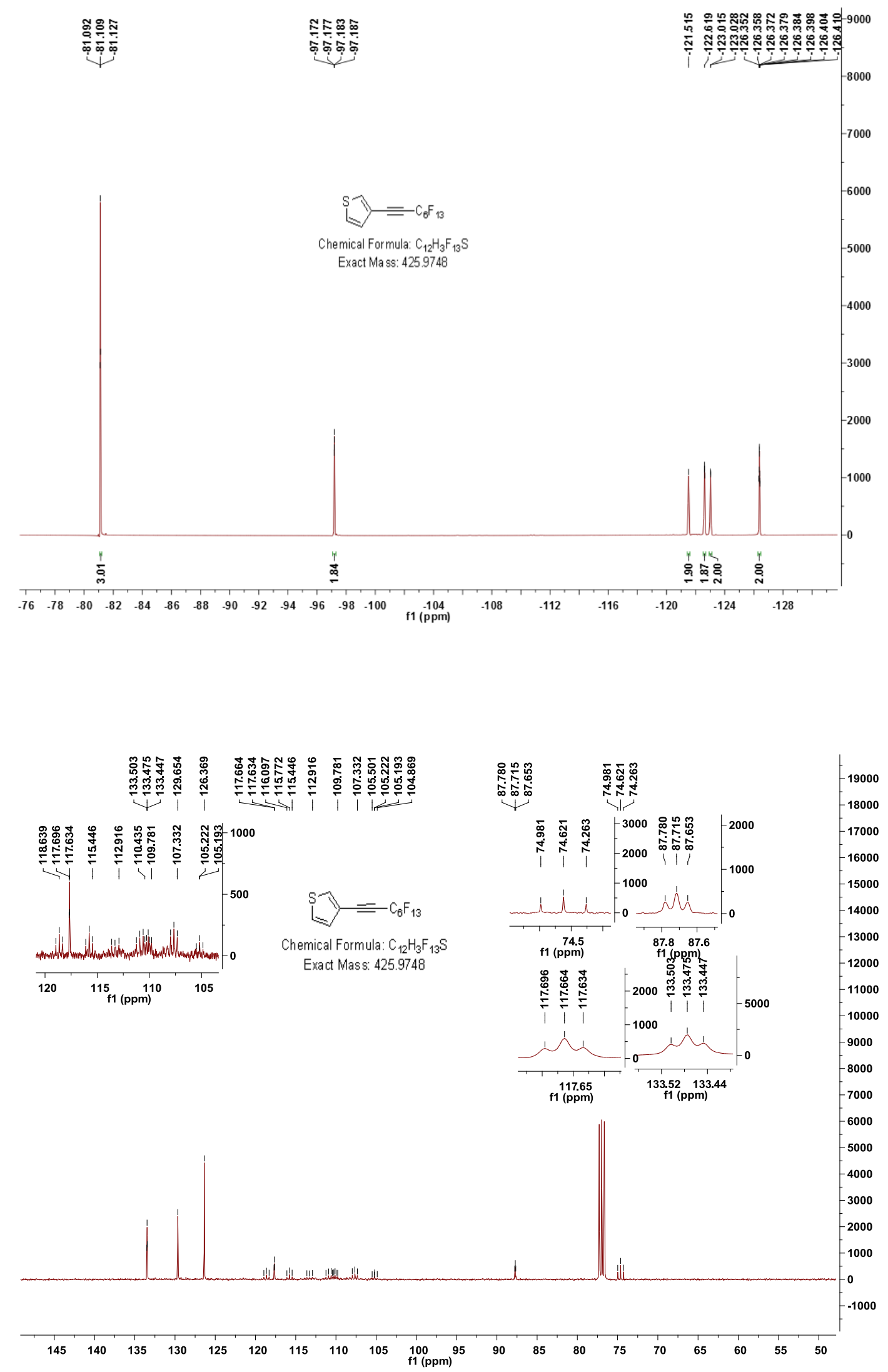
Methyl 4-(perfluorooct-1-yn-1-yl)benzoate (5n)
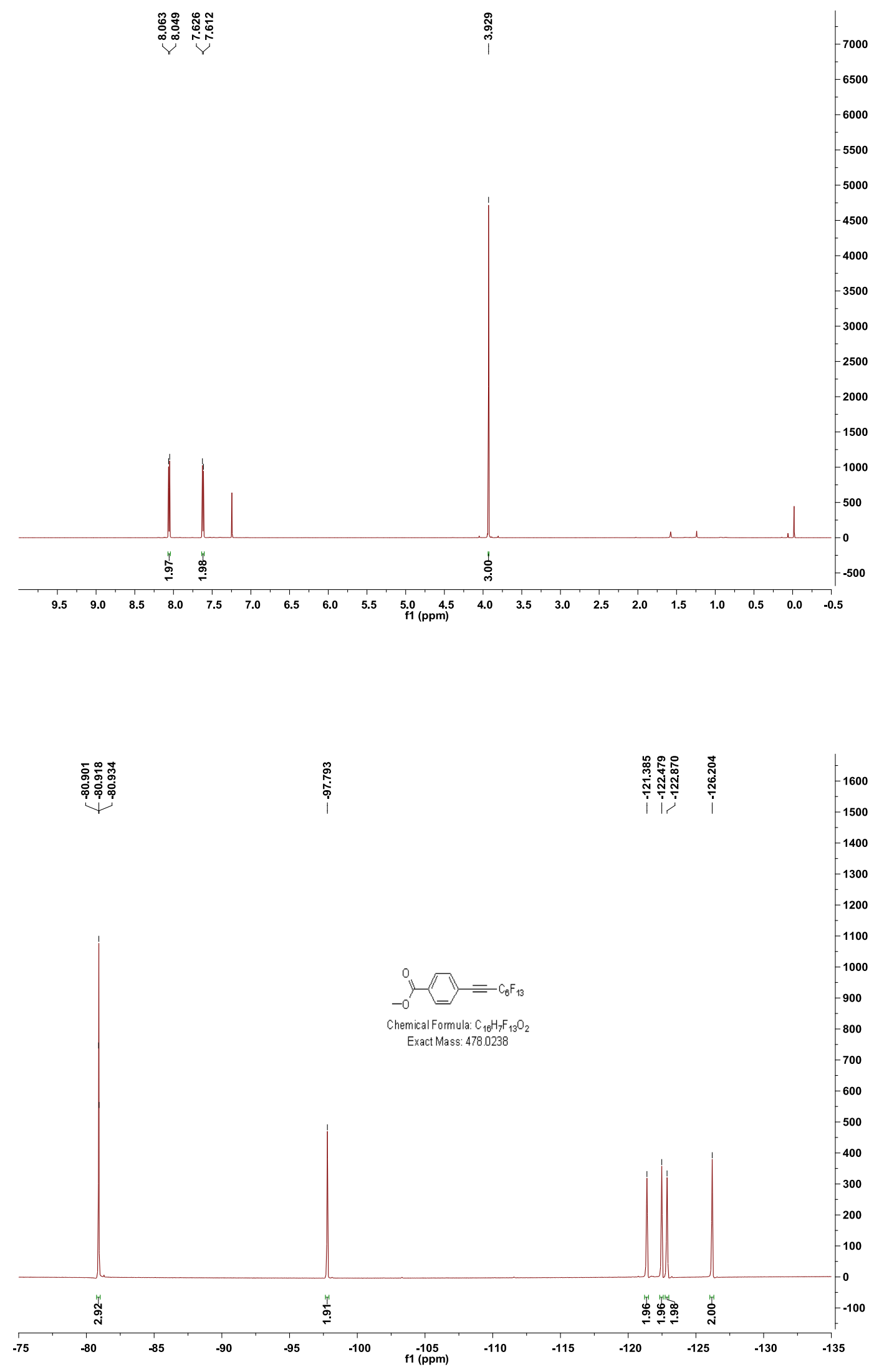


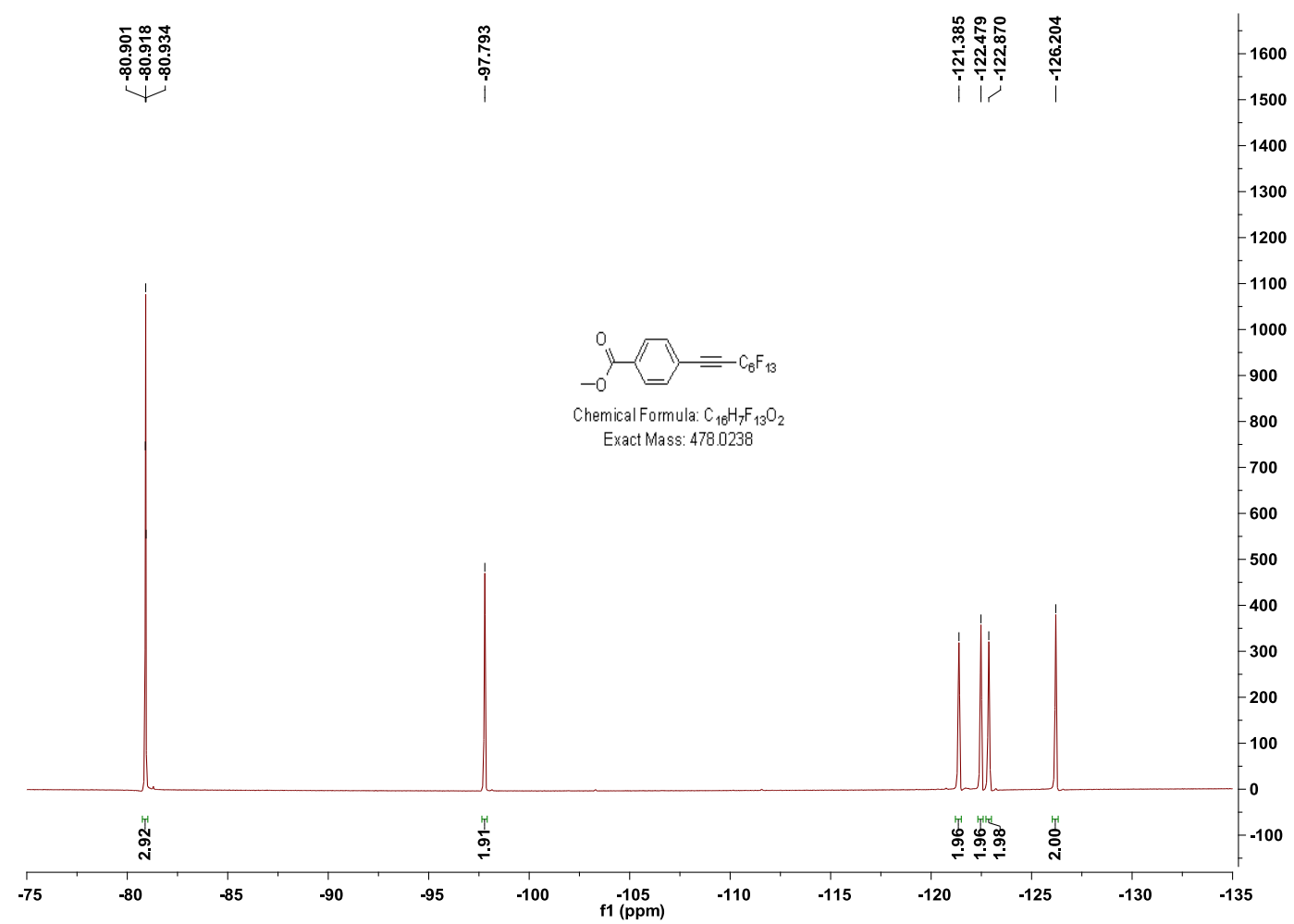

1-(perfluorooct-1-yn-1-yl)-4-propylbenzene (6a)

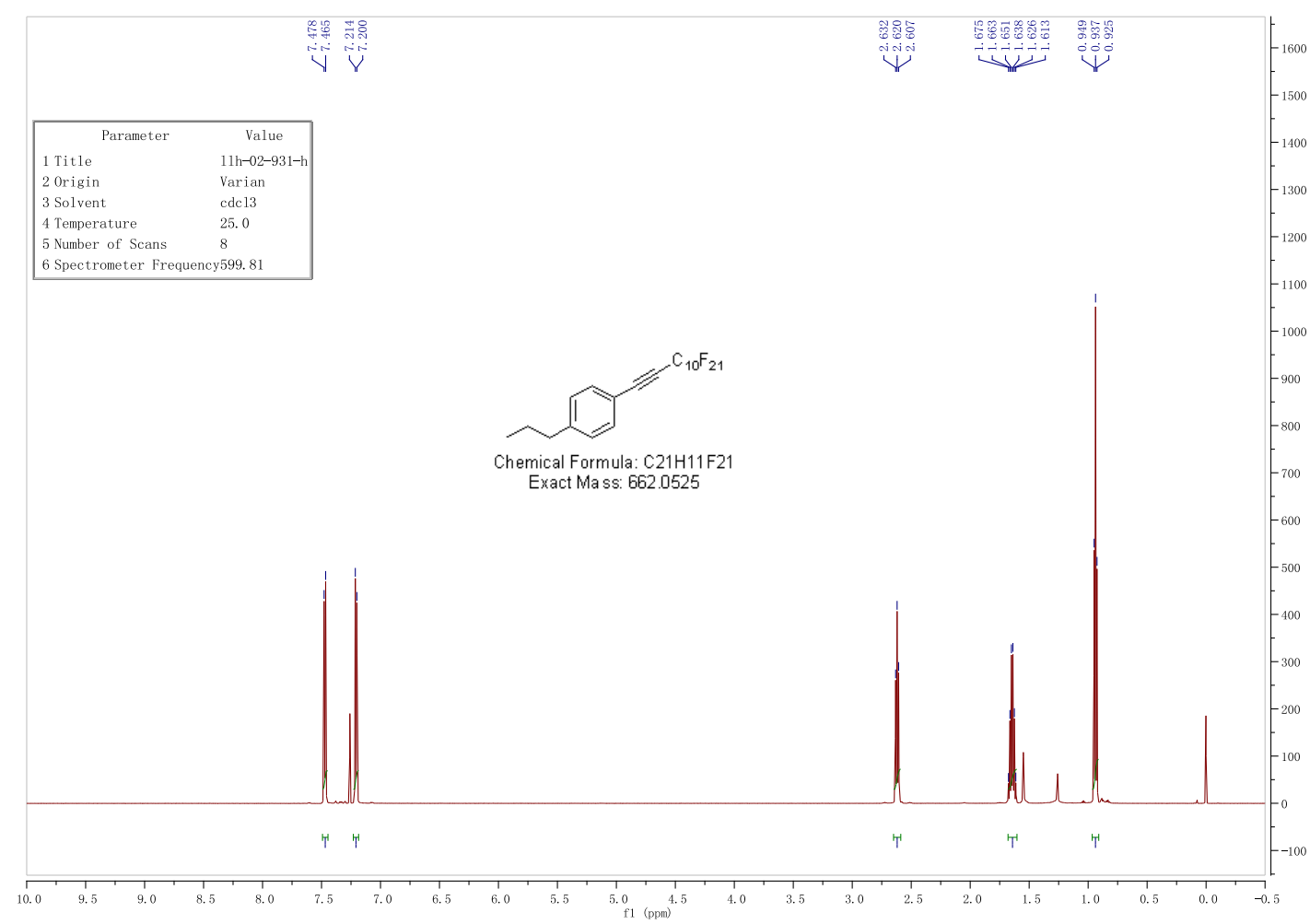



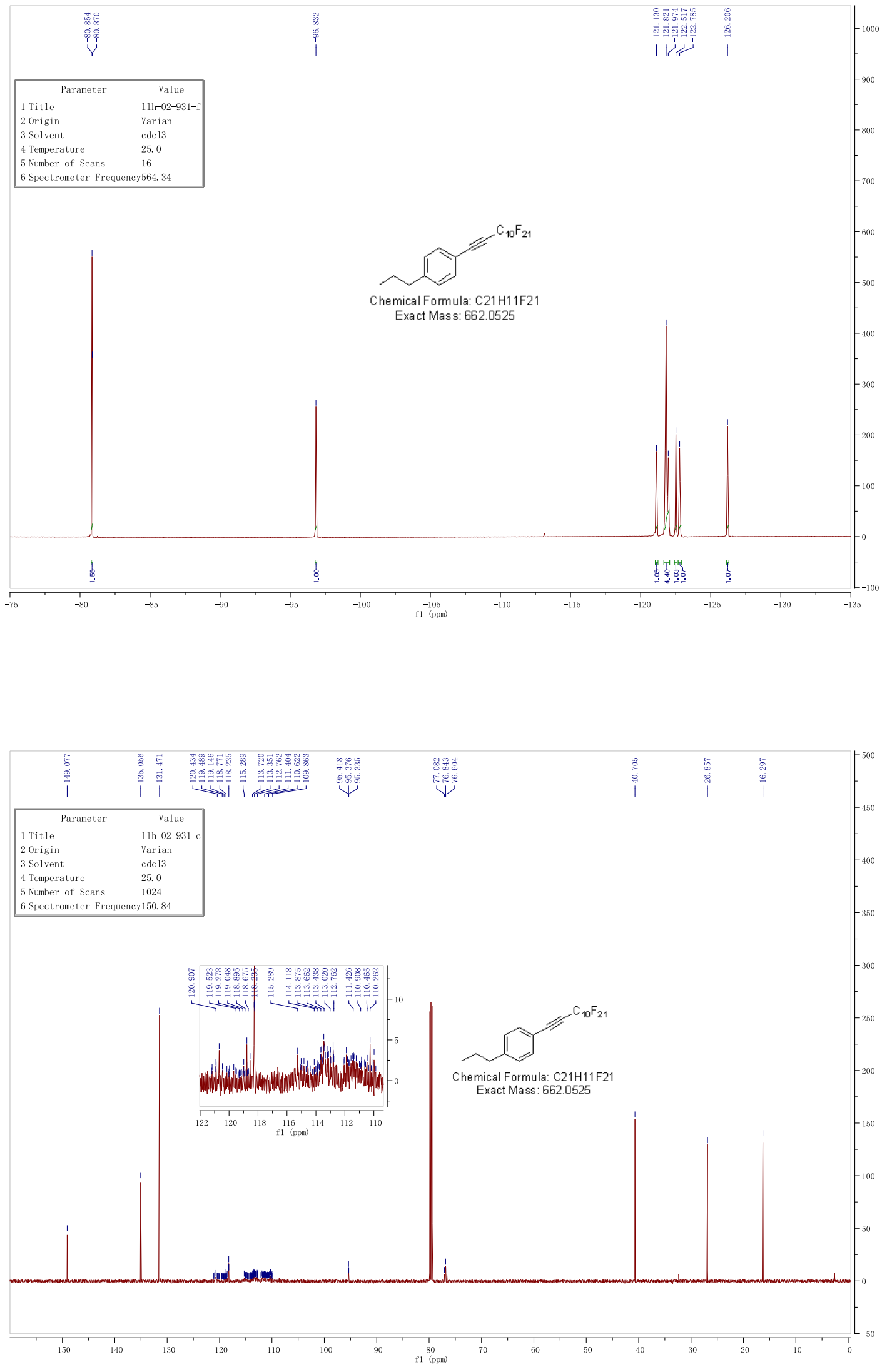
1-(pentyloxy)-4-(perfluorododec-1-yn-1-yl)benzene (6f)
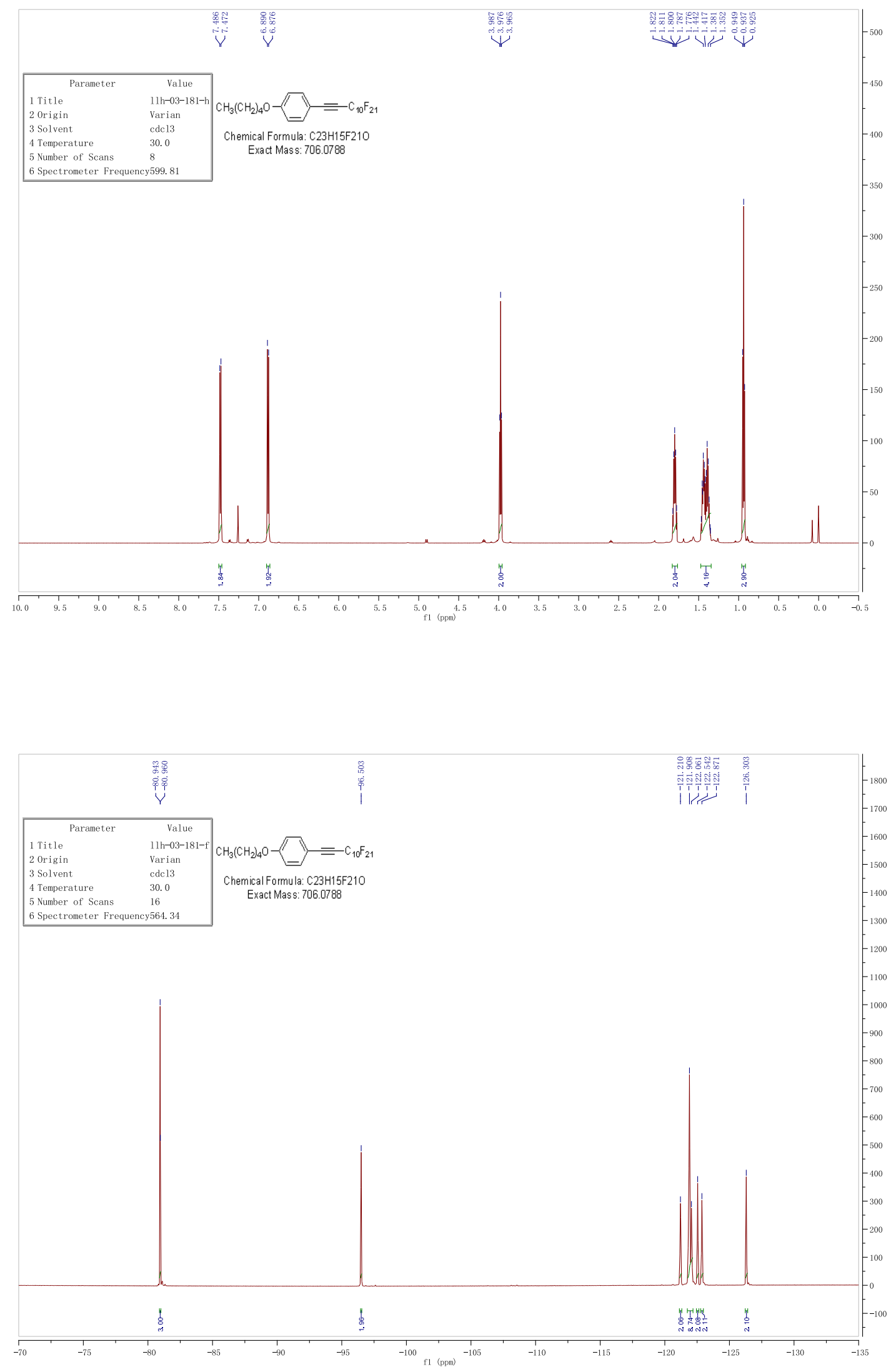


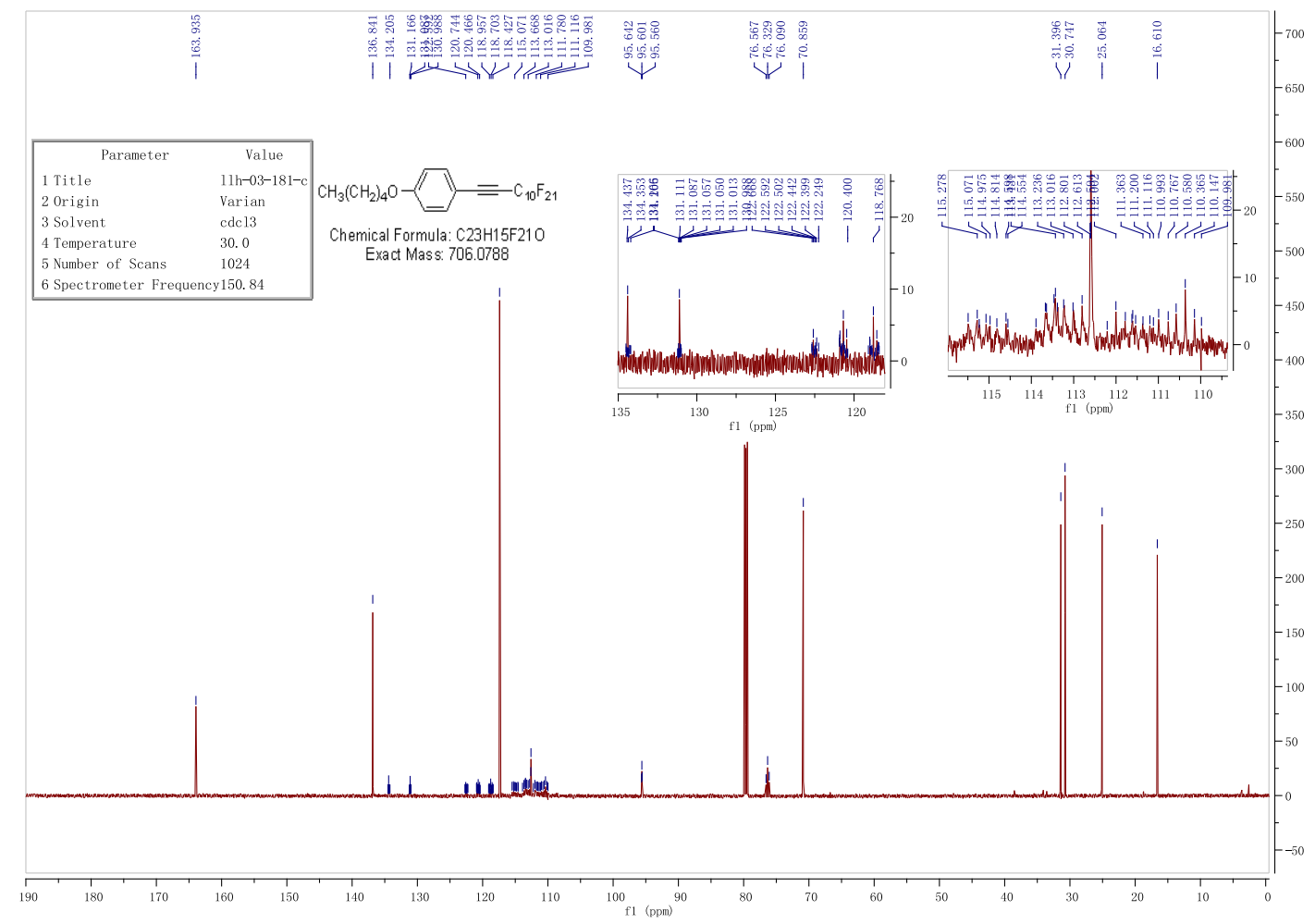

